Check for updates

Cite this: J. Mater. Chem. A, 2020, 8 , 10625

Received 9th March 2020

Accepted 7th May 2020

DOI: $10.1039 / d 0 t a 02755 c$

rsc.li/materials-a

\section{Photoelectrochemical water splitting: a road from stable metal oxides to protected thin film solar cells}

\author{
Carles Ros, (D) *a Teresa Andreu (D) ab and Joan R. Morante (iD) ab
}

Photoelectrochemical (PEC) water splitting has attracted great attention during past decades thanks to the possibility to reduce the production costs of hydrogen or other solar fuels, by doing so in a single step and powered by the largest source of renewable energy: the sun. Despite significant efforts to date, the productivities of stable semiconductor materials in contact with the electrolyte are limited, pushing a growing scientific community towards more complex photoelectrode structures. During the last decade, several groups have focused on the strategy of incorporating state of the art photovoltaic absorber materials (such as silicon, III-V compounds and chalcogenide-based thin films). The stability of these devices in harsh acidic or alkaline electrolytes has become a key issue, pushing transparent, conductive and protective layer research. The present review offers a detailed analysis of PEC devices from metal oxide electrodes forming a semiconductor-liquid junction to protected and catalystdecorated third generation solar cells adapted into photoelectrodes. It consists of a complete overview of PEC systems, from nanoscale design to full device scheme, with a special focus on disruptive advances enhancing efficiency and stability. Fundamental concepts, fabrication techniques and cell schemes are also discussed, and perspectives and challenges for future research are pointed out.

\section{Photoelectrochemical water splitting: introduction}

Since the beginning of the industrial revolution, economic growth has been driven by a continuous increase of power

${ }^{a}$ Catalonia Institute for Energy Research (IREC), Jardins de les Dones de Negre 1, Sant Adrià del Besòs, 08930, Barcelona, Spain. E-mail: cros@irec.cat; Tel: +34933562615 ${ }^{b}$ Universitat de Barcelona (UB), Martí i Franquès, 1, 08028 Barcelona, Spain consumption, ${ }^{1}$ which has been possible thanks to the availability, high energy density and low price of fossil fuels. The counter part of its exponential consumption increase has been significant alterations of our planet, some of them irreversible. This global climate change, attributed to anthropogenic greenhouse gas emission to the atmosphere, has risen sea levels and temperatures, causing ecological unbalance and exponential growth of the species extinction rate. In addition, mineral extraction of some specific elements up to the point of scarcity

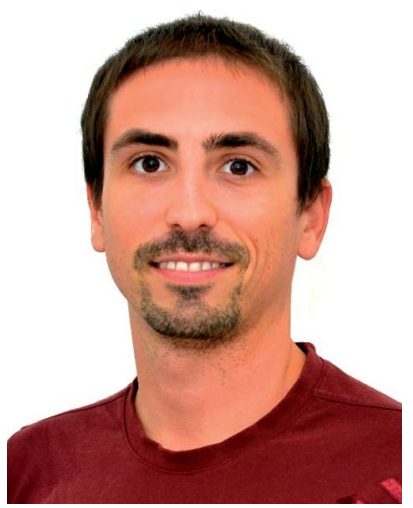

Dr Carles Ros Figueras is a postdoctoral research fellow in the Energy Storage and Energy Harvesting group in the Catalan Institute for Energy Research (IREC). Carles completed his bachelor of Physics (2013) and PhD from University of Barcelona (2019) for a thesis on protective layers for stable and efficient photoelectrodes for solar fuels production. His current research focuses on the development of electrodes and photoelectrodes for electrochemical water splitting and $\mathrm{CO}_{2}$ reduction in seawater-based electrolytes as means for energy storage.

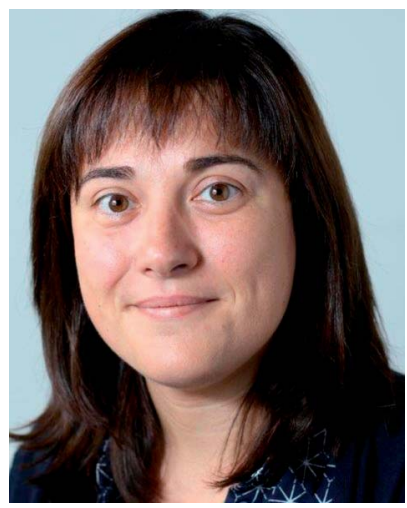

Dr Teresa Andreu is senior researcher at the Energy Storage group of IREC. She received the degree in Chemistry (1999) and PhD in Materials Science (2004) from the University of Barcelona. After a period in industry and academia, she joined IREC in 2009. Her current research is focused on emerging technologies for hydrogen generation and carbon dioxide conversion (photoelectrochemistry, heterogeneous catalysis and plasma-catalysis), solar fuels and redox flow batteries. She has been part-time lecturer at the materials department at UB (2014-2017) and UPC (2017-2019) and she is the author of more than 100 scientific publications and 4 patents. 
and the consumption of fossil fuels (overcoming the "Peak Oil", the maximum extraction rate) means the easy and cheap extraction of these is close to coming to an end. Some scientists have considered it a new geological era, the Antropocene, due to the scale of human-caused modifications on Earth's crust and its ecosystems. ${ }^{2}$

Renewable energy sources and energy saving strategies should be implemented globally, which must be favored by new legislations and technological improvements. Wind, solar and other clean energy sources have in common their intermittent energy production and thus, the need of energy storage technologies to balance energy production and consumption. Converting the surplus energy into chemical bonds such as hydrogen gas allows for later usage, grid distribution or longterm storage. With the sun being one of the most abundant energy sources, photoelectrochemical (PEC) water splitting is postulated as one of the most interesting technologies due to worldwide water availability and pollution-free products, enabling hydrogen as a clean energy vector. Currently, most hydrogen gas feedstock is being produced by methane steam reforming, producing $\mathrm{CO}_{2}$ as by-product, ${ }^{3}$ so clean methodologies are of great impact in this field.

PEC water splitting was discovered in the 70's by Fujishima and Honda, ${ }^{4}$ where $\mathrm{TiO}_{2}$, an n-type semiconductor material with $3 \mathrm{eV}$ band gap, in contact with an electrolyte, was able to absorb photons and generate enough potential to split the water molecule into hydrogen and oxygen, storing solar energy into chemical bonds, named "solar fuel". 5

Up to the 90's, authors like Bard stated the basis of PEC cells ${ }^{6}$ and some research works were published with photoactive materials like $\mathrm{TiO}_{2}$ (ref. 7 and 8) or $\mathrm{Ni}(\mathrm{OH})_{2}$ (ref. 9) and semiconductors from the photovoltaic industry such as $\mathrm{InP},{ }^{10} \mathrm{GaP}^{11}$ or $\mathrm{Si}^{12}$ although as will be detailed in this review many of them presented minimal stability, productivity or were fabricated with highly expensive materials or techniques. It is comprehensible that PEC water splitting develops simultaneously and with observable interactions with the photovoltaic and catalysis fields, as many fundamental concepts, analysis techniques and advances can be applied indistinctly.

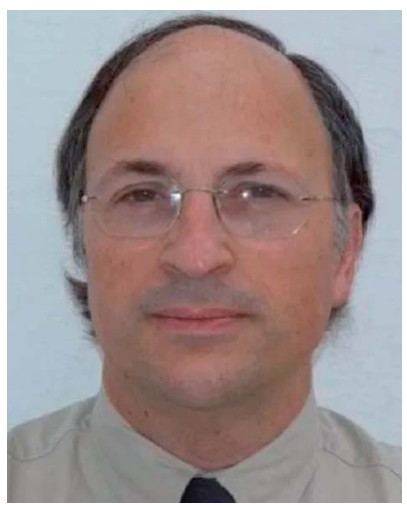

Professor J. R. Morante is, since 1985, full professor of the Faculty of Physics of the University of Barcelona. Since 2009 he has been the director of the advanced materials for energy of the IREC Institute and since 2015 he were appointed as director. His activities are devoted on energy conversion processes at the nano scale. His efforts are focused on the use of these processes for energy storage and the production of solar fuels, renewable electro/thermos synthesis of fuels and added value chemicals. He has co-authored more than 600 research publications with more than 29.000 citations.
But it not was until 2005 that the interest by the scientific community started a rapid increase, as can be seen in the number of published works containing "photoelectrochemical water splitting" in the Scopus database, from a dozen to up to 875 works being published in 2019. The reader will find in this article that the historical progress of PEC water splitting is quite entangled with the complexity of the devices, in a pursuit for efficient, stable and scalable photoelectrodes.

A PEC device can directly convert solar energy into hydrogen and oxygen (Fig. 1a), although nowadays photovoltaic (PV) cells can be directly coupled to water electrolyzers, such as alkaline electrolysis cells (EC) or proton-exchange-membrane (PEM) electrolyzers, ${ }^{13}$ both techniques consisting in mature technologies, as presented in Fig. 1b. However, one of the main advantages of PEC is being designed to work at lower current densities, in the range of tens of $\mathrm{mA} \mathrm{cm} \mathrm{cm}^{-2}$, reducing electrochemical overpotentials. This results in lower operation voltages in front of commercial electrolyzers, designed to operate with two orders of magnitude higher currents and thus, significantly higher efficiencies are possible. ${ }^{\mathbf{1 4}}$ Lower current densities enable alternative low cost and earth abundant catalysts to be used. In addition, PEC approach is a simpler architecture, reducing capital investment costs and electrical transportation losses.

However, PEC technology has remaining challenges to overcome: as the device will be in direct contact with the electrolyte, corrosion must be avoided, and device configuration is more limited. ${ }^{\mathbf{1 4}}$ For a large-scale implementation of these technologies, costs must be lower than hydrogen produced by fossil fuels, although environmental regulations and taxes could help in this direction. Nowadays, coupled PV-electrolyzer costs are not expected to reduce significantly, but PEC systems have a lot of possibilities ahead. ${ }^{\mathbf{1 5 , 1 6}}$

The main requirements to achieve competitive PEC water splitting are: (i) absorption of broad part of the solar spectra; (ii) efficient photogenerated electron-hole excitation and separation; (iii) minimized transport losses to the back contact and semiconductor-electrolyte surface; (iv) minimal overpotential on performing the hydrogen evolution reaction (HER) or the oxygen evolution reaction (OER); (v) long term stable operation; (vi) scalable device fabrication techniques; (vii) cost-effective and (viii) earth abundant materials. a.

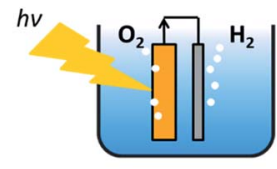

PEC b.

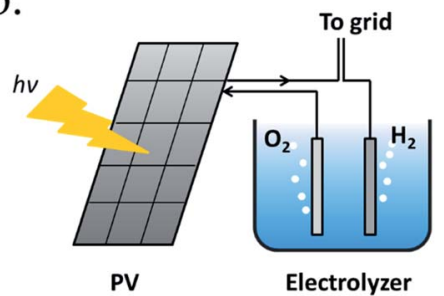

Fig. 1 (a) Scheme of a PEC system immersed in the electrolyte, where one of the electrodes is photoactive. (b) Scheme of a photovoltaic panel connected to an electrolyzer with the option to give or take current to the electrical grid. 
The aim of this review article is to show the progress of recent decades' investigations in PEC water splitting with a special attention to the main key parameters to drive PEC technology to be up-scaled: high productivity, long-term stability and cost-effective materials and techniques. Despite been a significant amount of publications in the field, focus has been put on works with disruptive ideas in the path of obtaining high productivity and stability photoelectrodes capable to fulfill market implementation. ${ }^{17}$ Metal oxides enhancement are reviewed, together with protective strategies for unstable semiconductors capable to generate higher productivities. Finally, cell implementation strategies and configurations are analysed, as well as future prospective challenges for efficient, stable and scalable PEC cells are discussed.

\section{Fundamental concepts}

Photoelectrochemical water splitting is a complex process, including several phenomena which must be optimized for an efficient device design. In this section, most fundamental ones are explained and depicted in Fig. 2: (a) light-matter interaction; (b) electron-hole pair generation; (c) charge separation and transport; (d) catalytic charge transfer to the electrolyte and (e) the water splitting reaction. As a result of photoelectrochemical water splitting, a current flow (f) is obtained between both electrodes.

\section{(a) Light-matter interaction}

When light strikes on matter it can be absorbed, reflected or transmitted (Fig. 3a). Across certain media such as liquid electrolytes, light can be slightly absorbed or reflected (scattered), what is considered attenuation. Thus, short propagation distance through the electrolyte is necessary to avoid significant losses. At the interface between two different media with different dielectric constant, a fraction of the incident light can suffer reflection, propagating back in the initial media. Strategies to modulate the divergence between dielectric constants are used in several fields, called "antireflective coatings", useful to minimize reflection for specific wavelengths ranges. Once inside the material, photons can be absorbed if its energy is higher than the band gap. In this case, photon energy will be transferred to atomic electrons, generating an electron-hole pair. The penetration depth is a measure of how deeply an irradiation can penetrate into a medium. It is defined as the depth at which the photons are absorbed by $1 / \mathrm{e}(37 \%)$, and is an important parameter in thin film semiconductors, as can range from $2 \mu \mathrm{m}$ for Si (at $555 \mathrm{~nm}$ wavelengths) to down to few nanometers for iron oxide. The nonreflected or absorbed light is considered transmitted.

\section{(b) Electron-hole pair excitation}

If a material absorbs a photon, the energy is transferred to an electron, which is excited to a higher energy level. In a semiconductor's case, electron states from individual atoms have an overall average energy state distribution forming a valence band and a conduction band. At absolute zero temperature, the highest energy occupied states define the valence band edge $\left(E_{\mathrm{v}}\right)$

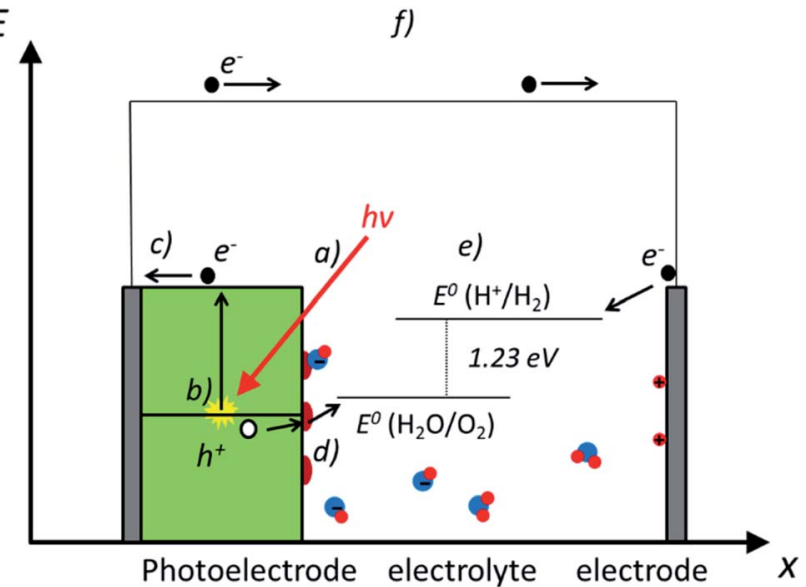

Fig. 2 Scheme illustrating the main phenomena involved in photoelectrochemical water splitting, where a photoanode is immersed in an aqueous electrolyte. (a) light-matter interaction, (b) electron-hole pair generation, (c) charge separation and transport, (d) catalysis and (e) the water splitting reaction, and (f) photocurrent associated to the photoelectrochemical (PEC) water splitting.

a.
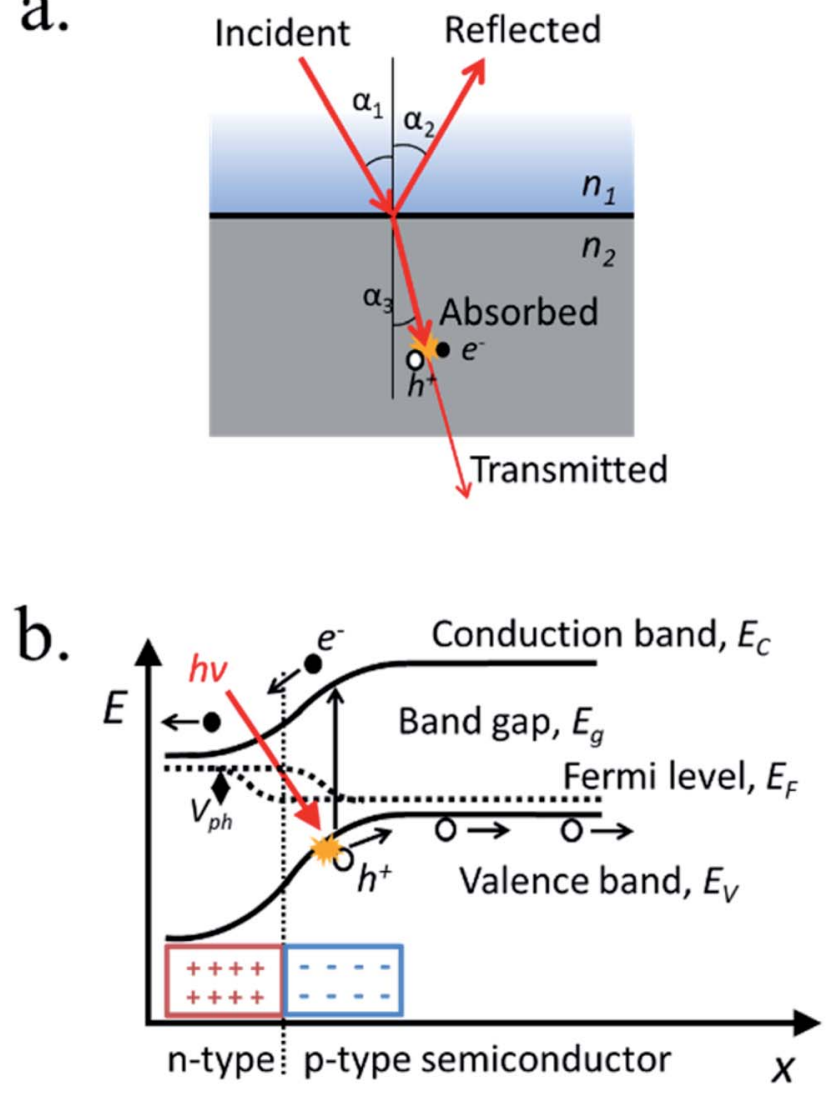

Fig. 3 (a) Scheme of a light beam incident on a two different mediums interface with different refractive index, depicting incident, reflected, absorbed and transmitted light and the formation of an electron-hole pair. (b) Energy band diagram of a $\mathrm{p}-\mathrm{n}$ junction presenting a photon absorbed and the movement of the electron and hole under the builtin electric field, together with the photogenerated voltage between Fermi levels. 
and the lowest energy vacant states define the conduction band edge $\left(E_{\mathrm{c}}\right)$, respectively. The energy difference between these two band edges, where no states are present, is the forbidden energy region, named the band gap $\left(E_{\mathrm{g}}\right)$.

After photon absorption, some of the valence band electrons $\left(\mathrm{e}^{-}\right)$are excited into the conduction band leaving an empty state in the network of covalent bonds, considered a "hole" $\left(\mathrm{h}^{+}\right)$. If photon's energy is larger than the band gap, the electron will dissipate that extra energy ("thermalize") until stabilizing in the conduction band edge, giving that extra energy to neighbor atoms in the form of thermal vibration and thus, not storing all original photon's energy in the excited electron-hole pair.

For semiconductors at a certain temperature, some of these atoms are spontaneously ionized, where electrons are excited to the conduction band and holes are created in the valence band. The nature of the majority carriers formed, i.e. free electrons or vacancies in the covalent structure, determines the $n$ - or $p$-type semiconductor behavior. This is normally governed by alterations in the crystal lattice material covalent network, where modifying the amount of acceptors (accepting a free electron) or donors (giving free electrons) is named "doping" the semiconductor, and there are several forms to do it. Among them, the presence of an element with different number of valence electrons (i.e.: a boron atom with 3 electrons in the external shell in a silicon covalent structure consisting on 4-links per atom results in an electron missing in the covalent bonding) or the formation of a sub-stoichiometric material (i.e.: oxygen vacancies in $\mathrm{TiO}_{2}$ are the responsible of n-type semiconductor behavior). The average states distribution energy is called the Fermi level $\left(E_{\mathrm{F}}\right)$. If Fermi level is closer to the valence band and majority carriers are holes it is considered a p-type semiconductor, and if it is closer to conduction band and electrons are majority carriers, an n-type one.

\section{(c) Charge separation and transport}

Light-induced electron hole pairs need to be separated to avoid eventual recombination, the process in which the excited electron releases its energy, "filling" a hole back in the valence band. High recombination rates make impossible to extract any current from photogenerated charges, thus efficient charge separation is needed. Thus, an external potential can be applied, or an internal built-in potential can be used to spontaneously separate photogenerated charges and consequently, to create a photovoltage and a photocurrent. By putting in contact a p-type and an n-type semiconductors a p-n junction is formed, where the average amount of free electrons or holes (Fermi levels) is equilibrated by charges diffusing from one to the other, forming a space-charge or depletion region where there is a strong electric field (Fig. 3b).

There are several structures forming built-in electric fields, among them:

- $\mathrm{p}-\mathrm{n}$ homojunction, where a semiconductor has two regions with different type character (i.e. p-type and n-type silicon).

- p-n heterojunction, where two different materials of different type character are in contact (i.e. n-type $\mathrm{TiO}_{2}$ and $\mathrm{p}$ type silicon).
- Schottky junction, where a semiconductor equilibrates with the free electrons energy level of a metallic film (i.e. Ni metal and n-type silicon).

- A semiconductor-liquid junction (SCLJ), where the semiconductor equilibrates with the ions adsorbed in the surface, forming a Helmholtz double layer (i.e. n-type $\mathrm{TiO}_{2}$ in an alkaline electrolyte).

Formed electric fields will drift generated charges to opposite directions, i.e. electrons to surface and holes to the back contact (Fig. 3b). For efficient charge transport, high conductivity is needed. Conductivity is governed by both carrier mobility and carrier concentration. Carrier mobility highly depends on impurities and defect concentration: electrons and holes highly scatter on crystallographic defects such as interstitial atoms or vacancies, plane dislocations, stacking faults or grain boundaries, losing some energy and changing direction. Meanwhile, carrier concentration is determined by the doping level, temperature and illumination intensity. All these parameters will be reflected in a higher resistance to charge transport.

\section{(d) Catalysis}

Once the electrons/holes reach the surface of the photoabsorber, a chemical reaction takes place. In water splitting, the hydrogen or oxygen evolution reaction, respectively. So, not only the charge separation and transport of electrons/holes to the surface is crucial but also, the efficiency of the water splitting reaction and how the electrons are transferred to the reactants to obtain the products. In this sense, catalysts play an important role, accelerating a chemical reaction.

An electrocatalyst is defined as a material repeatedly enhancing a certain electrochemical reaction without being consumed. Catalysts introduce alternative reaction paths with lower activation energy through forming alternative intermediate species on its surface. As the reaction will happen on the surface, normally very small amounts of catalysts are needed.

\section{(e) The water splitting reaction}

The water splitting reaction

$$
2 \mathrm{H}_{2} \mathrm{O} \rightarrow 2 \mathrm{H}_{2}(\mathrm{~g})+\mathrm{O}_{2}(\mathrm{~g})
$$

is a non spontaneous reaction. At room temperature, water can be split by applying an electrical potential between two electrical contacts, a cathode and an anode, immersed in an aqueous electrolyte, to drive two half-reactions, the hydrogen evolution reaction (HER) and oxygen evolution reaction (OER) (Fig. 1a and 4a). The complete reaction has a Gibbs free energy of $237.18 \mathrm{~kJ}$ per mol of produced $\mathrm{H}_{2}$, corresponding to a thermodynamic reversible potential of $1.23 \mathrm{~V}$. However, this value is theoretical, assuming ionic concentration of 1 molar, gases pressure of $1 \mathrm{~atm}$ and $298 \mathrm{~K}$. For different conditions, the potential value will vary following the Nernst equation, and the potentials $(E)$ are usually referenced in respect to the neutral hydrogen electrode ( $E$ vs. NHE) or the reversible hydrogen electrode ( $E$ vs. RHE), where the former is invariant with $\mathrm{pH}$ 
a.
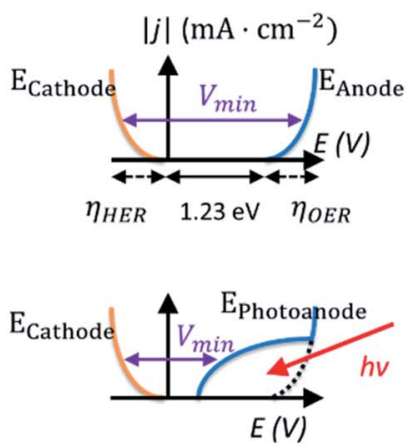

b.

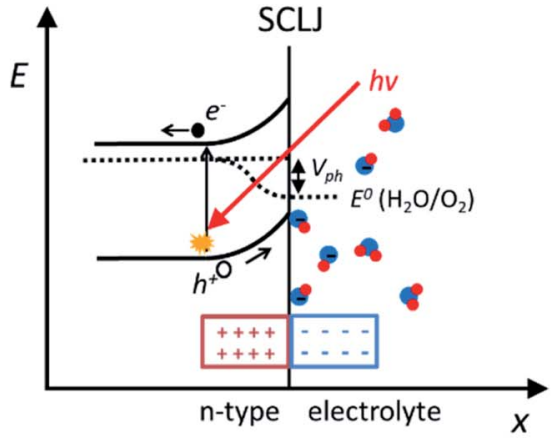

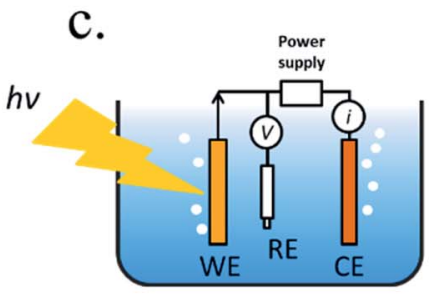

3-electrodes measurement

Fig. 4 (a) Absolute current versus voltage of the water splitting reaction with the overpotentials for HER and OER depicted (left) and the shape of the water splitting reaction if one of the electrodes is photoactive (right). (b) Energy bands diagram of a photoanode in contact with an alkaline electrolyte, consisting on (left to right) an n-type semiconductor, light-induced electron-hole pair being separated by the space-charge region in the semiconductor-liquid junction (SCLJ), the adsorbed molecules from the electrolyte forming the Helmholtz double layer and the OER redox potential. (c) A 3-electrodes measurement system consisting on a working electrode (WE), a reference electrode (RE), a counter electrode (CE) and a potentiostat measurement system, schematically consisting on a voltmeter, a current meter and a power supply.

following $E_{\mathrm{RHE}}=E_{\mathrm{NHE}}+0.059 \mathrm{pH}$. For instance, at different $\mathrm{pHs}$, the HER and OER standard potential values are:

HER:

$$
\mathrm{pH}=0,4 \mathrm{H}^{+}+4 \mathrm{e}^{-} \rightarrow 2 \mathrm{H}_{2}, E_{0}=0 \mathrm{~V} \text { vs. NHE }
$$

$\mathrm{pH}=14,4 \mathrm{H}_{2} \mathrm{O}+4 \mathrm{e}^{-} \rightarrow 2 \mathrm{H}_{2}+4 \mathrm{OH}^{-}, E_{0}=-0.83 \mathrm{~V}$ vs. $\mathrm{NHE}(3)$

OER:

$$
\begin{gathered}
\mathrm{pH}=0,2 \mathrm{H}_{2} \mathrm{O} \rightarrow \mathrm{O}_{2}+4 \mathrm{e}^{-}, E_{0}=1.23 \mathrm{~V} \text { vs. NHE } \\
\mathrm{pH}=14,4 \mathrm{OH}^{-} \rightarrow \mathrm{O}_{2}+2 \mathrm{H}_{2} \mathrm{O}, E_{0}=0.4 \mathrm{~V} \text { vs. NHE }
\end{gathered}
$$

Also, to drive these reactions kinetically efficient (with a significant current and thus, productivity), additional potentials are necessary for the catalysis, $\eta_{\mathrm{HER}}$ and $\eta_{\mathrm{OER}}$, named as overpotentials. The overpotential for the water splitting reaction is $\sim 0.4 \mathrm{~V}$ for $\sim 10 \mathrm{~mA} \mathrm{~cm}{ }^{-2}$ currents using state of the art catalysts. ${ }^{\mathbf{1 8 - 2 4}}$ The overpotential need to drive the reaction efficiently depends not only on the electrocatalyst nature, but also on the basic or acidic character of the electrolyte, the abundance of hydroxides $\left(\mathrm{OH}^{-}\right)$or protons $\left(\mathrm{H}^{+}\right)$, which plays a key role on the water dissociation kinetics. ${ }^{25}$ In addition, high ionic conductivity is necessary between the two electrodes, which can introduce another extra potential ( $\eta_{\text {ionic cond.) }}$ ) for large distances or reduced ion concentrations/ conductivity, resulting in an ohmic loss. Gases should be separated to avoid back-reactions if they diffuse to the opposite polarized electrode.

Adding all contributions, a minimum required voltage $\left(V_{\min }\right)$ is obtained:

$$
V_{\text {min }}(j)=1.23 \mathrm{eV}+\eta_{\mathrm{HER}}(j)+\eta_{\mathrm{OER}}(j)+\eta_{\text {ionic cond. }}(j)
$$

Record values down to $\sim 1.4 \mathrm{~V}$ for a current of around $10 \mathrm{~mA}$ $\mathrm{cm}^{-2}$ have been obtained. ${ }^{26,27}$

\section{(f) Photoelectrochemical (PEC) water splitting}

In PEC water splitting, photons absorbed by the semiconductor create electron-hole pairs, which are separated by the built-in electric field inside the photoelectrode, generated in the semiconductor-liquid junction (SCLJ) by semiconductor and electrolyte Fermi level equilibration. A double layer is formed, first described by Helmholtz ${ }^{28}$ nowadays extended by other authors ${ }^{29}$ formed by ions physically adsorbed to semiconductor's surface and a diffuse outer layer with exponentially decreasing potential. Electric neutrality is obtained by band bending generated inside the semiconductor. ${ }^{30}$ The built-in electric field can separate electron-hole pairs, generating photovoltage $\left(V_{\mathrm{ph}}\right)$ and photocurrent, as depicted in Fig. $4 \mathrm{a}$ and b. In a photoanode, holes are driven to photoelectrode's surface to perform the oxygen evolution, meanwhile electrons are collected by the back contact and close the circuit performing the proton reduction 
reaction in the counter electrode. Similarly, if the semiconductor built-in electric field drives electrons to the surface to perform the hydrogen evolution, it is considered a photocathode. For a significant photocurrent injected into the electrolyte to perform the water splitting reaction, photogenerated electron-hole pairs will suffer overpotentials for chargeseparation $\left(\eta_{\text {sep }}\right)$ and for charge transport $\left(\eta_{\text {trans }}\right)$ across the semiconductor, from the back contact and other elements in the circuit. Some authors have calculated a minimum band gap $\left(E_{\mathrm{g} \text { min }}\right)$ of the semiconductor material to be $>2.04 \mathrm{eV}$ (ref. 30 and 31) based on:

$$
E_{\mathrm{g} \min }=\eta_{\mathrm{trans}}+\eta_{\mathrm{sep}}+V_{\mathrm{min}}
$$

If the photopotential is generated by a single photoelectrode is not enough, an external bias can be applied to complete the reaction. This way, external power would be used, but it can help in extracting more power from the photoelectrode too.

Independent analysis of each electrode is possible by measuring it in a "three electrodes" cell configuration (or halfcell) (Fig. 4c), where a reference electrode is used (at a fixed potential in respect to the electrolyte). In this disposition, the required current is applied in the counter electrode (CE) by an external power supply (or "potentiostat") so that between the working electrode (WE) and a reference electrode (RE) there falls the desired potential. ${ }^{32}$ With this half-cell configuration, the incoming light conversion efficiency into gas given by this single electrode can be measured, named half-cell solar-tohydrogen (HC-STH) conversion efficiency.

$$
\text { HC-STH }(\%)=\frac{j_{\mathrm{ph}} \times\left(E_{\mathrm{H}_{2} \mathrm{O} / \mathrm{O}_{2}}-E\right)}{P_{\text {sun }}} \times 100
$$

where $j_{\mathrm{ph}}$ is the photocurrent density obtained under an applied bias $E$ (respect to RHE), $E_{\mathrm{H}_{2} \mathrm{O} / \mathrm{O}_{2}}$ is the equilibrium redox potential of oxygen evolution reaction $\left(1.23 \mathrm{~V} v s\right.$. RHE) and $P_{\text {sun }}$ is the standard solar AM 1.5 irradiation, $100 \mathrm{~mW} \mathrm{~cm}^{-2}$. Jiang et $a .^{33}$ published a thoughtful review of energy and quantum conversion efficiencies regarding PEC devices.

\section{Metal oxide photoelectrodes and their enhancement strategies}

Metal oxides present several interesting characteristics for PEC compared to other semiconductor materials, such as earth abundance and a relatively large bandgap that results in high photovoltage, required for water splitting. $\mathrm{TiO}_{2}$ was the first studied PEC semiconductor, back in the 70's. ${ }^{4}$ It is an earth abundant and inexpensive material which has a high stability in alkaline environments and favorable band edge alignment for the OER reaction, ${ }^{34}$ but for decades obtained photocurrents were far below $1 \mathrm{~mA} \mathrm{~cm} \mathrm{~cm}^{-2}$. This was mainly caused by a $3.2 \mathrm{eV}$ bandgap (absorbing under a 5\% of the solar spectrum corresponding to UV light), significant recombination rates and low conductivity due to crystallographic and electronic defects. ${ }^{35}$

To overcome $\mathrm{TiO}_{2}$ limitations, several strategies were applied in following decades: ${ }^{36}$ alternative metal oxide candidates, band gap modification, nanoscale material structuration, control of electronic defects by new synthesis techniques and posttreatments, surface-decoration with catalysts, creation of heterojunctions, etc. With these modifications, there has been a significant advance of overall productivity and stability.

\subsection{Metal oxide photoelectrode candidate materials}

Among all possible metal oxides, $\mathrm{TiO}_{2}$ (n-type, $\left.3.2 \mathrm{eV}\right)^{\mathbf{4 , 3 8 - 4 2}}$ has been always present as one of the most investigated materials, and other candidates have been widely studied too such as $\mathrm{Fe}_{2} \mathrm{O}_{3}$ (n-type, $2.2 \mathrm{eV}$ ), ${ }^{43-45} \mathrm{ZnO}$ (n-type, 3.3-3.4 eV), ${ }^{46,47} \mathrm{WO}_{3}$ (ntype, 2.6-2.8 eV), ${ }^{48-50} \mathrm{BiVO}_{4}$ (n-type, 2.3-2.5 eV), ${ }^{51-54} \mathrm{NiO}$ (ptype, $3.4 \mathrm{eV})^{55}$ and $\mathrm{Cu}_{2} \mathrm{O}$ (p-type, $2.0 \mathrm{eV}$ ). ${ }^{56}$ More materials have been tested, only some of them with remarkable success, as there are several criteria to be met: corrosion potentials less favorable than HER/OER reactions, proper band alignment for large photovoltage generation, and favorable band position for the desired redox reaction.

As it can be observed in Fig. 5, some materials are not useful for water splitting due to unfavorable band alignment, with band edges far from water redox potentials. ${ }^{37}$ To perform the HER reaction, conduction band must be at more negative potentials relative to $\mathrm{NHE}$ than the $\mathrm{H}^{+} / \mathrm{H}_{2}$ potential (black dashed line), and for the OER, at more positive potentials than $\mathrm{O}_{2} / \mathrm{H}_{2} \mathrm{O}$ (red dashed line). For a bias-free reaction, both conditions must be met.

Bard et al. ${ }^{57}$ Gerischer et al. ${ }^{58}$ and other works have discussed in which conditions corrosion reactions are less energetic and thus, thermodynamically more favourable than the HER/OER reaction. S. Chen and $\mathrm{L}$. Wang calculated thermodynamic oxidation and reduction potentials of several semiconductors and compared them to the OER/HER reaction, finding a significant portion of them require protection from corrosion (Fig. 5). ${ }^{37}$ Generally, a photoelectrode is stable to electron reduction if the self-reduction potentials are more negative relative to NHE than either the $\mathrm{H}^{+} / \mathrm{H}_{2}$ or conduction band minimum, and to holes oxidation if self-oxidation potentials are more positive than $\mathrm{O}_{2}$ / $\mathrm{H}_{2} \mathrm{O}$ or valence band maximum.

Some of these oxides, having $3 \mathrm{eV}$ or higher band gaps limit their theoretical maximum current to values lower than $1.8 \mathrm{~mA}$ $\mathrm{cm}^{-2}$, such as $\mathrm{NiO}, \mathrm{TiO}_{2}$ or $\mathrm{ZnO}$. Alternative interesting candidates in relation to the mentioned parameters are $\mathrm{BiVO}_{4}, \mathrm{WO}_{3}$, $\mathrm{Fe}_{2} \mathrm{O}_{3}$ and $\mathrm{Cu}_{2} \mathrm{O}$, with 2.0-2.5 eV band gaps and theoretical maximum photocurrents over $10 \mathrm{~mA} \mathrm{~cm}$ ch $^{-2,60}$ but they are prone to crystallographic disorder. They present significant electronic drawbacks: abundant superficial and internal recombination states, low carrier mobility and lifetime. Hence, optimized fabrication of these materials has turned into one of the main investigation fields. As an example, reducing $\mathrm{Fe}_{2} \mathrm{O}_{3}$ photoanode thickness or nanostructuring it can overcome the extremely short charge diffusion length and lifetime, reaching up to $4.3 \mathrm{~mA} \mathrm{~cm} \mathrm{~cm}^{-2}$ at $1.23 \mathrm{~V}$ vs. RHE, a $34 \%$ of its theoretical maximum photocurrent. ${ }^{43}$ Also, $\mathrm{WO}_{3}$ nanocrystals all grown with a (002) facet orientation have demonstrated to avoid multiple surface energies, and thus, OER overpotentials and kinetics. ${ }^{48}$ 


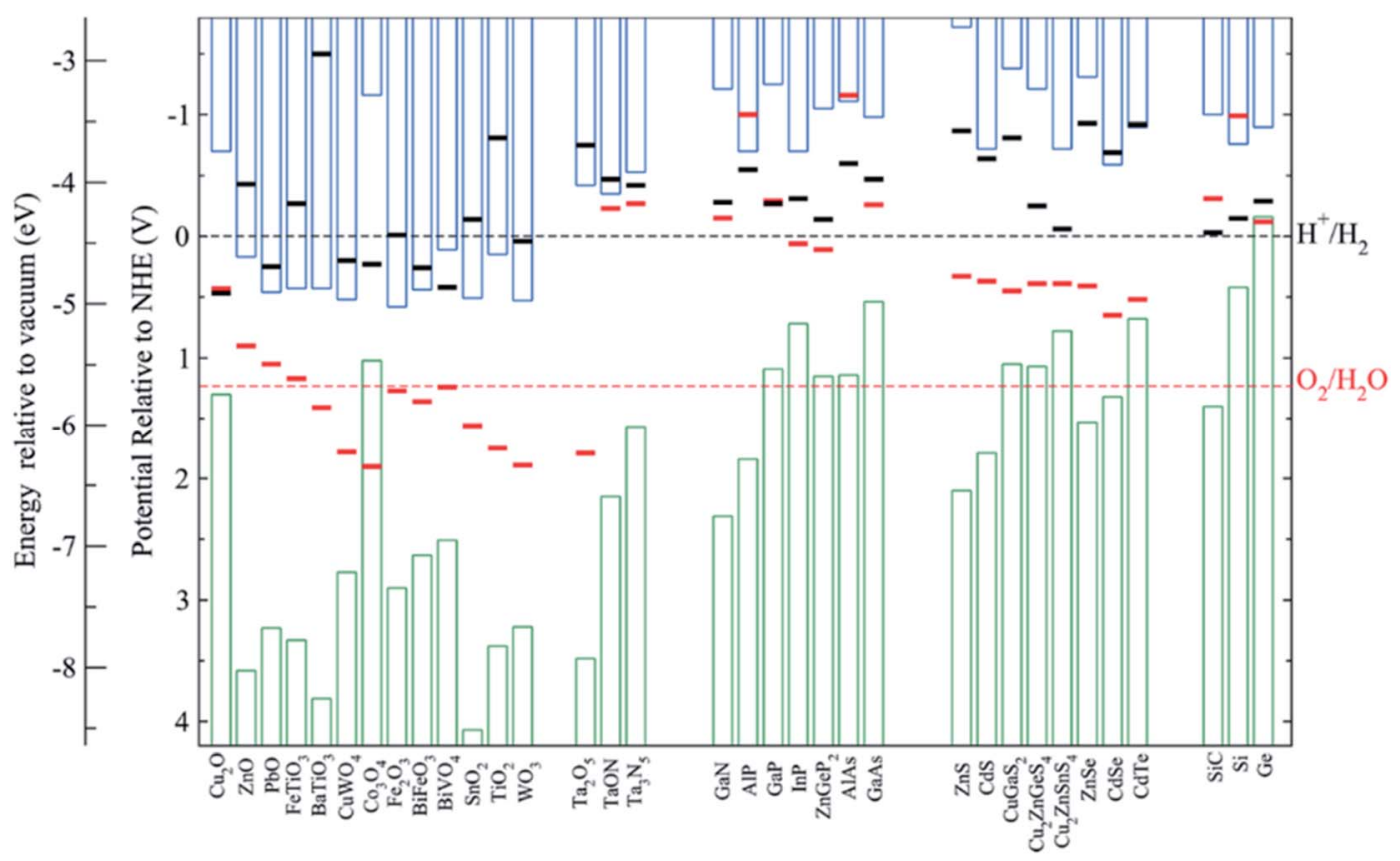

Fig. 5 Self-oxidation (red bars) and self-reduction potentials (black bars), and conduction (blue bars) and valence bands (green bars) relative to $\mathrm{NHE}$ and vacuum potentials for various semiconductors at $\mathrm{pH}=0,298.15 \mathrm{~K}$ and 1 bar. Reprinted with permission from (Chem. Mater., 2012, 24, 3659-3666). Copyright (2012) American Chemical Society. ${ }^{37}$

Even expecting high stability, thoughtful investigations have observed chemical and performance degradation by high $\mathrm{pH}$ electrolytes in photoanodes such as $\mathrm{BiVO}_{4}$ when protective overlayers or cocatalysts are not used. ${ }^{61}$ Further increasing materials complexity by multiple metal oxides have shown unprecedented photocurrents up to $2.4 \mathrm{~mA} \mathrm{~cm}^{-2}$ at $0.4 \mathrm{~V} v s$. RHE for $\mathrm{CuFeO}_{2}$ combined with $\mathrm{NiFe} /$ reduced graphene oxide layers. ${ }^{62}$ The PEC effect based on SCLJ is not limited to oxides. Others such as (oxy)nitrides and nitrides have presented interesting results. ${ }^{63}$ IrO $_{x}-\mathrm{TaON}$ photoanodes ${ }^{64}$ have shown up to 4 $\mathrm{mA} \mathrm{cm}{ }^{-2}$, or $\mathrm{CoO}_{x}-\mathrm{LaTiO}_{2} \mathrm{~N}$ nanoparticulate ones ${ }^{65}$ up to 8.9 $\mathrm{mA} \mathrm{cm} \mathrm{cm}^{-2}$ at $1.23 \mathrm{~V}$ vs. RHE. Although, much more work is needed in this path, as the amount of possible material combinations and fabrication techniques is enormous.

\subsection{Band gap modifications}

Large band gap metal oxides have energy band positions prone for water splitting, but lack significant visible light harvesting. Thus, many attempts have been made to modify their bandgap and increase their visible light absorption. ${ }^{66}$ Creating new states at energies inside the band gap by forming oxygen vacancies or doping with non-metals or transition metals enables smaller energy transitions, thus narrowing the optical band gap. As examples, air annealing ${ }^{67}$ on $\mathrm{TiO}_{2}$ modifies oxygen vacancies, or nitrogen and hydrogen doping ${ }^{68,69}$ was performed by Wang et al., giving a yellowish material and enhancing quantum efficiency in the previously inactive energy wavelengths of 450$600 \mathrm{~nm}$. S doping occupies oxygen vacancies and narrows the band gap, achieving visible light absorption, ${ }^{70}$ among others. ${ }^{71}$ Although, other works have discarded the decrease of the band gap and attribute the performance enhancement to better charge extraction due to increasing n-type semiconductor behaviour when treating samples in hydrogen reductive atmospheres. $^{72}$

However, these improvements have not reached more than a few \% efficiency increase, as creating states inside the band gap also creates detrimental recombination paths for photogenerated electron-hole pairs. Similar studies on bandgap modification by doping have been performed to other materials such as $\mathrm{WO}_{3}$ (ref. 73 and 74) and $\mathrm{ZnO}^{75-77}$

During recent years increased interest has been put to plasmonic nanocrystals to enhance the absorption of light below band gap energies. $\mathrm{TiO}_{2}$ nanotubes sensitized with $\sim 1.5 \mathrm{~nm}$ glutathione-capped $\mathrm{Au}_{x}$ nanoclusters displaying absorption below $525 \mathrm{~nm}$ enhanced light absorption for $\mathrm{TiO}_{2}$ photoanodes, significantly under visible light $(400-500 \mathrm{~nm})$ excitation. ${ }^{78,79}$ Zhang et $a l .{ }^{\mathbf{8 0}}$ demonstrated $20 \mathrm{~nm}$ gold nanoparticles were capable to increase light absorption in the visible range, but also enhance the UV conversion efficiency. Surface plasmon resonance in these gold crystals is proposed to inject hot electrons to the $\mathrm{TiO}_{2}$ conduction band. They found and increase from 1.22 to $2.25 \mathrm{~mA} \mathrm{~cm}^{-2}$ at $1.23 \mathrm{~V} v s$. RHE.

\subsection{Nanoscale material structuration}

Controlling material optical and electronic properties gave metal oxide photoelectrodes a significant push, but optimizing material's morphology by controlling growth process at the nanoscale enabled a completely new field. Nanoscale structuration increases the surface area in contact with the electrolyte, reducing electrochemical kinetic overpotentials by lower 
current densities. Light absorption and charge transport are also enhanced thanks to decoupling light penetration depth and photogenerated charges diffusion length with nanostructures, facilitating charge transport to the electrolyte by enhanced active surface. Planar devices require thicknesses sufficient to absorb a significant portion of the incident light, and photogenerated charges require diffusion lengths $\left(L_{\mathrm{D}}\right)$ large enough to reach the electrocatalytic surface and the back contact. In nanostructured devices, the absorption distance for photons is decoupled from the diffusion length of photogenerated charges and thus, allow for higher absorptions meanwhile reducing travel distance for charges, thus reducing current loss (Fig. 6a). ${ }^{\mathbf{8 1}}$ Moreover, larger active areas in contact with the electrolyte reduce the current density and thus, HER or OER overpotential. 3D structures such as micrometer-size $\mathrm{TiO}_{2}$ anodization, ${ }^{38,69,82-84}$ rutile $\mathrm{TiO}_{2}$ nanorods hydrothermal growth, ${ }^{72,85-87} \mathrm{WO}_{3}$ nanowires and nanoflakes, ${ }^{49,88} \mathrm{ZnO}$ nanorods, ${ }^{46,47,76,77} \mathrm{BiVO}_{4}$ (ref. 51), $\mathrm{Cu}_{2} \mathrm{O}^{59}$ and $\mathrm{Fe}_{2} \mathrm{O}_{3}$ (ref. 45, 89 and 90) have been fabricated with enhanced PEC performance.

For instance, $\mathrm{Cu}-\mathrm{Ti}-\mathrm{O}$ nanotube arrays formed by anodization demonstrated increased active surface (tube length, pore and wall thickness) and light absorption by changing the $\mathrm{Cu}-\mathrm{Ti}$ percentage, giving photocurrents from 0.035 to $0.065 \mathrm{~mA} \mathrm{~cm}^{-2}$ at $-1 \mathrm{~V}$ vs. $\mathrm{Ag} / \mathrm{AgCl}$ in $1: 1$ methanol/ $\mathrm{H}_{2} \mathrm{O}$ electrolyte. ${ }^{91} \mathrm{Cu}_{2} \mathrm{O}$ nanowires protected with $\mathrm{ZnO} / \mathrm{TiO}_{2} / \mathrm{RuO}$ present increased light absorption and charge separation thanks to nanostrcturation, $5 \mathrm{~mA} \mathrm{~cm} \mathrm{~cm}^{-2}$ for planar and $8 \mathrm{~mA} \mathrm{~cm} \mathrm{~cm}^{-2}$ when nanostructured at $0 \mathrm{~V}$ vs. RHE. ${ }^{59,92}$ By macro-mesoporous optimal structuration, $\mathrm{BiVO}_{4}$ photoanodes obtained photocurrents of $2 \mathrm{~mA} \mathrm{~cm}^{-2}$ compared with $0.5 \mathrm{~mA} \mathrm{~cm}^{-2}$ at $1.6 \mathrm{~V} v s$. RHE of the disordered porous films. ${ }^{93}$ Reducing material thickness can shorten the electrical path for photogenerated charges: i.e., $\mathrm{Fe}_{2} \mathrm{O}_{3}$ hematite photoanodes, due to few nanometers carrier diffusion lengths, require nanometer-scale thicknesses to minimize recombination loses. ${ }^{\mathbf{9 4 , 9 5}}$

Combining substrate structuration and nanoscale material deposition, light absorption and photogenerated charge generation and collection can be improved: i.e. controlling Modoped $\mathrm{BiVO}_{4}$ deposition in nanocone-shaped substrates, together with $\mathrm{Fe} / \mathrm{NiOOH}$ catalyst and appropriate phosphate buffered electrolyte achieved up to $6 \mathrm{~mA} \mathrm{~cm}^{-2}$ at $1.23 \mathrm{~V} v s$. RHE. ${ }^{96} \mathrm{TiO}_{2}$-nanorods photoanodes were proven to increase light absorption and thus, photocurrent, when deposited on microstructured glass substrates (Fig. 6b), increasing active area and lateral light incidence to the nanorods. ${ }^{72}$

\subsection{Controlling electronic structure and surface states}

To overcome problems such as inefficient charge separation and transport, generating higher and localized potential gradients through electronic doping is key. Metal, hydrogen or nitrogen doping, and oxygen vacancy control have been studied. $\alpha-\mathrm{Fe}_{2} \mathrm{O}_{3}$ has been doped with several cations such as $\mathrm{Si}, \mathrm{Ti}, \mathrm{Pt}$, $\mathrm{Cr}$, and Mo, finding a decrease of the recombination rate by increasing charge transfer and grain-boundary passivation, ${ }^{\mathbf{9 7 - 1 0 0}}$ or $\mathrm{BiVO}_{4}$ with $\mathrm{Li}$ atoms to enhance bulk charge separation. ${ }^{101}$ CoFe-PBA decoration modified surface states electronic levels enhancing $\mathrm{Fe}_{2} \mathrm{O}_{3} / \mathrm{Fe}_{2} \mathrm{TiO}_{5}$ interfacial charge transfer kinetics. ${ }^{102}$ Also, partially electrochemical reduction to $\mathrm{Fe}_{2} \mathrm{O}_{4}$ (a more conductive phase) can form beneficial conduction paths and reduce recombination. ${ }^{103} \mathrm{BiVO}_{4}$ has been modified both with $\mathrm{W}$ and Mo dopants and by hydrogen treatment to form oxygen vacancies. ${ }^{104}$ For example, porous $\mathrm{BiVO}_{4}$ can double photoactivity with a $2 \%$ Mo incorporation ${ }^{105}$ and potential gradient can be enhanced by gradual incorporation of $\mathrm{W}$ during deposition (Fig. 6c), ${ }^{106}$ or from 0.3 up to $3.5 \mathrm{~mA} \mathrm{~cm}^{-2}$ at $1.6 \mathrm{~V} v s$. RHE by hydrogenation at $300{ }^{\circ} \mathrm{C}$ thanks to increased donor density, enhancing electron-hole separation and transport. ${ }^{107} \mathrm{BiVO}_{4}$ Fermi level has been shown to rise while water exposure due to superficial oxygen decreasing, partially reducing $\mathrm{BiVO}_{4} \cdot{ }^{108} \mathrm{TiO}_{2}$ electronic band structure has also been intensively studied, where the depletion region was optimized in nanorod structures by vacancy formation with thermal treatments under ammonia $^{87}$ or hydrogen ${ }^{72}$ atmosphere, increasing its photocurrent up to $1.2 \mathrm{~mA} \mathrm{~cm} \mathrm{~cm}^{-2}$ at $1.23 \mathrm{~V}$ vs. RHE.

Also, minimizing superficial electronic states, when acting as trap states, is interesting to reduce photogenerated electronhole recombination and thus, enhancing PEC efficiency. This can be achieved controlling the synthesis and post-treatments, and incorporating other metals on the surface to fill the traps and to act as OER catalysts. $\mathrm{Fe}_{2} \mathrm{O}_{3}$ photoanodes surface recombination can be reduced by $\mathrm{CoO}_{x},{ }^{109} \mathrm{Ga}_{2} \mathrm{O}_{3}$ (ref. 109 and 110) or $\mathrm{TiO}_{2}$ (ref. 111) surface states passivation. $\mathrm{TiO}_{2}$ surface recombination rate was lowered by removing detrimental chlorine atoms (blocking oxygen evolution active sites) by a $250{ }^{\circ} \mathrm{C}$ annealing treatment, ${ }^{85}$ or by increasing hydroxyl groups acting as hole trap sites after ammonia treatments. ${ }^{87}$ Depositing atomically-thin films covering the surface is also a very effective strategy to supress detrimental superficial states, avoiding recombination paths and contributing to shifts in the band positions of the metal oxide photoelectrode respect to the electrolyte, enhancing obtained potentials. ${ }^{\mathbf{1 1 2 , 1 1 3}}$ Optimal postfabrication temperature and atmosphere annealing control has a key role in many metal oxides such as $\alpha-\mathrm{Fe}_{2} \mathrm{O}_{3}$, where morphology, Sn doping, and introduction of oxygen vacancies, enhances significantly the performance in a low oxygen annealing atmosphere. ${ }^{114}$

\subsection{Surface decoration with cocatalysts}

Photoelectrodes such as $\mathrm{Fe}_{2} \mathrm{O}_{3}, \mathrm{CuO}_{2}$ or $\mathrm{TiO}_{2}$ have suitable surface states to directly perform the desired reaction, but the use cocatalysts can enhance their performance thanks to favourable superficial energetics, improving reaction kinetics. Examples of these catalysts are Pt, $\mathrm{MoS}_{2}$ or $\mathrm{RuO}_{x}$ for the HER reaction and $\mathrm{Ni} / \mathrm{FeOOH}, \mathrm{CoPi}$ or $\mathrm{IrO}_{x}$ for the OER (Fig. 6d). ${ }^{19,35,116-118}$ Some of these cocatalysts are noble metals (Pt, Ru, Ir, ...), scarce and expensive for large-scale deployment, what has pushed investigation in earth-abundant alternative efficient electrocatalysts..$^{21,115,119}$

In the HER case, photocathodes such as $\mathrm{Cu}_{2} \mathrm{O}$ have been decorated with Pt (best performing HER catalyst) and $\mathrm{RuO}_{x}{ }^{59}$ and also earth abundant $\mathrm{MoS}_{2}$ cocatalysts. ${ }^{20,115}$ Tilley et al. used $\mathrm{RuO}_{x}$ or Pt as catalysts and an $\mathrm{AZO} / \mathrm{TiO}_{2}$ protective layer (also 
a.

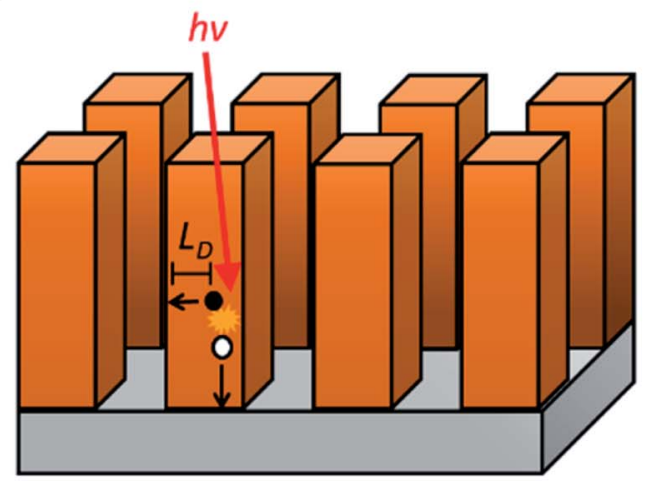

b.

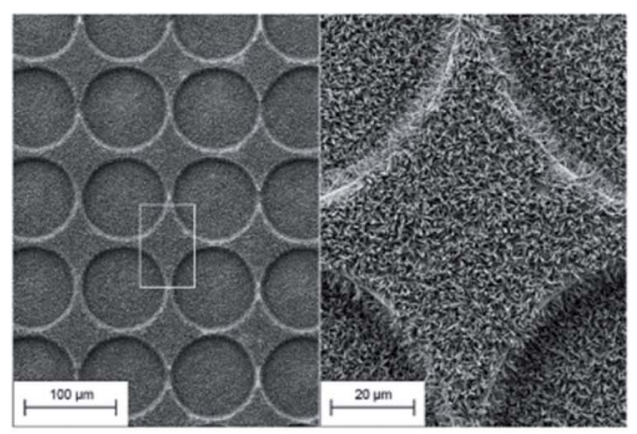

C.

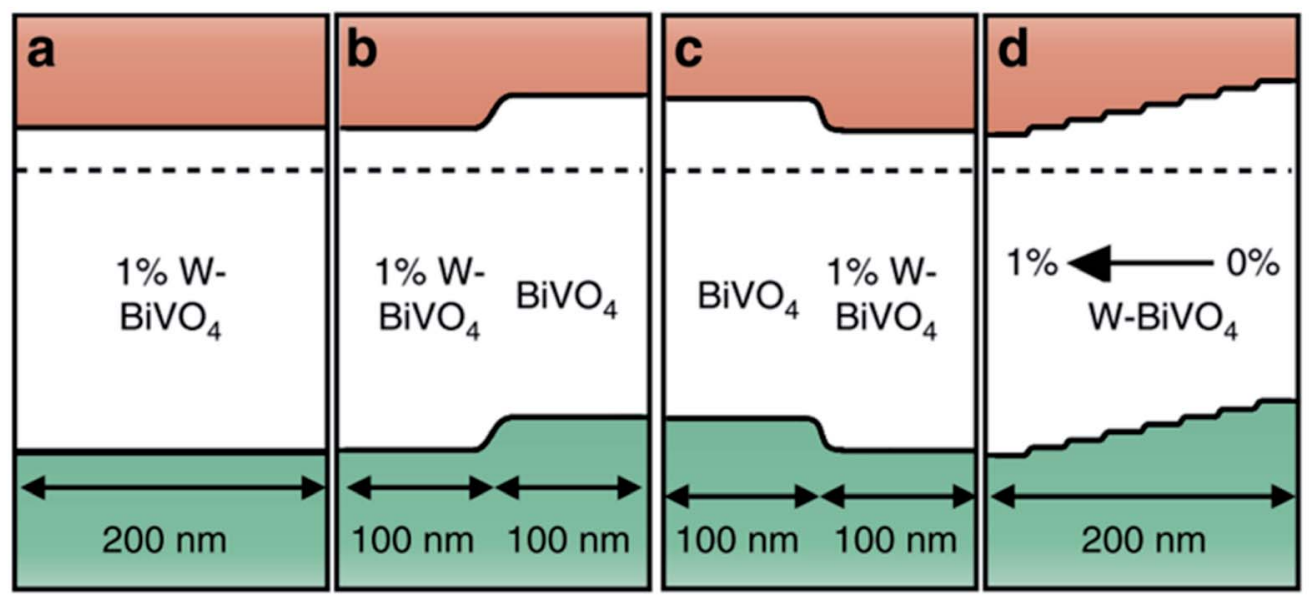

d.

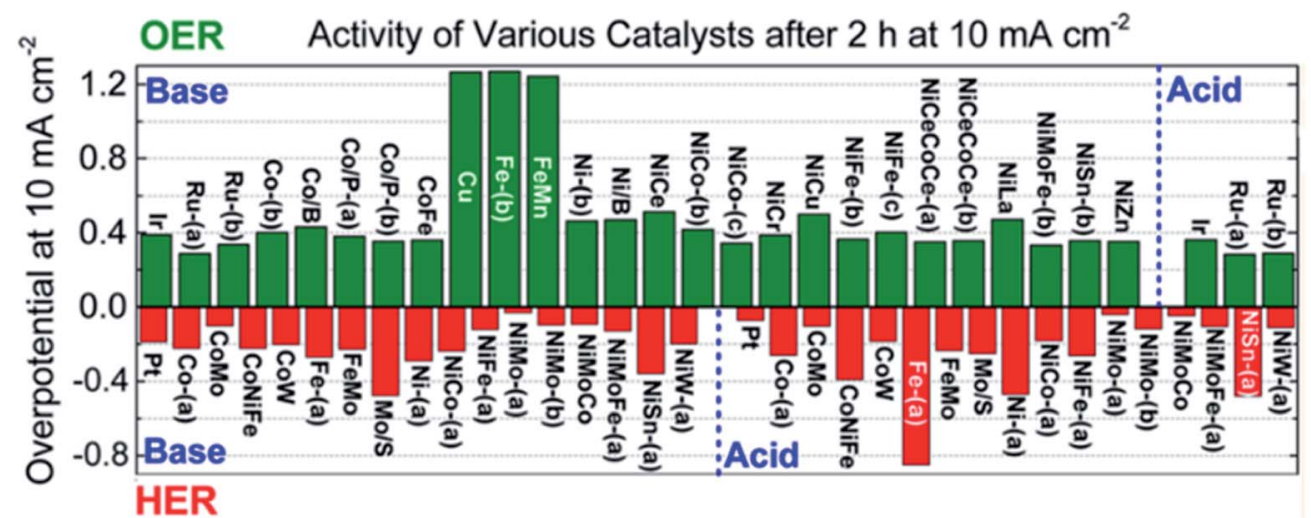

Fig. 6 (a) Requirements for light absorption and charge diffusion lengths $\left(L_{D}\right)$. In nanostructured devices, the absorption distance for photons is decoupled from the diffusion length of photogenerated charges. (b) Glass/FTO substrate microstructuration covered by $\mathrm{TiO}_{2}$ nanorods deposited by hydrothermal. Reprinted with permission from (J. Phys. Chem. C, 2018, 122, 3295-3304). Copyright (2018) American Chemical Society. ${ }^{72}$ (c) Energy band diagrams of different $\mathrm{W}$ doping configurations of $\mathrm{BiVO}_{4}$ photoanodes, enhancing charge separation and transport. Reprinted with permission from (Nat. Commun., 2013, 4, 1-7). Copyright (2013) Springer Nature. ${ }^{106}$ (d) Overpotentials for $10 \mathrm{~mA} \mathrm{~cm}^{-2} \mathrm{currents}$ of several OER and HER catalysts in acidic and basic electrolytes. Reprinted with permission from (J. Am. Chem. Soc., 2015, 137, 4347-4357). Copyright (2015) American Chemical Society. ${ }^{115}$ 
forming an heterojunction) to obtain over $0.55 \mathrm{~V} v s$. RHE onset potential and $5 \mathrm{~mA} \mathrm{~cm}{ }^{-2}$ photocurrents for $\mathrm{Cu}_{2} \mathrm{O}$ photocathodes. ${ }^{120}$ Amorphous $\mathrm{MoS}_{2}$ allowed earth-abundant $\mathrm{Cu}_{2} \mathrm{O}$ for up to $5.7 \mathrm{~mA} \mathrm{~cm}^{-2}$ at $0 \mathrm{~V} v s$. RHE at $\mathrm{pH} 1 .^{121}$

OER reaction is a complex four electron process, with slow kinetics in most of the surfaces. ${ }^{95}$ Enhancing reaction kinetics or reducing potential barriers thanks to cocatalysts have improved the performance of $\mathrm{TiO}_{2}$ and $\mathrm{Fe}_{2} \mathrm{O}_{3}$ photoanodes. ${ }^{122}$ For example, hierarchically nanostructured $\mathrm{TiO}_{2}$ photoanodes decorated with $\mathrm{Au}$ particles doubled photocurrent up to $2 \mathrm{~mA}$ $\mathrm{cm}^{-2}$ at $1.23 \mathrm{~V}$ vs. $\mathrm{RHE} ;{ }^{123}$ or $\alpha-\mathrm{Fe}_{2} \mathrm{O}_{3}$ ones obtained up to $15 \%$ current increase and over $200 \mathrm{mV}$ cathodic shift with Cobalt phosphate (Co-Pi) electrocatalyst. ${ }^{124} \mathrm{Co}-\mathrm{Pi}$ also improved $\mathrm{BiVO}_{4}$ photoanodes performance up to $1.7 \mathrm{~mA} \mathrm{~cm}^{-2}, 53,105$ and $\mathrm{FeOOH}$ catalyst incorporation in a $0.1 \mathrm{M} \mathrm{KH}_{2} \mathrm{PO}_{4}+0.1 \mathrm{M} \mathrm{Na}_{2} \mathrm{SO}_{3}$ electrolyte, increased $\mathrm{BiVO}_{4}$ anodic photocurrent to $2.0 \mathrm{~mA} \mathrm{~cm}{ }^{-2}$ at 1.23 vs. RHE. ${ }^{52}$

\subsection{Metal oxide heterojunctions}

Up to now, improvement strategies for single metal oxides have been analysed, but the combination of different metal oxides opens a whole field of opportunities. By the introduction of other materials layers or substrates, charge separation can be improved by forming heterojunctions.

For photoanodes, several authors have studied the $\mathrm{WO}_{3} /$ $\mathrm{BiVO}_{4}$ heterojunction, obtaining up to $4 \mathrm{~mA} \mathrm{~cm}{ }^{-2}$ at $1.23 \mathrm{~V} v$. RHE, almost doubling productivity obtained by each oxide separately. ${ }^{\mathbf{8 8 , 1 2 5}}$ The band energy difference of the two materials enhances charge separation, and different band gaps allow for increased light absorption. Also, covering a $\mathrm{BiVO}_{4}$ photoanode with $\mathrm{ZnFe}_{2} \mathrm{O}_{4}$ overlayer increased its photocurrent and decreased the onset potential, helped in making it resistant to alkaline electrolytes, sustaining $3 \mathrm{~mA} \mathrm{~cm}^{-2}$ at $1.23 \mathrm{~V} v s$. RHE. ${ }^{51}$

For photocathodes, $\mathrm{Cu}_{2} \mathrm{O}$ was covered with an $\mathrm{AZO} / \mathrm{TiO}_{2} / \mathrm{Pt}$ multilayer grown by atomic layer deposition (ALD), obtaining stable and up to $2 \mathrm{~mA} \mathrm{~cm}{ }^{-2}$ photocurrents at $0 \mathrm{~V} v s$. RHE. ${ }^{\mathbf{9 2}}$ Similar structures but on $\mathrm{Cu}_{2} \mathrm{O}$ nanowires and with $\mathrm{RuO}_{x}$ as catalyst increased the photocurrent up to $8 \mathrm{~mA} \mathrm{~cm}^{-2}$ at $0 \mathrm{~V} v s$. RHE, almost the double than the same $\mathrm{Cu}_{2} \mathrm{O} / \mathrm{AZO} / \mathrm{TiO}_{2} / \mathrm{RuO}_{x}$ structure on planar photoelectrodes. ${ }^{59}$

Other works have used 3D nanostructuration combined with heterojunction formation with different bandgap materials used to create core-shell structures to obtain the best of each part. For example, porous $\mathrm{WO}_{3}$ layers grown on top of $\mathrm{Si}$ microwires have been deposited, enhancing light absorption and photogenerated charge collection and transport (Fig. 7a). ${ }^{126-128}$ Liu et al. demonstrated a Z-scheme photoelectrode depositing $\mathrm{TiO}_{2}$ nanorods on the top of Si microwires, making each of the tree-like structures a bias-free photoelectrode. ${ }^{129} \mathrm{TiO}_{2}$ nanorods on top of $\mathrm{Si}$ microwires combine large and small bandgap materials too (Fig. $7 \mathrm{~b}$ and c), ${ }^{\mathbf{1 2 9 , 1 3 0}}$ although much work is still needed to overcome interfacial detrimental charge recombination paths. The strategy to use small band gap semiconductors such as Si opens a completely new field of scheme possibilities, increased productivities and new challenges, which will be discussed in following sections.

\subsection{Overall metal oxide enhancement}

As has been reviewed over Section 3, there are several strategies to enhance the performance of metal oxide photoelectrodes, and the best performing works are those using several of them in a synergistic way. For photocurrents over $2 \mathrm{~mA} \mathrm{~cm}{ }^{-2}$ band gaps shorter than $3 \mathrm{eV}$ are mandatory, material selection is key. Band gap modification was demonstrated possible, although with reduced photocurrent increase together with the introduction of significant recombination rates. Increasing the absorption for energies below band gap with plasmonic surface resonance has presented disruptive results and more work will be needed in this field. Meanwhile, heterojunction formation with different materials opens an enormous amount of possibilities to put together the best characteristics of different materials and to increase the maximum photovoltage and photocurrent.

Nanoscale structuration of the photoelectrode into nanowires, nanorods or other structures has enhanced some low charge mobility materials such as $\mathrm{TiO}_{2}$ and $\mathrm{Fe}_{2} \mathrm{O}_{3}$ thanks to reducing diffusion length of photogenerated charges together with increased active area. This nanostructuration is only interesting if highly ordered crystalline structures are generated, with high charge mobility and ordered surfaces. An increased defective surface could simultaneously enhance open bonds and electronic states at the surface, increasing the recombination rate. The best results using nanoststructuration have been the ones where the photoelectrodes are synthesized with techniques such as hydrothermal growth, capable to fabricate highly ordered crystalline nanostructures.

Finally, catalyst incorporation has revealed to be key if significant currents are to be obtained. Metal oxide surfaces have been demonstrated favourable for the OER reaction but, if photocurrents are to be increased at least up to $10 \mathrm{~mA} \mathrm{~cm}$, efficient kinetics are also necessary and this has only possible with some materials as presented in Fig. $6 \mathrm{~b}$.

The work of Luo et al., with $\mathrm{Cu}_{2} \mathrm{O}$ nanowires wrapped by $\mathrm{AZO}, \mathrm{TiO}_{2}$, and $\mathrm{RuO}_{x}$ layers, is a good example on how combining nanostructuration, synthesis optimization, multilayer heterojunction and cocatalyst decoration makes it possible to approach the theoretical maximum photocurrent of $14 \mathrm{~mA} \mathrm{~cm}^{-2} .{ }^{59}$ These extra layers also protected the $\mathrm{Cu}_{2} \mathrm{O}$ photoabsorber from corrosion, as it would reduce to metallic $\mathrm{Cu}$ due to monovalent copper oxide having the redox potentials within the bandgap..$^{92}$

\section{Short band gap semiconductors for PEC water splitting}

In the previous section, strategies to overcome the main drawbacks presented by metal oxide photoelectrodes for water splitting were discussed. The successful candidates and modification strategies capable of obtaining photocurrents higher than $8 \mathrm{~mA} \mathrm{~cm}^{-2}$ with significant photovoltages are very few. In parallel to PEC water splitting development, the photovoltaic field (PV) science and industry has optimized photoabsorbers and fabrication techniques up to commercial devices with minimal recombination and transport losses. PV productivities 
a.

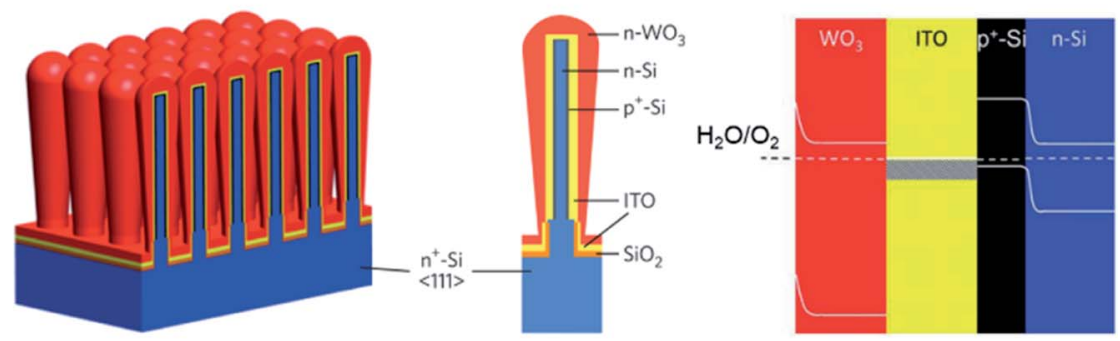

b.

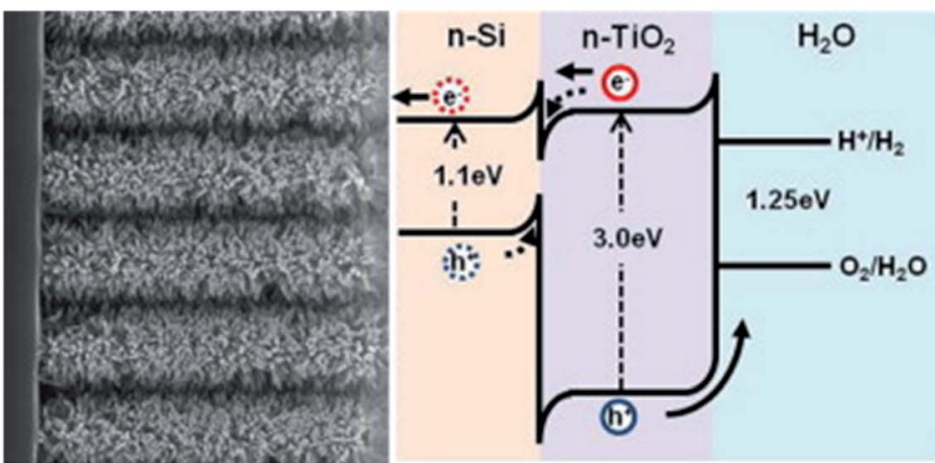

Branched $\mathrm{TiO}_{2} / \mathrm{Si}$ NWs photoanode

C.
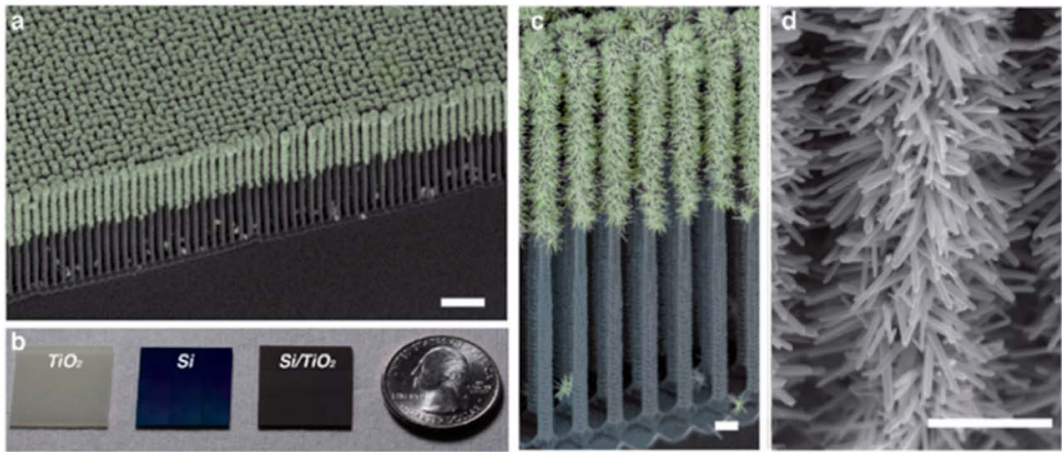

Fig. 7 (a) Scheme of an $\mathrm{np}^{+}-\mathrm{Si} / \mathrm{WO}_{3}$ tandem structure including an ITO film in-between forming an ohmic contact (left) and its corresponding band diagram (right). Reprinted with permission from (Energy Environ. Sci., 2014, 7, 779). Copyright (2014) Royal Society of Chemistry. ${ }^{126}$ (b) SEM image of $\mathrm{TiO}_{2}$ nanorods grown on $\mathrm{n}$-Si microwires to form an heterojunction and its corresponding band diagram. Reprinted with permission from (Energy Environ. Sci., 2014, 7, 779). Copyright (2014) Royal Society of Chemistry. ${ }^{130}$ (c) Fully integrated tandem structure with the top part of Si microwires covered by $\mathrm{TiO}_{2}$ nanorods and bottom part not, forming a "tree" tandem structure. Reprinted with permission from (Nano Lett., 2013, 13, 2989-2992). Copyright (2013) American Chemical Society. ${ }^{129}$

have been based on short band gap materials (1-1.5 eV) capable of absorbing the majority of visible spectrum, with materials achieving large carrier mobility thanks to minimized defects and disorder. ${ }^{\text {131-134 }}$ Monocrystalline silicon-based solar cells, giving photocurrents over $40 \mathrm{~mA} \mathrm{~cm}^{-2}$ and $700 \mathrm{mV}$ open circuit photovoltages are nowadays largely dominating the market thanks to relatively cheap price and material abundance, several years operation stability and efficiencies over 22\%. Monocrystalline silicon has not been the only photoabsorber commercialized: polycrystalline and amorphous silicon, together with CdTe, GaAs and CIS/CIGS have been already commercialized, and other semiconductors such as perovskites or CZTSSe are emerging rapidly (Fig. 8). ${ }^{131}$

During the last decade, implementing short band gap materials in PEC water splitting has attracted much interest, thanks to all the knowledge and development from PV industry and thus, the possibility to obtain significantly higher outputs than with metal oxides. Although, the use of these 
photoabsorbers presents extra challenges added to the photovoltaic ones. Not having a large band gap, and thus photovoltage, will require a tandem structure combining $\sim 1.1$ and 1.6-1.8 eV semiconductors photovoltages or an external bias to use all of their capacity, as it will be reviewed in Section 8.2, tandem PEC devices. Moreover, monolithic photoelectrodes must be immersed in the electrolyte, preferably in acidic or alkaline electrolytes where the electrochemical activity is highly enhanced. But these electrolytes are normally corrosive for most of the presented photovoltaic materials. Strategies to overcome these instabilities must be found to enable these materials for PEC water splitting.

\subsection{Fundamentals of materials corrosion}

In PEC devices, years-long photoabsorber sustained activity will be necessary for cost-effective devices, thus materials facing the electrolyte have to be thermodynamically stable in the selected electrolyte or extremely low corrosion kinetics must be involved, as discussed in Section 3.1.

Some possible corrosion mechanisms can be material dissolution into the electrolyte, superficial insulator layer formation, or chemical detrimental modifications of the photoabsorber, all of them capable of disabling PEC activity. Pourbaix diagrams, where the electrochemical stability for different redox states of an element as a function of $\mathrm{pH}$ is plotted, present a first approximation to predict the theoretical thermodynamic stability of a certain material in an aqueous environment. ${ }^{\mathbf{1 3 8}}$ They provide data if there will be a state of oxidation change (i.e. passivation) and/or a phase change (i.e. dissolution) of a certain material when varying the applied potential or electrolyte's pH. Some examples are presented in Fig. 9. If complex nanostructures are used as catalytic surfaces, their corrosion (chemical and mechanical) must also be taken in account. ${ }^{139}$

\subsection{Small band gap semiconductors corrosion examples in aqueous electrolytes}

Each material is affected by corrosion in different ways, depending on most favourable reaction governed by $\mathrm{pH}$ or applied potentials, so it must be analysed in its specific conditions. For example, silicon, by far the most used PV photoabsorber, has been reported to corrode through different processes depending on the used electrolyte. ${ }^{\mathbf{1 4 0 - 1 4 4}}$ Both in HER or OER potentials, silicon stability will depend on $\mathrm{pH}$, being oxidation in acidic or dissolution in alkaline. The self-limited passivation reaction of Si forming a thin $\mathrm{SiO}_{2}$ layer in acidic electrolytes $(\mathrm{pH} \sim 0),{ }^{145}$ a transparent but highly insulator layer, will eventually stop charge injection into the water splitting reaction. Whereas, formed $\mathrm{SiO}_{2}$ dissolves in alkaline electrolytes ( $\mathrm{pH} \sim 14$ ) and will continuously etch the photoelectrode forming recombination paths for photogenerated charges or even dissolving the $\mathrm{p}-\mathrm{n}$ junction, rapidly losing photocurrent. ${ }^{\mathbf{1 4 0 , 1 4 1 , 1 4 5}}$ Thus, in acidic electrolytes selflimited $\mathrm{SiO}_{2}$ formation in pinholes will not significantly affect overall performance if the rest of the surface is protected, ${ }^{\mathbf{1 4 6}}$ but in alkaline electrolytes will not stop etching the silicon beneath, and thus, eventually fatal for the photoelectrode. ${ }^{145}$

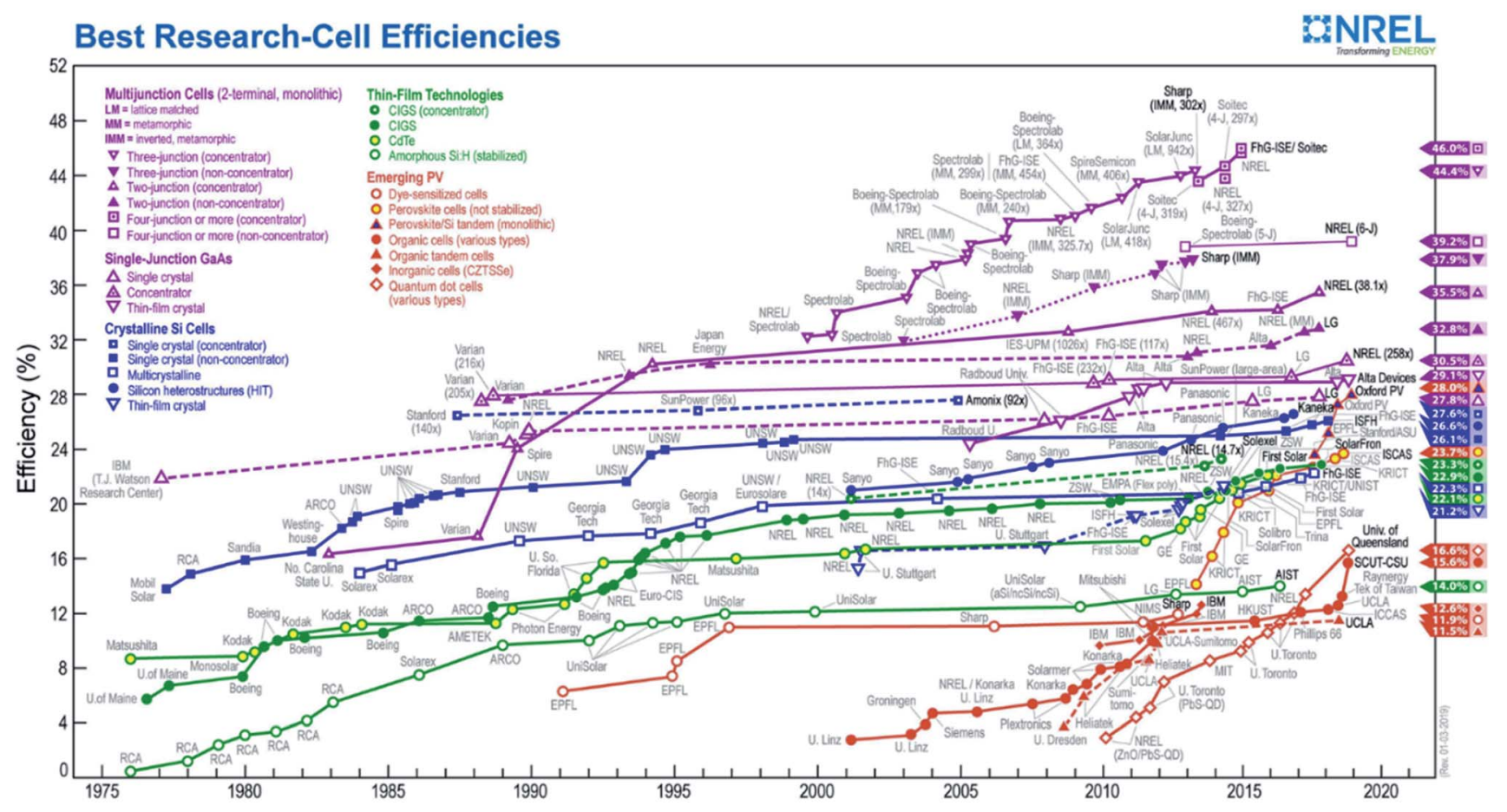

Fig. 82019 plot of highest-recorded photovoltaic efficiency by year of various photovoltaic devices classified by technology (colours). Prepared by the National Renewable Energy Laboratory (NREL, http://www.nrel.gov). 
Regarding other PV cells based on photoabsorbers such as cadmium-telluride (CdTe), copper-indium/gallium-selenide (CIS/CIGS/CGS) or its earth-abundant alternative, copper-zinctin-sulphide/selenide (CZTS/Se), their own structure is based on a multiple materials stack, also containing transparent conductive oxides (TCO, like In : $\mathrm{SnO}_{2}$ (ITO) or $\mathrm{Al}: \mathrm{ZnO}(\mathrm{AZO})$ ) and n-type CdS, forming the $\mathrm{p}-\mathrm{n}$ junction. $\mathrm{ZnO}^{147,148}$ and $\mathrm{SnO}_{2}$ (ref. 147, 149 and 150) are not stable in highly acidic or alkaline electrolytes or reductive potentials, as they form soluble species. ${ }^{147,150}$ Regarding $\mathrm{CdS}^{151-153}$ and also CdTe, ${ }^{154} \mathrm{Cd}$ dissolves in highly acidic and alkaline electrolytes, ${ }^{\mathbf{1 5 5}}$ and is thermodynamically stable only at significant cathodic overpotentials, not attained without applied bias. Cu-based photoabsorber (CIS, CIGS, CZTS, ...) are complex multielement films, highly electronically sensible to vacancies, and would be significantly degraded in contact with electrolytes, although losing the $\mathrm{p}-\mathrm{n}$ junction with CdS is the main degradation factor.

Among other emerging photovoltaic materials, ${ }^{131}$ there is none expected to be highly stable for PEC applications under direct contact with the electrolyte. Cells fabricated with silicon, no matter if it is monocrystalline, polycrystalline, HIT, amorphous or micro/nanocystalline ${ }^{156}$ will suffer from dissolution or passivation when exposed to alkaline or acidic electrolytes, respectively, as discussed previously. Perovskites, a highly promising PV material, have a main drawback: significant degradation under humidity, ${ }^{157}$ what would require extra encapsulation efforts, especially if put to work in contact with aqueous electrolytes, although some works have fabricated perovskite-based photoelectrodes ${ }^{\mathbf{1 5 8}}$ with special efforts in protecting them. ${ }^{\mathbf{1 5 9}}$ Organic solar cells have been implemented in PEC $^{\mathbf{1 6 0}}$ but require careful selection of redox couples, limiting their efficiency and pointing in stability problems. Dye sensitized solar cells (DSSC) or Grätzel cells, molecular dye decoration of a $\mathrm{MO}_{x}$ framework as an intermediate to OER/HER catalyst presents significant instability of the molecular dye in the used potentials and electrolytes ranges. Thus, low productivities are expected, ${ }^{161}$ or full cell encapsulation would be required, then further connected to the electrolyte with an external circuit, forming a PV-EC device configuration. ${ }^{\mathbf{1 6 2}}$

\section{Protective layers to implement photovoltaic photoabsorbers into water splitting}

Several strategies are possible to implement highly active photoabsorber materials into PEC water splitting avoiding their corrosion. Some authors have functionalized the surface of semiconductors with organic reagents like two-step chlorination/alkylation ${ }^{\mathbf{1 6 3}}$ or by an alkylation through the halogenation/ Grignard route ${ }^{164}$ to suppress corrosion, with relative success, but the majority of efforts have been put on depositing inorganic layers onto the photoabsorber to separate it from direct contact with the electrolyte. ${ }^{\mathbf{1 1 2 , 1 6 5}}$ Protective ultrathin layers of any material must consider even very slow dissolution rates (chemical or mechanical) for long-term operating devices, especially when considering flow systems and direct contact with gas bubbling.

These protective layers must allow electrical conduction, be thermodynamically stable, and optically transparent. M. F. Lichterman et al. stated all the properties under the acronym "SABOR", meaning "Stable in the thermodynamic, kinetic, and mechanical senses when incorporated onto the semiconductor, immersed in the electrolyte, and operated at the potentials of interest; Active catalytically for the OER/HER, either possessing intrinsic catalytic activity or integrating the activity of a cocatalyst; capable of providing Built-in electronic asymmetry to allow for the separation of electrons and holes, or to allow for a separate buried junction to perform efficiently; Optically transparent to provide optical properties that are optimized for the transmission of light; and, capable of providing low Resistance, to allow for charge-carrier conduction with minimal performance loss due to $i R$ drops". ${ }^{166}$

With protective layers incorporation, device complexity increases but photovoltage will now be governed by a solid-state junction rather than by the photoabsorber-electrolyte junction, increasing the possible materials candidates to be used. The extra layer can either form an heterojunction, or protect a buried junction. In addition, if the protective layer is not catalytic, an extra catalyst (layer or particles) must be added to reduce overpotentials. Although several interesting heterojunction strategies have been demonstrated for PEC water splitting electrodes with more or less success, focus will be put on extracting maximum efficiency from the photoabsorbers, using these extra layers to protect the photovoltaic-like junctions and the different techniques to deposit them.

\subsection{Thin film deposition techniques}

Thin film technology has become one of the main fields of study last decades, from basic sciences to industrial processes. Controlling material deposition at the nanoscale opens a whole new world of possibilities by combining physical and chemical properties from single or multiple element materials with overcoming intrinsic limitations due to phenomena only happening at the nanoscale. ${ }^{\mathbf{1 6 7}}$ For example, titanium dioxide, a wide band gap metal oxide, considered insulator at the macroscale, is conductive at the nanoscale; or metals, highly visible-light reflective and absorptive, can be turned into transparent if deposited few nanometers thick. There are a large amount of deposition techniques and variations among them for diverse applications, but some of the most used ones for inorganic thin film protective layers have been selected.

There are many non-vacuum liquid and chemical-based thin film deposition techniques, but not all of them are used to synthesize protective layers for different reasons. Among the liquid-based thin film deposition techniques, dip coating, spin coating or chemical bath deposition $(\mathrm{CBD})^{\mathbf{1 6 8}}$ are the more used ones, but require direct contact of the photoabsorber with a liquid, what might alter its superficial chemical state and thus, performance. In addition, liquid-based techniques normally produce either porous, not homogeneous at the nanoscale or abundant-pinhole films compared to vacuum 
a.
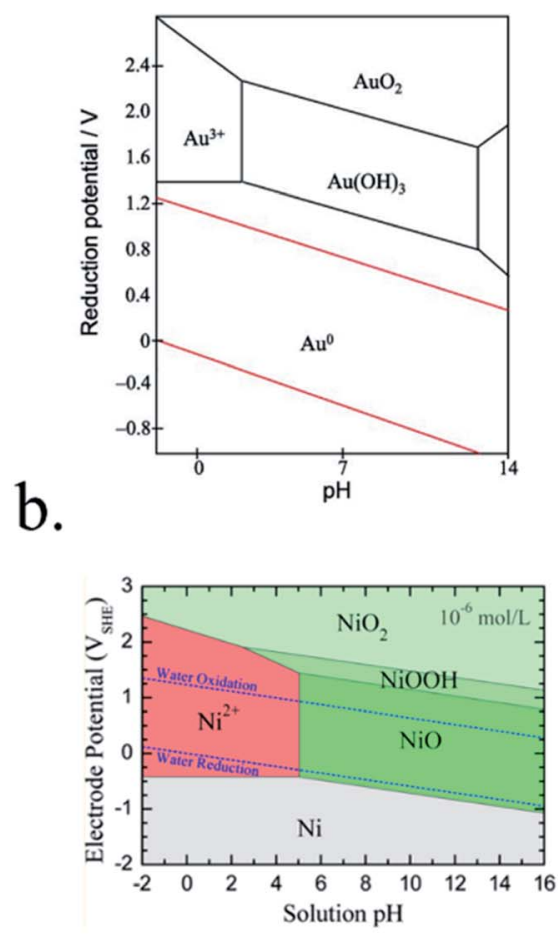

c.

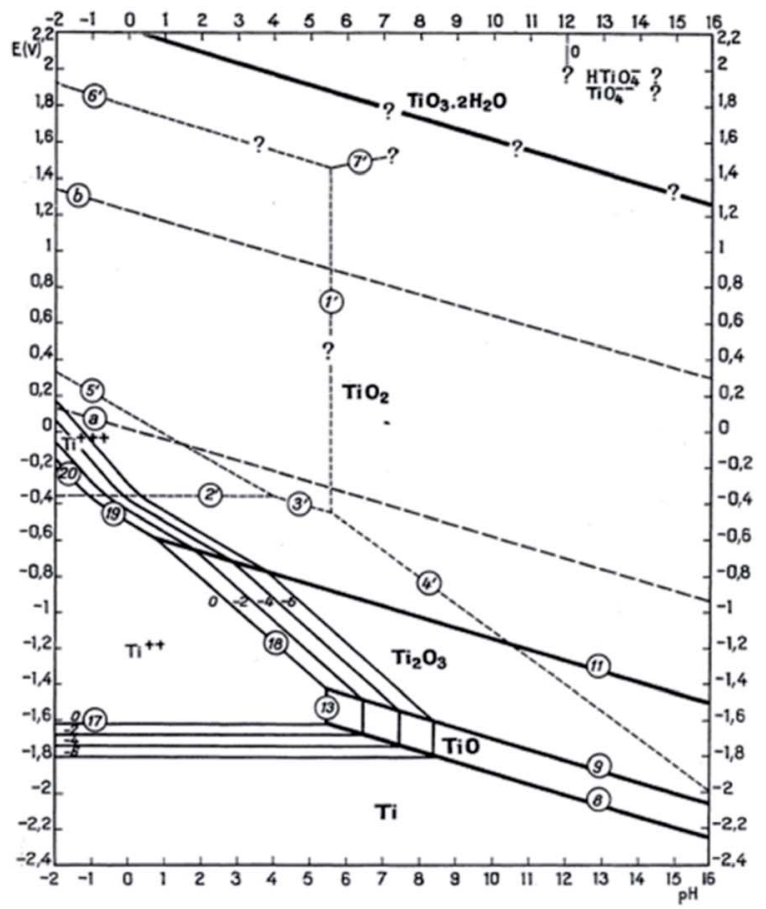

Fig. 9 Examples of Pourbaix diagrams of (a) gold (reproduced from Huayhuas-Chipana et al. ${ }^{135}$ ) (b) nickel (reprinted with permission from (J. Phys. Chem. C, 2017, 121, 9782-9789). Copyright (2017) American Chemical Society. ${ }^{136}$ ) and (c) titanium in aqueous electrolytes (reprinted with permission from Parsons ${ }^{137}$ copyright (2017) J. Electroanal. Chem. Interfacial Electrochem.).

technologies, and to eliminate precursor residues or crystallize them they require thermal post-treatments, which can create cracks in the protective layer or affect the photoabsorber. For example, solution-deposited $\mathrm{TiO}_{2}$ by spin-casting or spray pyrolysis presented significant pinholes, allowing electrolyte to penetrate and dissolve the photoabsorber, being fatal for the device even with $80 \mathrm{~nm}$ thick layers. ${ }^{169}$

Electroplating is one of the oldest techniques to form metallic thin films since the $19^{\text {th }}$ century. Generally known as electrochemical deposition, ${ }^{170}$ a conductive substrate (in our case, the photoabsorber) is introduced in an electrolyte containing the desired thin film precursor ions and, under controlled polarization, a redox reaction occurs, forming a film of electrodeposited material in the surface of the electrode (Fig. 10a). It can be extended to any material capable to be deposited in a certain potential window that will depend on the electrolyte media, and is very interesting thanks to its easiness and the wide range of materials possible to be deposited, from metals to metal oxides and sulphides, even with nanoscale morphology control. It requires no vacuum, usually it is carried out at room or moderate temperatures, and with affordable infrastructure, like a power supply, lab equipment and the precursor materials. As drawbacks, it is highly depending on the substrate, that needs to be conductive, and has a moderate throwing power (the capacity to deposit an uniform film over an irregular substrate), not suitable for nanostructured substrates where a high aspect ratio is required. In some cases, nucleation promote the formation of particles rather than a layer, such as electrodeposited Ni oxide/hydroxide, a transparent, chemically resistant and catalytic material, that forms porous layers, ${ }^{23,171}$ not isolating the substrate from electrolyte, whereas NiO deposited by sputtering creates a solid impermeable layer. ${ }^{172}$ Also, the substrate will be in direct contact with the electrolyte and its properties can be affected. Many works have used electrochemical techniques to deposit catalytic particles or films to enhance OER or HER kinetics on already previously protected semiconductors. ${ }^{173}$

Vacuum technologies allow for an inert and controlled atmosphere deposition, favourable for more homogeneous deposited films and process-control. ${ }^{168}$ Among the physical vapour deposition (PVD) techniques, thermal evaporation is one of the simplest, where a crucible is heated to high temperatures, vaporizing the materials contained. ${ }^{168,174}$ Evaporated particles will travel and solidify forming a film on top of a substrate (Fig. 10b). However, as different elements vaporize at different temperatures, the technique is useful for single element metals but has reduced stoichiometry reproducibility for mixes elements. Evaporated metallic films have been used as intermediate, protective or catalytic layers in water splitting. Sputtering deposition ${ }^{175,176}$ is based on an inert gas (i.e. argon) being ionized and accelerated towards a blank, impacting with high energies and removing particles which will travel until 
a.

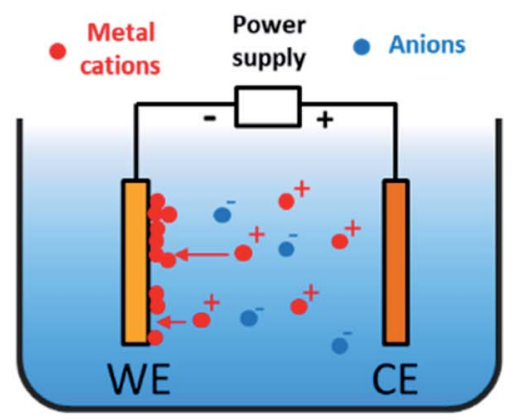

Electrochemical deposition

b.

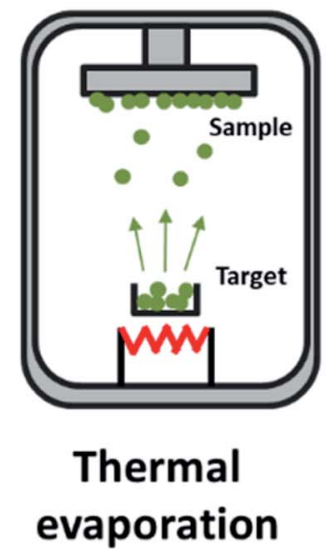

c.

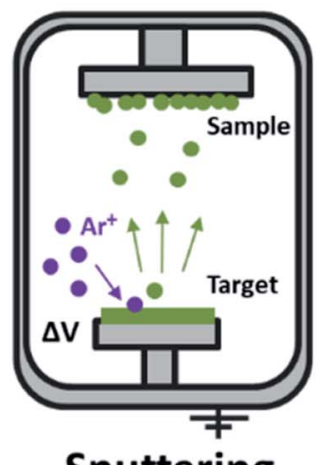

Sputtering

Fig. 10 Representative schemes of thin film deposition techniques by (a) electrochemical deposition, (b) thermal evaporation and (c) sputtering.

being deposited in our substrate (Fig. 10c). Direct current (DC) sputtering is useful for conductive blanks (materials to be deposited), and radio-frequency (RF) sputtering allows insulator materials deposition. In reactive sputtering, other gases can be introduced at low pressures in the chamber, reacting with the traveling particles before being deposited (i.e. the oxygen presence can be controlled to tune metal oxides stoichiometry and with this, electrical, optical or other characteristics). Sputtering has been widely used to deposit catalysts ${ }^{177}$ and protective layers, thanks to the material possibilities, among them stoichiometry-controlled oxides such as $\mathrm{TiO}_{2}$ (ref. 178 and 179) or $\mathrm{NiO}^{172}$ and no dependence on used substrate. Some authors have required layers such as $8 \mathrm{~nm}$ Ti to prevent damaging sensible photoabsorbers such as amorphous Si during the sputtering process, as the process is energetic and the deposition-atmosphere could also affect the absorber, ${ }^{177}$ and some have reported arcs during plasma attack the deposited film, forming pinholes and more electronically-defective material. ${ }^{166}$ Other less used PVD techniques are pulsed laser deposition (PLD), ${ }^{180,181}$ where very high energy laser pulses vaporize blank's surface with very high stoichiometry control, and molecular beam epitaxy (MBE), ${ }^{182,183}$ a slow and expensive

technique where material is formed atomically depositing layer by layer. As PVD techniques are based on high vacuum directional depositions, obtained layers are not conformal, what would not protect highly rugose photoabsorbers or 3D structures.

Chemical vapour-based deposition (CVD) techniques are usually based in temperature-controlled vacuum chambers where introduced precursor gases react, creating the desired products in solid form deposited on a substrate ${ }^{184}$ (Fig. 11a). Single or multiple element layers can be deposited, nitrides, oxides, metals or any other meanwhile the selected precursors react forming a solid product. Plasma enhanced-CVD (PECVD) is a variation where precursor gases react or decompose due to an ionizing plasma, arc discharge or microwave excitation, allowing different reactions, precursors or products independent of temperature. ${ }^{185}$ There is wide experience on metal oxides deposited by CVD, also as protective layers.

Atomic layer deposition (ALD) is a variation of CVD in which precursors are introduced in the chamber sequentially, first reported in the $60^{\prime}$ by researchers in the Soviet Union under the name "molecular layering". ${ }^{186}$ One of the precursors is introduced to the chamber in an inert gas flow, saturating substrate's surface with the precursor, and then all the non-chemisorbed precursor is removed by the gas flow (Fig. 11b). A second gas is then introduced (normally $\mathrm{H}_{2} \mathrm{O}, \mathrm{O}_{3}$ or $\mathrm{NH}_{3}$ ), reacting and forming a conformal submonolayer of the final desired product. This way, control of the layer growth in the sub-nanometer scale
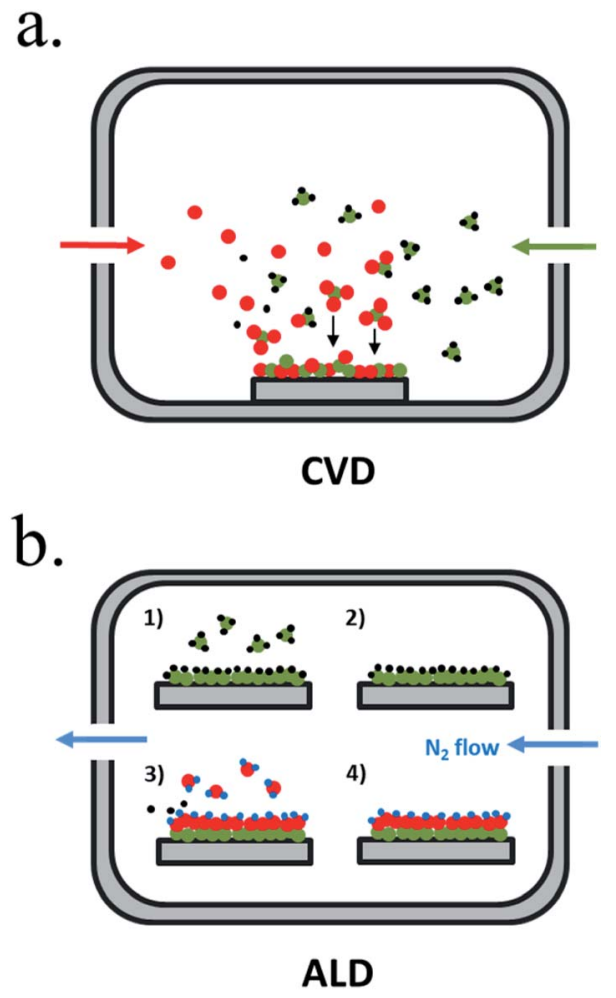

Fig. 11 Representative schemes of thin film deposition techniques by (a) chemical vapour deposition (CVD) and (b) atomic layer deposition (ALD). 
is attained, where final thickness depends on the number of cycles of this process. ${ }^{187}$ ALD is maybe the best candidate to ensure complete surface coverage thanks to saturated deposition steps and thus, to obtain a pinhole-free protective layer. ${ }^{188}$ ALD also presents lower temperature crystallization due to absorbed molecule mobility but is much more time consuming than CVD. ${ }^{\mathbf{8 1 , 1 8 9}}$ It has been used for many photoabsorbers and protective materials, even in industrial scale as essential part of high-k gate dielectrics manufacturing, although much more work is needed. ${ }^{189}$ For covering $3 \mathrm{D}$ nanostructures, ALD is the best candidate, due to the self-limited conformal deposition, and has been used in high ratio structures. ${ }^{81}$

\subsection{Strategies and materials for protective films}

There are many paths to protect semiconductors from corrosion. In Fig. 12 it was summarized the protective strategies, classified according to an increase in device complexity. From stable semiconductors forming SCLJ with the electrolyte (a), the introduction of metallic layers (thin enough to be transparent) as catalysts and/ or to form Schottky junctions (b). Few nanometers thick oxide layers, thin enough to be tunneled, were introduced to increase stability in harsh environments (c). For further stability, thicker transparent films (usually oxides) several tens of nanometers thick can be used, also capable to form an heterojunction with the photoabsorber (d). To maximize charge separation and thus, photoelectrode efficiency, buried junctions can be used, where the protective layer will mainly act as a conductor (e). Finally, the next logical step is use a cable as conductor, forming a non-monolithic device where the photovoltaic part can be located outside of the electrolyte and connected to the electrocatalyzer in a PV-EC configuration (f).

5.2.1. Metallic thin films. Some of the first protective layers used for short bandgap photoelectrodes were metallic (Fig. 12b), which in contact with the photoabsorber created a Schottky junction, being mandatory proper band alignment to extract maximum photovoltage. ${ }^{\mathbf{1 9 0}}$ Noble metals such as platinum, palladium, silver, rhodium, ruthenium and gold were sputtered or thermally/electron-beam evaporated on silicon ${ }^{191-195}$ and on other photoabsorbers such as n-GaP, ${ }^{11} p^{-}$ $\mathrm{WSe}^{\mathbf{1 1}}$ or $\mathrm{p}$-InP, ${ }^{\mathbf{1 0}}$ not achieving significant stabilities. Maier et $a l .{ }^{196}$ demonstrated 60 day stability of a electrochemically deposited Pt-protected p-Si photocathode in acidic conditions, although significant series resistance was observed due to $\mathrm{SiO}_{2}$ interface caused by acid oxidation, presenting $0.3 \mathrm{~V} v s$. RHE onset potential and photocurrents of $10 \mathrm{~mA} \mathrm{~cm}^{-2}$ at $0 \mathrm{~V} v s$. RHE, far from Si possibilities.

Kenney et al. $^{\mathbf{1 9 7}}$ fabricated a Ni-protected a silicon photoanode and found that non electrolyte-permeable thick enough metallic layers were also too thick to allow light to reach the photoabsorber. Electrolyte intermixing in the metallic layer (partially oxidized, $\mathrm{Ni} / \mathrm{NiO}$ ) also helped to increase the built-in potential for $2 \mathrm{~nm}$ Ni layers, compared with the $\geq 5 \mathrm{~nm} \mathrm{Ni} / \mathrm{n}$ Si Schottky junction (Fig. 13a and b). To achieve a good ( $>80$ h) stability, a K-borate + Li-borate solution ( $\mathrm{pH}$ 9.5) was used. Metallic film permeability in the few nanometers scale was used by Laskowski et al. ${ }^{198}$ to form an n-Si/5 nm-Ni/10 nm-Au dual a.

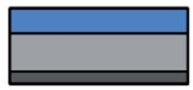

Electrolyte

Stable semiconductor

Back contact

b.

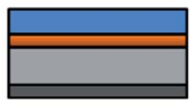

+ Metallic layer

$\rightarrow$ Catalyst

$\rightarrow$ Schottky junction

c.

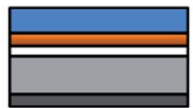

+ Ultrathin oxide layer

$\rightarrow$ MIS junction

d.

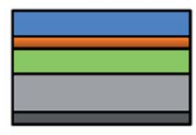

+ Thick oxide layer

$\rightarrow$ Heterojunction

e.

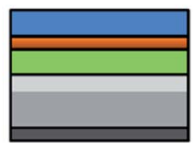

+ Buried junction

$\rightarrow$ Protective layer as ohmic conductor

f.

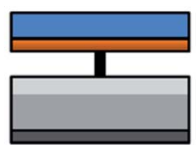

+ external connection

$\rightarrow$ semiconductor not exposed to electrolyte

Fig. 12 Schemes summarizing significant steps in photoelectrode device complexity regarding protective strategies.

working electrode to simultaneously track Ni redox potentials. In another work, Sartori et al. enhanced a p-Si photocathode's built in potential, and thus onset potential, with a simple $5 \mathrm{~nm}$ Ti protective layer together with Pt catalyst particles. ${ }^{199}$ Obtained photocurrent reached over $25 \mathrm{~mA} \mathrm{~cm}{ }^{-2}$, but stability was poor. Feng et al. used similar structure but with $\mathrm{Ni}$ as catalyst, obtaining more overpotential for the HER reaction. ${ }^{\mathbf{2 0 0}}$

Although interesting results have been obtained with a metallic protective layer, the full potential of the photoabsorbers in long-term stabilities cannot be exploited due to insufficient stability, significant light absorption in the metallic layer and significant recombination in the Schottky junction due to extra states in the interface and Fermi level pinning, lowering photovoltage. ${ }^{201}$

To overcome metallic film transparency limitations, some works have proposed microstructured surfaces, with Pt islands ( $\sim 30 \mathrm{~nm}$ thick) in contact with $\mathrm{p}-\mathrm{Si}$, and $\mathrm{SiO}_{2}$ covering the rest of the surface, in a balance between surface coverage of catalytic metal and oxide-protected light absorption regions ${ }^{\mathbf{1 4 6}}$ (Fig. 13c).

Regarding the limitations of metal-photoabsorber Schottky junctions, Seger et al. ${ }^{202}$ proposed a buried silicon $\mathrm{p}-\mathrm{n}$ homojunction in 2012 to maximize electron-hole separation, with a thin $\mathrm{Ti}$ metallic film which partially oxidized to $\mathrm{TiO}_{2}$ in the acidic electrolyte and using $\mathrm{MoS}_{2}$ as catalyst. This way, up to 16 $\mathrm{mA} \mathrm{cm} \mathrm{cm}^{-2}$ were obtained at $0.2 \mathrm{~V}$ vs. RHE (with $0.6 \mathrm{~V}$ photovoltage) and $1 \mathrm{~h}$ stability. Similar buried junction structure was used by Mei et al. ${ }^{203}$ using 2-6 $\mathrm{nm} \mathrm{Ir} / \mathrm{IrO}_{x}$ as protective layer in acidic electrolyte, avoiding detrimental $\mathrm{SiO}_{x}$ formation. 
a.
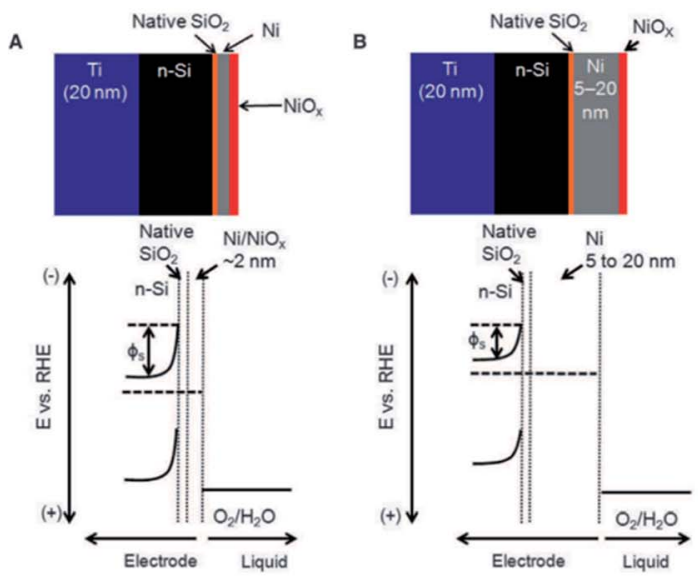

b.

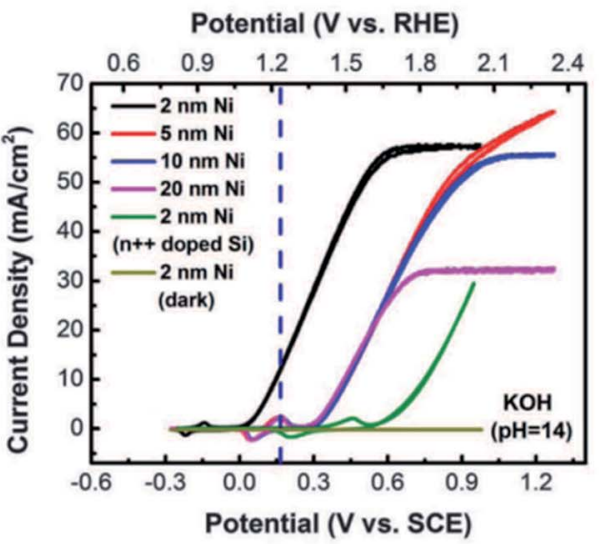

c.

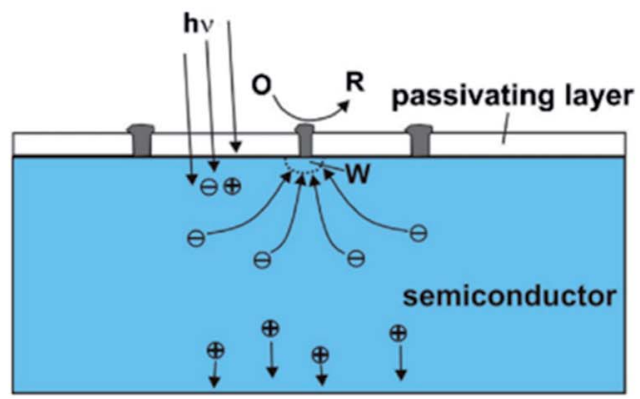

Fig. 13 (a) Scheme of $n$-Si photoanodes protected and catalysed by few nanometer-thick Ni films, demonstrating the effect of extremely thin layers compared to thicker ones. (b) Cyclic voltammogram response of the same $\mathrm{Ni}$-protected silicon photoanodes with different $\mathrm{Ni}$ thicknesses, presenting higher photopotential for $\sim 2 \mathrm{~nm}$ films and light absorption if thicker than $10 \mathrm{~nm}$. Reprinted with permission from (Science, 15 Nov 2013, vol. 342, issue 6160, pp. 836-840). Copyright (2013). ${ }^{197}$ (c) Scheme showing photogenerated charges being collected by the depletion formed between a semiconductor and metallic isles embedded in an insulator transparent protective layer. Reprinted with permission from (Electrochim. Acta 2011, 56, 1072610736). Copyright (2011) Elsevier. ${ }^{146}$

5.2.2. Tunnel-thick protective films. Insulator thin films (Fig. 12c), mainly oxides, have been studied to protect water splitting photoelectrodes thanks to their chemical stability. However, the system must still be capable to inject the photogenerated charges across the insulator layer and into the electrolyte to perform the water splitting reaction efficiently. For that, tunnelling-distance-thick films in the few nanometers scale have been combined with catalytic films or particles, forming a metal-insulator-semiconductor (MIS) or semiconductor-insulator-semiconductor (SIS) scheme. Advantages of these structures are the passivation of photoabsorber surface states and the suppression of Fermi level pinning, ${ }^{\mathbf{2 0 4 , 2 0 5}}$ but insulator oxides must be maintained under $3 \mathrm{~nm}$ thick to avoid significant tunnelling resistances. ${ }^{\mathbf{1 8 6}}$ ALD allows the fabrication of ultrathin conformal oxides, expected to be pinhole-free. ${ }^{206}$

Silicon dioxide $\left(\mathrm{SiO}_{2}\right)$ was first studied due to its natural occurrence when $\mathrm{Si}$ is exposed to acidic electrolytes on a $\mathrm{n}-\mathrm{Si}$ / $\mathrm{SiO}_{2} / \mathrm{Pt}$ photoanode, with poor results. ${ }^{207}$ Esposito et al. ${ }^{208}$ fabricated a $2 \mathrm{~nm}$ thick $\mathrm{SiO}_{2}$ protected MIS photocathode by controlling the oxidation with rapid thermal oxidation (RTO) and depositing 30/20 nm Ti/Pt islands. Pt was used as HER catalyst, but $\mathrm{Ti}$, with lower work function, enhanced photovoltage and also served as adhesion layer. Although 20/30 nm metallic islands are not transparent, controlling the pitch distance and diameter they could maximize light absorption and catalysis up to photocurrents of $20 \mathrm{~mA} \mathrm{~cm}^{-2}$ at $0 \mathrm{~V} v s$. RHE and $0.55 \mathrm{~V}$ vs. RHE onset potential in $0.5 \mathrm{M} \mathrm{H}_{2} \mathrm{SO}_{4}$, with reported 2 h stability.

n-Type silicon photoanodes were fabricated with $\mathrm{SiO}_{2}$ and Ir as catalyst with photovoltages exceeding $500 \mathrm{mV}$ and saturation photocurrents about $30 \mathrm{~mA} \mathrm{~cm} \mathrm{~cm}^{-2}$, although an ultrathin $\mathrm{TiO}_{2}$ protective layer was needed to stop rapid further Si oxidation at oxidative potentials and stabilize for over $8 \mathrm{~h}$ the photoanodes in acidic, neutral or basic media $^{\mathbf{2 0 6 , 2 0 9}}$ (Fig. 14a and b). Planar and nanopilar p-InP was $3 \mathrm{~nm} \mathrm{n}-\mathrm{TiO}_{2}$-protected and $2 \mathrm{~nm} \mathrm{Ru}$ film was added as catalyst, achieving $0.76 \mathrm{~V} v s$. RHE onset potentials and significant photocurrents of $37 \mathrm{~mA} \mathrm{~cm}{ }^{-2}$ stable for some hours. ${ }^{210}$ Photoanodes without the $\mathrm{TiO}_{2}$ degraded rapidly during the first hour. In this scheme, increasing $\mathrm{TiO}_{2}$ layer thickness turned into lower trap-mediated thickness-dependent conductivity indicating the importance of using a thin $\mathrm{TiO}_{2}$ layer for efficient tunnelling-mediated electron transport. ${ }^{206,211-213}$ $490 \mathrm{mV}$ photovoltage was also obtained substituting ultrathin $\mathrm{TiO}_{2}$ by $\mathrm{Al}_{2} \mathrm{O}_{3}$, finding that tunnelling layers of a thickness $>2 \mathrm{~nm}$ introduce an intermediate resistance, lower than insulator $\mathrm{SiO}_{2}$ but higher than defect-conductive $\mathrm{TiO}_{2} \cdot{ }^{\mathbf{2 1 4 , 2 1 5}}$ Crystalline $\mathrm{TiO}_{2}$ was found to reduce insulator-thicknessdependent photovoltage loss in metal-insulator-semiconductor (MIS) type photoanodes, in comparison with amorphous $\mathrm{TiO}_{2}\left(\mathrm{ALD}\right.$-fabricated at $170{ }^{\circ} \mathrm{C}$ ), due to dielectric constant increase, with a record photovoltage of $623 \mathrm{mV}{ }^{216}$ $\mathrm{TiO}_{2}$ was proven as one of the best candidates, highly protective, and has been identified to be conductive for thicker than $10 \mathrm{~nm}$ layers, where tunnelling is highly nonprobable. Indeed, hopping via trap states situated $\sim 1 \mathrm{eV}$ below the conduction band was considered the conduction mechanism in photoanode's case ${ }^{217}$ following the concept of "defect band" conductivity, first proposed by Campet et al. ${ }^{218}$ This will be further discussed in the next section together with other thicker conductive oxides protective layers. 
a.

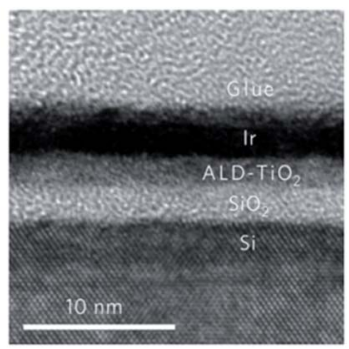

b.
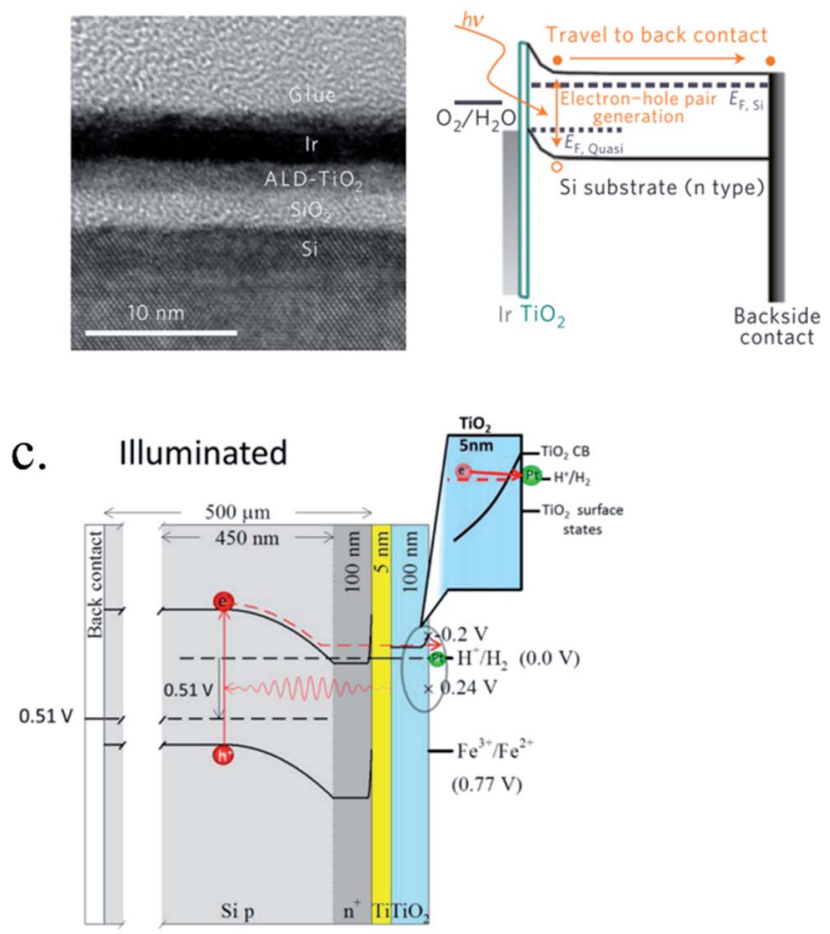

Fig. 14 (a) TEM image of an ultrathin $\mathrm{ALD}-\mathrm{TiO}_{2}+\mathrm{SiO}_{2}$ protective layer for a silicon photoanode. (b) Equivalent energy band diagram under illumination. Reprinted with permission from (Nat. Mater., 2011, 10(7), 539-44). Copyright (2011) Springer Nature. ${ }^{206}$ (c) Energy band diagram of a $5 \mathrm{~nm} \mathrm{Ti} / 100 \mathrm{~nm}-\mathrm{TiO}_{2}$ protected silicon photocathode having a buried $\mathrm{p}-\mathrm{n}$ junction under illumination. Reprinted with permission from (J. Am. Chem. Soc., 2013, 135, 1057-1064). Copyright (2013) American Chemical Society. ${ }^{227}$

Ultrathin oxides, like metallic thin films, are difficult to fabricate being impermeable and pinhole-free for devices lasting hundreds of hours, and majority of the presented works lack long-term stabilities and device fail mechanisms over large device's area.

5.2.3. Conductive transparent oxides and other protective films. Increasing the protective layer thickness (Fig. 12d and e) can overcome the stability limitations present in ultrathin metallic or insulating coatings, by avoiding possible electrolyte permeability or reducing pinholes and cracks probability. For films thicker than $5 \mathrm{~nm}$, tunnelling conductivity is not possible, thus material electronic properties (interfacial potential barriers, band alignment, charge mobility, band bending, etc.) must be taken into account, in addition to chemical stability (as explained in Section 4). Also, protective layers must be intrinsically transparent and conductive, reducing candidates to mid band gap (2-5 eV) semiconductors, transparent to significant part of the visible spectra while not being insulator materials, such as $\mathrm{Al}_{2} \mathrm{O}_{3}$ and $\mathrm{SiO}_{2}\left(E_{\mathrm{g}}>9 \mathrm{eV}\right)$. Luckily the majority of metal oxides studied for protective layers are earth abundant and nontoxic as needed for device scalability. ${ }^{219}$

For an efficient conductivity through protection layers, minimal losses in bulk resistance and semiconductor- electrolyte interface must be attained. The protective layers do not need to be as conductive as conventional transparent conductive oxides as only vertical (some tens of nanometers) conductivity is needed, not in-plane several hundred microns as in solar cells. In general, n-type metal oxide semiconductors have been used to protect photocathodes, based on electrons migrating from the photoabsorber, through the protective layer, and injected in the HER. Fermi level close to the conduction band should help both to form a $\mathrm{p}-\mathrm{n}$ heterojunction and for favourable alignment with the n-type part of the $\mathrm{p}-\mathrm{n}$ buried junction. Likewise, p-type semiconductors have been proposed for photoanodes and have efficient OER catalytic surfaces. ${ }^{118,173,219,220}$ The role of cocatalysts on top of the protective layer and the electrolyte is majorly governed by the pinch-off effect, where with few nanometers thick layers, cocatalysts do not really form a Schottky barrier, and rather what is called "adaptive junctions". ${ }^{221}$ Although, material specificities and the formation of recombining contacts have made materials such as $\mathrm{TiO}_{2}$ highly versatile, multiple strategies are possible controlling deposition conditions, oxygen stoichiometry and other metals incorporation for better conductivity or catalysis. $^{213}$ Transparent and conductive oxides used in the microelectronics industry, such as ITO and AZO, were expected to have good band offsets and conductivity, but their stability and performance resulted very poor. ${ }^{\mathbf{2 1 8 , 2 2 2}}$ With thick oxides protective layers such as $\mathrm{TiO}_{2}, \mathrm{NiO}, \mathrm{CoO}_{x}$ and $\mathrm{MnO}$, among others, better results have been achieved in terms of productivity and stability, with tens of $\mathrm{mA} \mathrm{cm}^{-2}$ achieved, minimal resistances introduced and several hundred hours, even thousands, of operation tests.

(a) $\mathrm{TiO}_{2}$. Titanium dioxide has been one of the most studied materials as protective layer for small band gap photoelectrodes thanks to its transmittance, relatively good electrical properties and chemical stability. It is an earth abundant metal oxide found in nature and with several fabrication routes, such as anodization, hydrothermal, sol-gel and, for protective layers, mostly known to be fabricated by sputtering and ALD, giving compact layers in comparison with other solution-deposited ones. ${ }^{169} \mathrm{TiO}_{2}$ is a n-type semiconductor with $\sim 3.2 \mathrm{eV}$ band gap, ${ }^{6,178}$ permitting almost complete optical transmittance for visible light spectra, although thanks to its good chemical stability some works have used it also for back-illuminated photoelectrodes. $^{223}$ Its n-type semiconductor behaviour is known to be caused by oxygen vacancies and thus, $\mathrm{Ti}^{3+}$ states with energy levels close to the conduction band, giving free electrons. $\mathrm{TiO}_{2}$ is known to have significant oxygen mobility under polarization or under different atmospheres annealing, locally forming conductive filaments acting as degenerate ntype material across the whole layer, ${ }^{224-226}$ explaining various mechanisms reported depending on fabrication and working conditions. $^{186}$

Photocathodes protection with thick $(\sim 100 \mathrm{~nm})$ sputtered $\mathrm{TiO}_{2}$ was first reported in 2013 by Seger et al. ${ }^{227}$ in a pn ${ }^{+}-\mathrm{Si} /(5$ $\mathrm{nm}) \mathrm{Ti} /(100 \mathrm{~nm}) \mathrm{TiO}_{2} / \mathrm{Pt}$ structure, where favourable band alignment between $\mathrm{n}^{+}-\mathrm{Si}, \mathrm{Ti} / \mathrm{TiO}_{2}$ and $\mathrm{TiO}_{2} / \mathrm{Pt}$ interface (behaving like an ohmic contact due to high dopant density of $\mathrm{TiO}_{2}$ and high energy sputtered Pt, rather than like a Schottky 
junction ${ }^{228,229}$ ) introduced negligible resistance or overpotential (Fig. 14c). These findings show the system acting equivalently to a solar cell in series with the catalyst metal. They demonstrated conductivity through the conduction band, also explained to be electron polaron hopping through the $\mathrm{Ti}^{3+}$ states close to the conduction band $(\sim 0.3 \mathrm{eV}),{ }^{230}$ although the transition temperature between both mechanisms is reported to be about $300 \mathrm{~K}$ (room temperature) ${ }^{231}$ and probably both mechanisms are simultaneously active. Seger $e t$ al. introduced a $5 \mathrm{~nm}$ Ti layer previous to $\mathrm{TiO}_{2}$ reactive-sputtering deposition to prevent $\mathrm{Si}$ substrate from oxidation, a strategy followed by other works ${ }^{145,178,223,232}$ based on oxygen migration to lowest Gibbs oxide formation energy and thus, oxygen scavenging from Si to $\mathrm{Ti}^{2}{ }^{233,234} \mathrm{Up}$ to $20 \mathrm{~mA} \mathrm{~cm}^{-2}$ at $0.3 \mathrm{~V} v$ s. RHE and $70 \mathrm{~h}$ of stability were obtained under illumination, corroborating the photoabsorber-protective layer strategy. In following works, durability was studied, reporting the need of $400{ }^{\circ} \mathrm{C}$ post-annealing to $\mathrm{ALD}-\mathrm{TiO}_{2}$ protective layers synthetized at $200{ }^{\circ} \mathrm{C}$ to reach from 8 to $480 \mathrm{~h}$ of stability at $0.3 \mathrm{~V} v$ s. RHE in $1 \mathrm{M} \mathrm{HClO}_{4}{ }^{235} \mathrm{An}$ increase of doping level under the $400{ }^{\circ} \mathrm{C}$ annealing was considered to be the reason of significantly higher conductivity, reducing depletion barrier between the $\mathrm{TiO}_{2}$ and electrolyte, allowing electrons to tunnel through, ${ }^{236}$ similar results to Liang et al. ${ }^{237}$ increasing donor level by hydrogen doping upon deposition.

In recent studies from our group, the ALD layer fabrication key parameters for optimal conductivity through $100 \mathrm{~nm} \mathrm{TiO}{ }_{2}$ layers were found to be highly related to conductivity through crystalline regions of the film for protective layers both on photocathodes $^{238}$ and photoanodes. ${ }^{239}$ Also, amorphous regions were found to be unstable and dissolve in cathodic acidic HER conditions (Fig. 15a and b). The lower crystallization temperature of $\operatorname{ALD}\left(\sim 165{ }^{\circ} \mathrm{C}\right)$ in front of others such as sputtering (requiring deposition or post-treatments at $400{ }^{\circ} \mathrm{C}$ ) 235 makes it an ideal technique to avoid degradation of photoabsorber semiconductors sensible to thermal treatments. ${ }^{240,241}$ The low deposition temperature was possible thanks to the wide temperature window for $\mathrm{TiCl}_{4}$ precursor. ${ }^{242}$ Deposition techniques such as high power impulse magnetron sputtering (HPIMS $)^{145}$ have been used to increase layer's density and thus, minimizing pinholes to avoid electrolyte penetration and anisotropic etch corrosion by $\mathrm{KOH}$ (Fig. $15 \mathrm{c}$ and d). $\mathrm{TiO}_{2}$ conduction band is close to the HER potential, and with sufficient dopant levels (i.e. oxygen vacancies), electrons can overcome by tunnelling the small potential barrier formed and reach the catalyst. ${ }^{227}$ Platinum, an expensive noble metal, has been widely used due to its superior cost-efficiency trade-off, and some works have demonstrated the scalability of very small amounts of platinum nanoparticles to drive the PEC water splitting industry to the terawatt level. ${ }^{243}$

Regarding photoanodes, although $\mathrm{TiO}_{2}$ should not be expected to be a good hole-conduction layer, in 2014, Hu et al..$^{217}$ discovered that depositing amorphous $\mathrm{TiO}_{2}$ on $\mathrm{Si}, \mathrm{GaAs}$, and $\mathrm{GaP}$ conduction was possible for films up to $143 \mathrm{~nm}$ thick (grown by ALD at $150{ }^{\circ} \mathrm{C}$ and Ni coated). Energy states about $1 \mathrm{eV}$ inside the forbidden band were observed by high resolution XPS (Fig. 16a). Conductivity through intra-band gap levels a.

b.
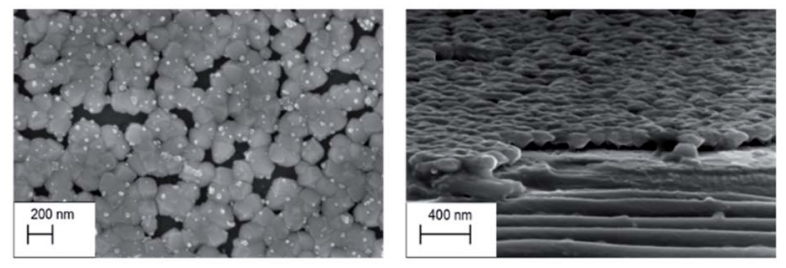

c.

d.
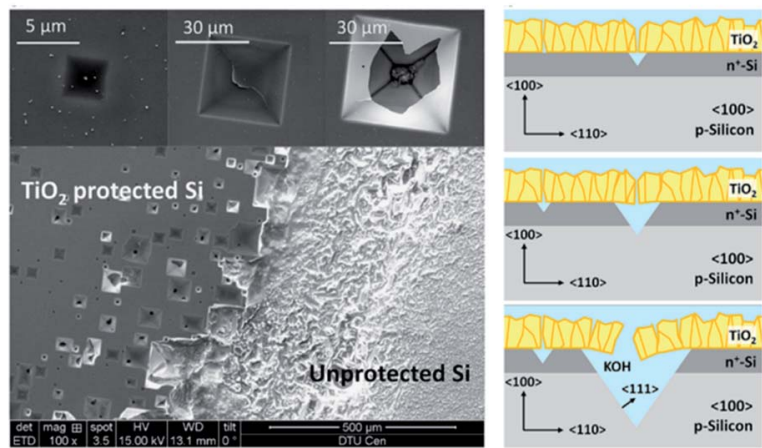

Fig. 15 (a) Top and (b) cross section SEM images of an almost-crystalline $\mathrm{TiO}_{2}$ layer after a stability test in $0.5 \mathrm{M} \mathrm{H}_{2} \mathrm{SO}_{4}$, wherein dissolution of the amorphous region between crystals can be seen. Reprinted with permission from (ACS Appl. Mater. Interfaces, 2017, 9, 17932-17941). Copyright (2017) American Chemical Society. ${ }^{238}$ (c) SEM images of a $\langle 100\rangle \mathrm{Si} \mathrm{TiO}_{2}$-protected and unprotected after immersion in $1 \mathrm{M} \mathrm{KOH}$ for 3 days. (d) Schematics of the anisotropic etching process forming characteristic inversed pyramids. Reprinted with permission from (Sol. Energy Mater. Sol. Cells, 2016, 144, 758-765). Copyright (2016) Elsevier. ${ }^{145}$

was also explained by K. Sivula as "Leaky titania" (Fig. 16b), ${ }^{244}$ based on the concept theorized by Campet et al. time ago, ${ }^{218}$ and following works performed thoughtful energy band calculations to explain it. ${ }^{179,245}$ Deeper studies are necessary, as weak traces of anatase have been reported down to $140{ }^{\circ} \mathrm{C} .{ }^{242}$ McDowell et al. ${ }^{179}$ found $\mathrm{TiO}_{2}$ films conduction behaviour not unique to amorphous phase (Fig. 16c) and with no relation to carbon or nitrogen impurities, although high temperature treatments turn the system insulator by forming a more-stoichiometric material, reducing available electronic states. Several works have studied thermal treatments under different partial pressures of oxygen and forming gas to understand how conductivity is affected by it. ${ }^{179,186} \mathrm{Nb}$ doping could be a strategy to increment $\mathrm{TiO}_{2}$ conductivity, ${ }^{246,247}$ but very good conductivity has already been demonstrated if properly fabricated. Other photoabsorbers such as CdTe have been protected with "leaky" amorphous $\mathrm{TiO}_{2}$, with $21 \mathrm{~mA} \mathrm{~cm}{ }^{-2}$ and $435 \mathrm{mV}$ photovoltage. ${ }^{248}$ Nickel overlayer was found to be mandatory for proper contact with the conductive $\mathrm{TiO}_{2},{ }^{217}$ pinning $\mathrm{TiO}_{2}$ energies to $\mathrm{Ni}$ states and removing the rectifying space-charge region from the $\mathrm{TiO}_{2} /$ solution interface; ${ }^{166,249}$ this is known for $\mathrm{Ni}$ as "adaptive" catalyst. ${ }^{221} \mathrm{Up}$ to $100 \mathrm{~h}$ stability and $40 \mathrm{~mA} \mathrm{~cm}^{-2}$ at $2 \mathrm{~V} v s$. RHE were obtained in $1 \mathrm{M} \mathrm{KOH}$, with $100 \mathrm{~nm} \mathrm{Ni}$ islands as catalyst. ${ }^{217}$ 
a.

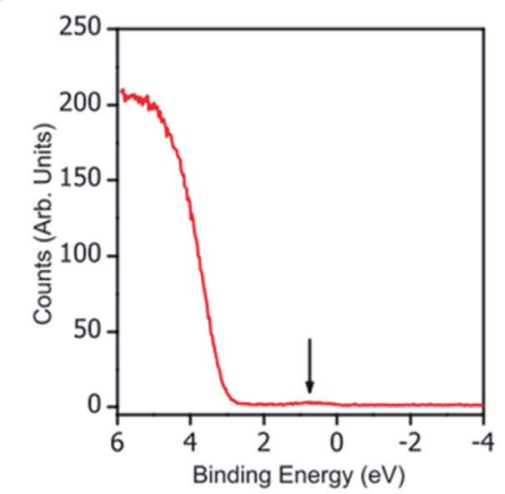

b.

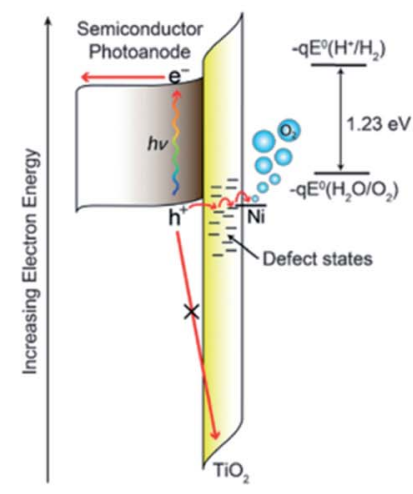

C.
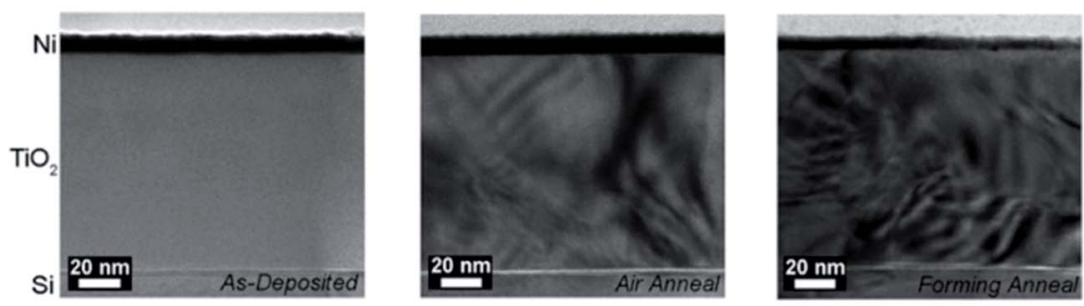

d.
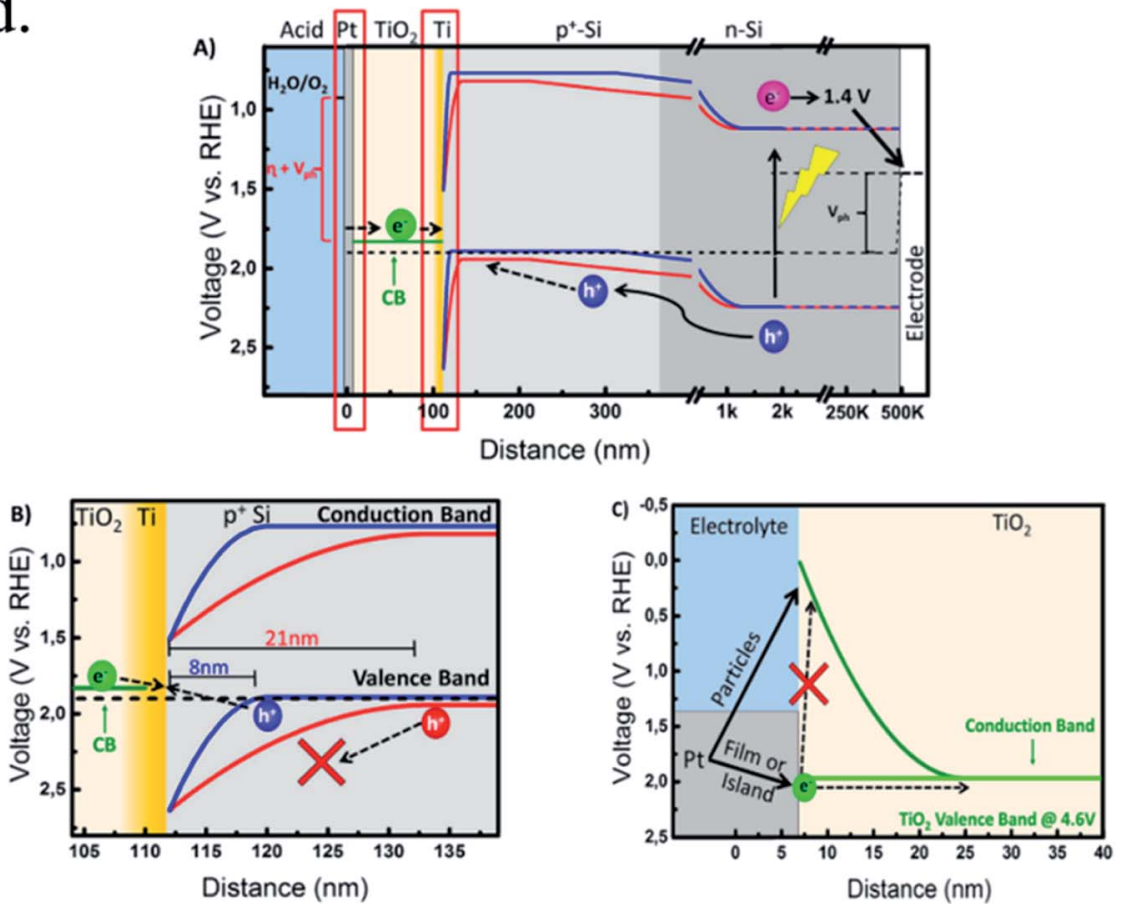

Fig. 16 (a) XPS spectrum of $44 \mathrm{~nm}-\mathrm{TiO}_{2}$ presenting states inside the band gap. Reprinted with permission from (Science, 30 May 2014 , 344(6187), 1005-1009). Copyright (2014) The American Association for the Advancement of Science. ${ }^{217}$ (b) Schematic energy band diagram to explain the "Leaky" conductivity through intra-band gap states for $\mathrm{TiO}_{2}$-protected photoanodes. Reprinted with permission from (ChemCatChem, 2014, 6, 2796-2797). Copyright (2014) John Wiley and Sons. ${ }^{244}$ (c) Alternative energy band diagram proposed by Mei et al. where electrons are injected into the conduction band and recombine with $\mathrm{p}^{+}-\mathrm{Si}$ in an ohmic contact. Reprinted with permission from (J. Phys. Chem. C, 2015, 119, 15019-15027). Copyright (2015) American Chemical Society. ${ }^{252}$ (d) HRTEM images of as-deposited TiO 2100 nm layers, and air annealed and forming annealed samples presenting crystallinity. Reprinted with permission from (ACS Appl. Mater. Interfaces, 2015, 7, 1518915199). Copyright (2015) American Chemical Society. ${ }^{179}$ 
Although, in 2015, B. Mei et al. ${ }^{178}$ designed $\mathrm{TiO}_{2}$-protected (by sputtering at $400{ }^{\circ} \mathrm{C}$ ) photoanodes and photocathodes where conduction band electron transport was proposed instead of intra-bandgap hole conduction. In the highly doped $\mathrm{p}^{+} / \mathrm{TiO}_{2}$ interface, holes from the photoabsorber are considered to recombine with electrons from the conduction band of crystalline $\mathrm{TiO}_{2}$. Electrons are injected in the $\mathrm{TiO}_{2}$ conduction band from the metallic Pt catalyst avoiding $\mathrm{TiO}_{2} /$ electrolyte rectifying junction ${ }^{236}$ and would allow efficient OER (Fig. 16d) stable for over $60 \mathrm{~h}$ when using $8 \mu \mathrm{m}$ Pt islands. In a solid-state measurement for PV applications, Man et al. ${ }^{250}$ studied n-Si and p-Si devices with amorphous $\mathrm{TiO}_{2}$ deposited by CVD at $100{ }^{\circ} \mathrm{C}$, and found a clear hole blocking behaviour, what would support conduction-band conductivity. Since then, $\mathrm{ALD}_{-\mathrm{TiO}}$-protected silicon nanowire photoanodes stability has been pushed up to $>2000 \mathrm{~h}$ with $40 \mathrm{~nm} \mathrm{NiCrO}_{x}$ catalyst film in $1 \mathrm{M} \mathrm{KOH}^{251}$

In a recent work published by our group, ${ }^{239}$ completely amorphous $\mathrm{TiO}_{2}$ layers deposited by $\operatorname{ALD}\left(100^{\circ} \mathrm{C}\right)$ are found to completely block charge transfer, meanwhile at 150 and $300{ }^{\circ} \mathrm{C}$ preferential conductivity paths are observed correlated to defective regions in crystalline $\mathrm{TiO}_{2}$, supporting the conduction band-supported conductivity. These more conductive regions can be correlated to degenerately doped conductive filaments formation, a property known for $\mathrm{TiO}_{2} \cdot{ }^{224-226}$ Confusion with the so-called "leaky amorphous $\mathrm{TiO}_{2}$ " might come from local crystallinity at the nanoscale, as it is deposited at temperatures (150-250 ${ }^{\circ} \mathrm{C}$ and sometimes post-treated at 300 or higher ${ }^{179}$ ) which are above crystallization. We proved XRD detection is not capable to observe single crystals but they are crucial to conductivity even down to $150{ }^{\circ} \mathrm{C}$, as detected by micro-Raman and i-AFM.

Not so good conductivity stability was found when permeable $5 \mathrm{~nm}$ NiFe catalyst was used, and the logarithmic decay over $450 \mathrm{~h}$ was attributed to a self-limited passivation of preferential conductivity paths. ${ }^{239}$ Carefully reviewing the literature, $\mathrm{TiO}_{2}$ conductivity stability in alkaline electrolytes is not so clear to be intrinsic to $\mathrm{TiO}_{2}$ or due to using non-permeable catalysts and high polarizations hindering diminishments (up to $2.07 \mathrm{~V}$ vs. $\left.\mathrm{RHE}^{248}\right)$.

(b) NiO. Several works have also studied nickel oxide (NiO) protective layers for water splitting photoelectrodes due to its abundance and chemical resistance, stability, transparency and catalytic properties. With a $3.8-4 \mathrm{eV}$ bandgap ${ }^{253,254}$ it is not expected to absorb any visible light. Although, significant defects on NiO structure ( $\mathrm{Ni}$ reduced atoms) can reduce transparency, ${ }^{245,255-257}$ even presenting electrochromism in specific cases caused by $\mathrm{Ni}^{3+}$ species such as $\mathrm{NiOOH} .{ }^{\mathbf{1 6 6 , 2 5 6}}$ It has been mainly used for photoanodes protection due to its p-type semiconductor behaviour ${ }^{258}$ prone to hole conductivity (and electron-blocking properties ${ }^{259}$ ) with relatively low resistivity. ${ }^{257,260} \mathrm{NiO}$ has high valence band position as it is based on a d-orbital rather than typical $\mathrm{O} 2 \mathrm{p},{ }^{261}$ being slightly reductive to $\mathrm{O}_{2}$ evolution potential, where an accumulation layer will be formed introducing no band bending overpotential. ${ }^{155}$ Although few works have used it for photocathodes, i.e. a $\mathrm{Cu}_{2} \mathrm{O}$ electrode $10 \mathrm{~nm}-\mathrm{NiO}$ protected ${ }^{262}$ with $70 \%$ retained current after $20 \mathrm{~min}$ in neutral $\mathrm{pH}, \mathrm{NiO}$ is reduced in acidic electrolytes ${ }^{\mathbf{1 5 5}}$ and cathodic HER potentials. ${ }^{263}$

Its p-type semiconductivity is given by point defects and $\mathrm{Ni}^{2+}$ vacancies, and is explained by the Mott-Hubbard insulator theory. ${ }^{155}$ The $\mathrm{Ni}^{2+}$ vacancies contribute with extra oxygen in the structure, which is compensated by oxidation of nickel sites to $\mathrm{Ni}^{3+}$ states, electron acceptors. ${ }^{\mathbf{2 6 4 - 2 6 7}}$ Changes in these favorable imperfections due to atomic reorganization caused by temperature treatments, oxygen partial pressure or different layer growth process are crucial in achieving a conductive layer (Fig. 17a). ${ }^{155,254,257,264,268,269} \mathrm{NiO}$ films are known to present oxygen anions migration under polarization, ${ }^{270}$ up to filament formation, ${ }^{271}$ which must be taken in account as stoichiometry modifications can reduce or enhance conductivity.

Nickel is known to be one of the best earth-abundant OER catalysts in alkaline media, ${ }^{272}$ where it is highly stable. First trials on nickel-based protective layers were performed directly depositing metallic Ni on top of the photoelectrode and letting it oxidize in contact with the electrolyte, but the hydroxide formed is highly porous and permeable ${ }^{273-275}$ after oxyhydroxide species restructuration (migration) during initial operation, ${ }^{272}$ hydrating up to $10 \mathrm{~nm}$ deep. Thicker Ni films, to protect the semiconductor beneath, would still contain a metallic layer, partially absorbing light and reducing photocurrent. ${ }^{197}$

Nickel-based electrocatalysts are known to be enhanced after cycling at positive potentials, ${ }^{172}$ related to $\mathrm{NiO}$ hydration to $\mathrm{NiOOH}^{254}$ and incorporation of other metal traces, like $\mathrm{Fe}^{272,276-278}$ (with higher activated-state stability with higher amount of Fe incorporated ${ }^{279}$ and optimized OER catalysis with a 3:1 $\mathrm{Ni}: \mathrm{Fe}$ ratio $^{280}$ ), Co, ${ }^{272} \mathrm{Ru}^{141}$ or more complex like NiFeP. ${ }^{281}$ The surface of nickel oxide is affected in its surface by alkaline electrolytes, forming oxy-hydroxides and porous nanoflakes with high surface area ${ }^{272,275}$ although it is stabilized by the presence of Co, partially inhibiting oxyhydroxide formation and restructuration. ${ }^{272}$ These hydroxides $\left(\mathrm{Ni}(\mathrm{OH})_{2}\right)$ and oxy-hydroxides (NiOOH), important in various fields of chemistry and physics, ${ }^{273}$ are not expected to create significant potential barriers with $\mathrm{NiO}$ beneath due to the porous and adaptive junction thanks to abundant electronic states and electrolyte penetration on first nanometers. ${ }^{221,282}$ Also, it is known to be the responsible of the efficient OER catalysis.

First NiO protected silicon $\mathrm{p}-\mathrm{n}$ junction was performed in 1987 presenting several high overpotential. ${ }^{283}$ In 2014, Mei et $a .^{284}$ used reactive sputtering to deposit $50 \mathrm{~nm}$ thick NiO layers on a buried $\mathrm{np}^{+}$-Si homojunction previously protected with $5 \mathrm{~nm} \mathrm{Ni}$. It is reported inactive to OER if no pre-treatment in Fe-containing electrolyte was performed (Fig. 17b). This achieved over $300 \mathrm{~h}$ stability of silicon photoanodes in $1 \mathrm{M}$ $\mathrm{KOH}$ with $14 \mathrm{~mA} \mathrm{~cm}^{-2}$ at $1.3 \mathrm{~V} v$ s. RHE. Soon after, Sun et al. ${ }^{172}$ reported $75 \mathrm{~nm}$ thick RF-sputtered NiO-protected photoanodes giving $30 \mathrm{~mA} \mathrm{~cm}^{-2}$ at $1.73 \mathrm{~V}$ vs. RHE over $1200 \mathrm{~h}$ (Fig. $17 \mathrm{c}$ and d), where some defects attributed to arc-discharges during RFsputtering were observed and partial oxygen pressure during synthesis is highly important in resulting conductivity. ${ }^{254} \mathrm{III}-\mathrm{V}$ semiconductors such as InP could also be protected with the same kind of layers for over $48 \mathrm{~h}$ (ref. 256) or CdTe, HTJ-Si or a- 
a.

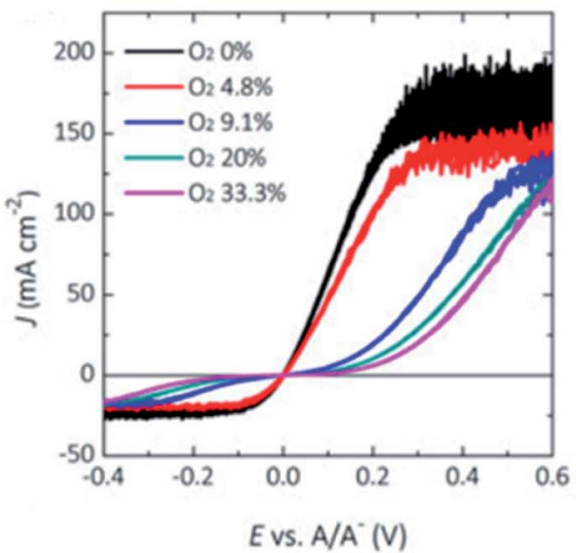

c.

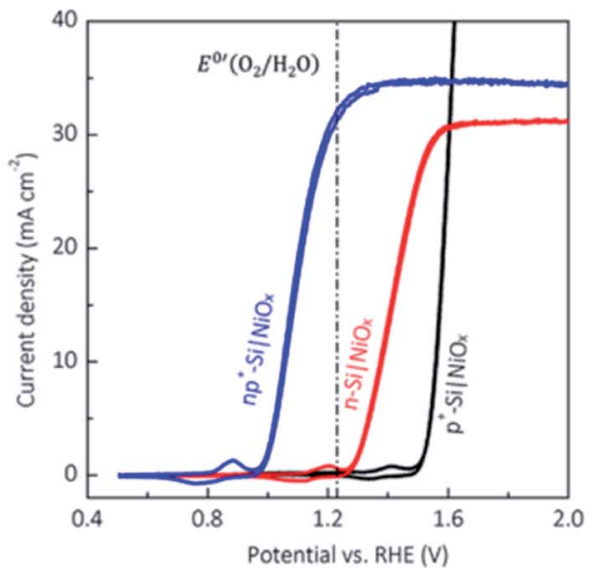

e.

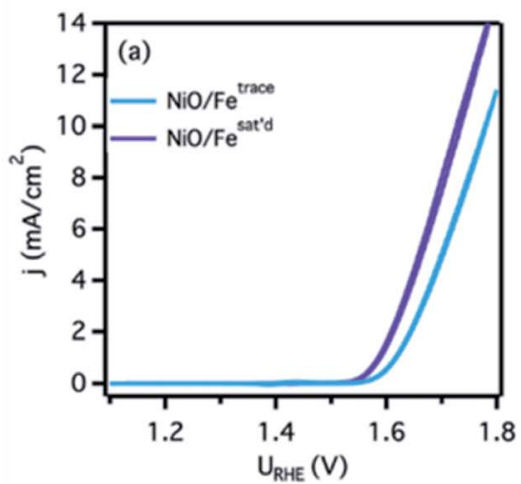

b.

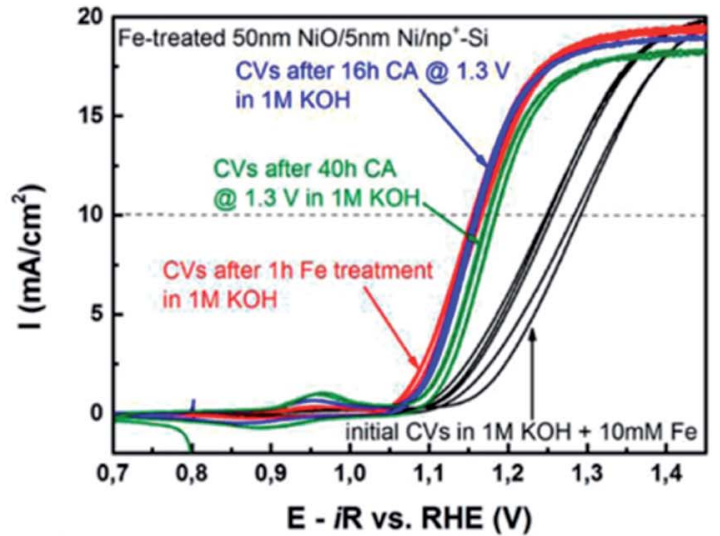

d.

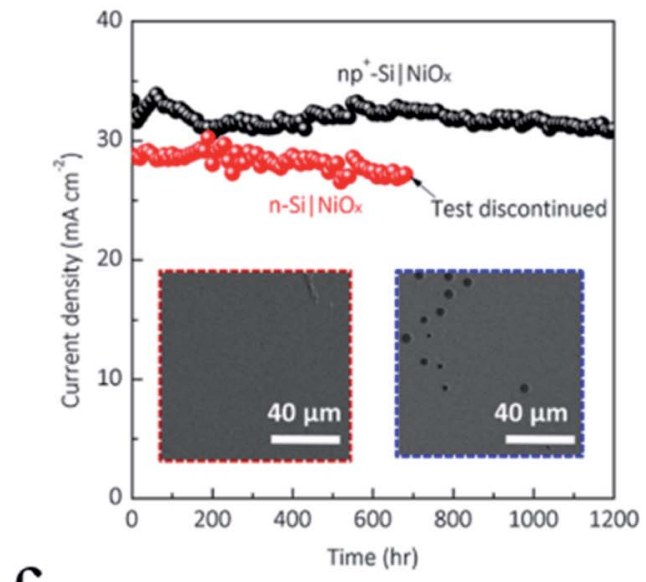

f.

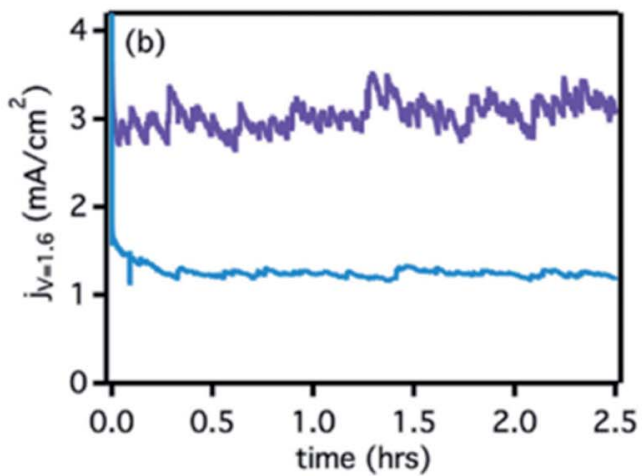

Fig. 17 (a) Cyclic voltammograms of $\mathrm{NiO}$ layers in $0.35 \mathrm{M} \mathrm{Fe}(\mathrm{CN})_{6}{ }^{3-} / 0.050 \mathrm{M} \mathrm{Fe}(\mathrm{CN})_{6}{ }^{4-}$ in $1.0 \mathrm{M} \mathrm{KCl}$ as supporting electrolyte, demonstrating higher oxygen partial pressure during deposition reduces conductivity. Reprinted with permission from (Proc. Natl. Acad. Sci. U. S. A., Mar 2015, 112(12), 3612-3617). Copyright (2015) NAS. ${ }^{254}$ (b) Cyclic voltammograms of Fe-treated NiO thin films on $\mathrm{p}^{+} \mathrm{n}$-Si photoanodes presenting initial activation. Reprinted with permission from (J. Phys. Chem. Lett., 2014, 5, 3456-3461). Copyright (2014) American Chemical Society. ${ }^{284}$ (c) Cyclic voltammograms and (d) stability at $1.73 \mathrm{~V}$ vs. RHE measurement of NiO layers protecting $\mathrm{n}-\mathrm{Si}$ and $\mathrm{np}^{+}$-Si photoanodes, where higher photopotential can be observed with a buried junction and up to $1200 \mathrm{~h}$ stability. Measurements in $1 \mathrm{M} \mathrm{KOH}$ and 1 sun illumination. Reprinted with permission from (J. Phys. Chem. Lett., 2015, 6, 592-598). Copyright (2015) American Chemical Society. ${ }^{172}$ (e) Cyclic voltammograms and (f) stability measurements of anodes ALD NiO coated with traces (blue) and saturated (purple) Fe present in the $0.1 \mathrm{M} \mathrm{KOH}$ electrolyte, where higher activity and stability is obtained with more Fe present. Reprinted with permission from (Adv. Energy Mater., 2015, 5, 1500412). Copyright (2015) John Wiley and Sons. ${ }^{279}$ 
Si : H over 100 h. $^{254}$ Significant advance was obtained compared with previous attempts from 2012 with sol-gel NiO reaching $\sim 1 \mathrm{~mA} \mathrm{~cm}^{-2}$ and losing $50 \%$ of performance in $1 \mathrm{~h}$ (ref. 285) or $2013 \mathrm{NiRuO}_{x}$ sputtered to form an heterojunction with n-Si giving over $1 \mathrm{~h}$ stability with not much photovoltage. ${ }^{141}$ ALD has only been used for NiO electroactive films few times, ${ }^{279}$ with $\mathrm{Ni}(\mathrm{Cp})_{2}$ and $\mathrm{O}_{3}$ as precursors at $275{ }^{\circ} \mathrm{C}$ deposition temperature. 3-18 nm thick films were found more resistive when ALD deposited than by other techniques together with the need of Fe atoms incorporation for sustained OER current (Fig. 17e and f).

$\mathrm{NiO}$ silicon photoanodes protected with $50 \mathrm{~nm}$ thick films grown by ALD at temperatures of $100-300{ }^{\circ} \mathrm{C}$, and found to be highly stable over $1000 \mathrm{~h}$ but only if periodically depolarized. ${ }^{286}$ This reversible degradation mechanism was attributed to higher oxidation states like $\mathrm{NiO}_{2}$ being formed, being less catalytic and less conductive, but it must be further analysed. Significant resistance increase at higher than $100{ }^{\circ} \mathrm{C}$ deposition temperatures was found, together with less defective films, pointing at a reduction of the p-type behaviour and making the films more insulator. Similar to the $5 \mathrm{~nm}$ Ti film pre-deposited for $\mathrm{TiO}_{2}$-protective layers, ${ }^{227}$ a metallic $\mathrm{Ni}$ film could help in avoiding insulator $\mathrm{SiO}_{2}$ detrimental layer formation.

(c) $\mathrm{CoO}_{x}$. Cobalt oxide $\left(\mathrm{CoO}_{x}\right)$ is a metal oxide similar to $\mathrm{NiO}$ in many aspects. With p-type semiconductor behaviour and high conduction band edge, it is favourable to hole conductivity and as electron blocking layer. ${ }^{155}$ It is expected to be transparent to large part of visible spectra due to its $\sim 2.3 \mathrm{eV}$ band gap. ${ }^{287,288}$ It is hydroxylated in contact with alkaline media into $\mathrm{CoOOH}$, a known stable and active catalyst for $\mathrm{O}_{2}$ evolution (OER), ${ }^{289}$ forming nanosheet/ nanoflake structures ${ }^{\mathbf{2 9 0 , 2 9 1}}$ (Fig. 18a). Its OER catalysis is highly enhanced by fabricating it already containing $\mathrm{Fe}^{291,292}$ or incorporating Fe from the electrolyte ${ }^{291}$ with low overpotentials $\left(\sim 250 \mathrm{mV}\right.$ (a) $\left.10 \mathrm{~mA} \mathrm{~cm}{ }^{-2}\right)$, close to NiFe. ${ }^{290}$ Depositing few nanometers $\mathrm{ALD} \mathrm{CoO}_{x}$ on $\mathrm{np}^{+}$-Si photoanodes up to $30 \mathrm{~mA} \mathrm{~cm}^{-2}$ were obtained by Yang et al. $1.4 \mathrm{~V} v s$. RHE in $1 \mathrm{M} \mathrm{NaOH}$ and 1 sun illumination stable for $24 \mathrm{~h} .{ }^{293}$

Bae et al. ${ }^{287}$ sputter-deposited $50 \mathrm{~nm}$ thick $\mathrm{NiCoO}_{x}$ protective layers on back-illuminated photoanodes, reaching stabilities over $72 \mathrm{~h}$ and $22 \mathrm{~mA} \mathrm{~cm}^{-2}$ at $1.23 \mathrm{~V} v$ s. RHE at pH 14 and further enhanced by $\mathrm{Fe}$ traces incorporation from the electrolyte. Xing et al. ${ }^{294}$ co-sputtered $\mathrm{CoO}_{x}$ with $3-8 \%$ vanadium $70 \mathrm{~nm}$ thick layers on $2 \mathrm{~nm}$ Cr protected $\mathrm{p}^{+} \mathrm{n}$-Si textured photoanodes, with almost $30 \mathrm{~mA} \mathrm{~cm}^{-2}$ at $1.23 \mathrm{~V}$ vs. RHE. Zhou et al. ${ }^{295} \mathrm{CoO}_{x}$ pro- $^{2}$ tected by ALD an n-silicon photoanode containing a thin $\mathrm{SiO}_{2}$ layer to form a SIS heterojunction, reaching $570 \mathrm{mV}$ photovoltage and $30 \mathrm{~mA} \mathrm{~cm}^{-2}$ at $1.23 \mathrm{~V} v$ s. RHE and stable for up to $2500 \mathrm{~h}$ at $1.63 \mathrm{~V} v s$. RHE in $1 \mathrm{M} \mathrm{KOH} \mathrm{(Fig.} \mathrm{18b-d).} \mathrm{Burke} \mathrm{et} \mathrm{al.}{ }^{291}$ cathodically electrodeposited $\mathrm{Co}_{1-x} \mathrm{Fe}_{x}(\mathrm{OH})_{2} \sim 50 \mathrm{~nm}$ thick finding that the incorporation of Fe reduced up to 100 times OER overpotential compared to pure $\mathrm{CoOOH}$ thanks to strong Co-Fe coupling up to $60 \% \mathrm{Fe}$, but at higher amounts,
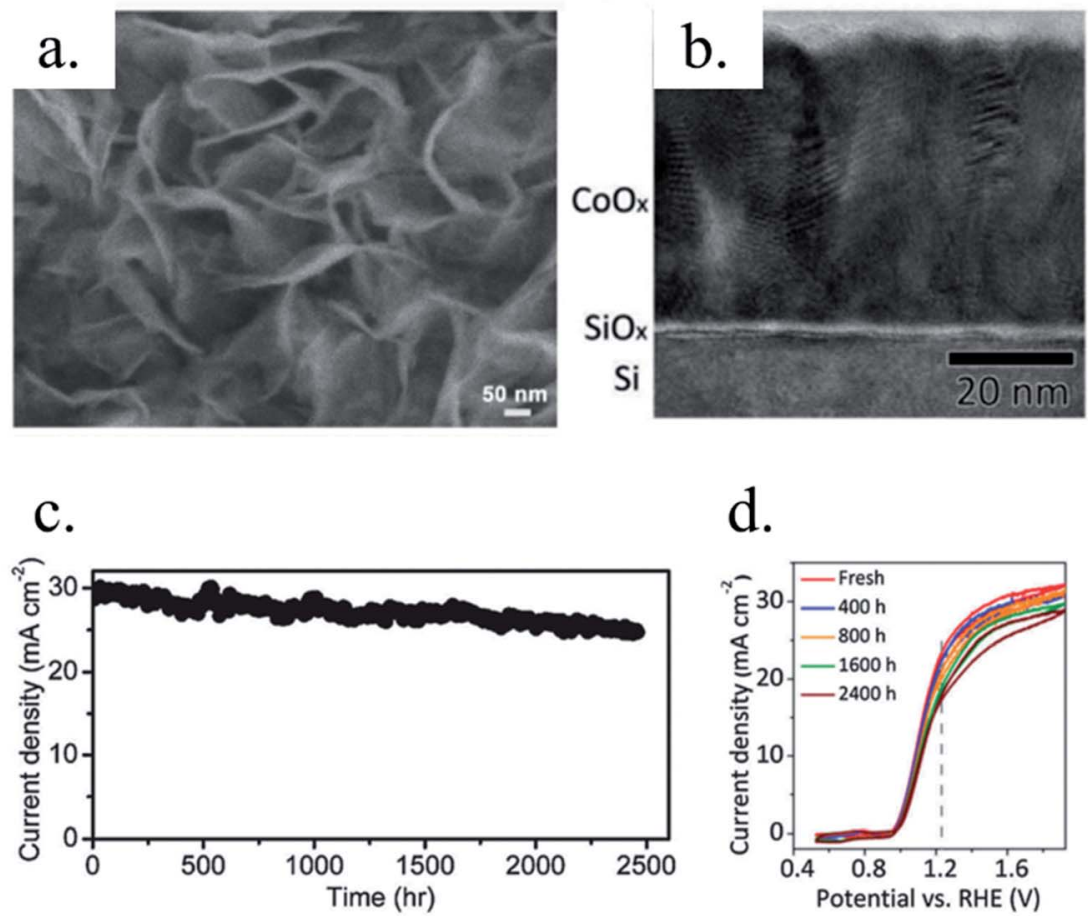

Fig. 18 (a) SEM image of $\mathrm{Co}(\mathrm{OH})_{2}$ electrodeposited for 2 min. Reprinted with permission from (Nanoscale, 2016, 8, 9667-9675). Copyright (2015) RSC. ${ }^{290}$ (b) High resolution cross section TEM images of polycrystalline $\mathrm{CoO}_{x}$-protected $\mathrm{n}$-Si photoelectrode. (c) Stability measurement at $1.63 \mathrm{~V}$ vs. RHE and (d) cyclic voltammogram of the $\mathrm{CoO}_{x}$-protected $\mathrm{n}$-Si photoelectrode under 1.1 sun illumination in $1 \mathrm{M} \mathrm{KOH}$. Energy Environ. Sci., 2016, 9892 - published by The Royal Society of Chemistry (RSC) on behalf of the Centre National de la Recherche Scientifique (CNRS) and the RSC. ${ }^{295}$ 
conductivity was reduced and the layer dissolved as $\mathrm{FeOOH}$ is soluble in basic mediums unless incorporated in $\mathrm{NiOOH}$ or $\mathrm{CoOOH}$. This would suggest $\mathrm{CoOOH}$ acts as "conductive, chemically stable, and intrinsically porous/electrolytepermeable host for Fe, which substitutes Co atoms and serves as the (most) active site for OER catalysis". Other metals such as $\mathrm{Ru}$ or $\mathrm{Rh}$ have been combined with $\mathrm{CoO}_{x}$ to further reduce its OER. ${ }^{296}$ Tung et al. ${ }^{289}$ found one of the causes of long-term instability is volume expansion on phase change due to hydroxylation to $\mathrm{CoOOH}$, and thus, nanoscale structuration can prevent detachment and efficiency loss.

(d) Other conductive protective layers. Back in 1987, Kainthla et $a l .{ }^{297}$ protected $\mathrm{n}$-Si with $\mathrm{MnO}$ achieving stable photoanode for $650 \mathrm{~h}$ giving $1 \mathrm{~mA} \mathrm{~cm}{ }^{-2}$ at $1.6 \mathrm{~V} v s$. RHE in $0.5 \mathrm{M} \mathrm{K}_{2} \mathrm{SO}_{4}$ solution. In 2012, up to $20 \mathrm{~nm}$ ALD MnO films were used by Strandwitz et al. ${ }^{\mathbf{1 4 0}}$ to protect $\mathrm{n}$-Si and obtained almost $30 \mathrm{~mA}$ $\mathrm{cm}^{-2}$ at $1.5 \mathrm{~V} v s$. RHE in $1 \mathrm{M} \mathrm{KOH}$ and $550 \mathrm{mV}$ photovoltage, but not stable for more than $10 \mathrm{~min}$. They also found film thickness increase introduced significant resistance, affecting fill factor.

Transparent and conductive thallium oxide $\left(\mathrm{Tl}_{2} \mathrm{O}_{3}\right)$ was deposited 3-4 $\mu \mathrm{m}$ thick by Switzer et al. ${ }^{298}$ protecting an n-Si photoanode. A SIS junction was formed, with over $500 \mathrm{mV}$ photovoltage and $33 \mathrm{~mA} \mathrm{~cm}{ }^{-2}$ photocurrent with a $\mathrm{Fe}(\mathrm{CN})_{6}{ }^{3+/ 4+}$ redox couple, although thallium is a toxic and expensive material with quite low abundance. ${ }^{299}$ $\sim 100 \mathrm{~nm}$ sputtered $\mathrm{n}$-type $\mathrm{Nb}_{2} \mathrm{O}_{5}$ formed an heterojunction with p-type GaP in a work by Malizia et al., ${ }^{300}$ achieving $710 \mathrm{mV}$ photovoltage, although its stability was found less than $\mathrm{TiO}_{2}$ protective layers in $1 \mathrm{M} \mathrm{HClO}_{4}$ attributed to $\mathrm{Nb}_{2} \mathrm{O}_{5}$ detachment and thus, Pt cocatalyst loss (Fig. 19a). Avoiding pinholes corroding photoabsorber beneath is important, as some materials such as $\mathrm{Nb}_{2} \mathrm{O}_{5}$, with expected good stability in acidic environments, ${ }^{301}$ will not stop corrosion from beneath.

For GaP nanowires, Standing et al. ${ }^{302}$ directly grew a $20 \mathrm{~nm}$ electrochemically produced oxide $\mathrm{Ga}_{2} \mathrm{O}_{3}$ slightly increasing photovoltage and enhancing stability before depositing either Pt or $\mathrm{MoS}_{2}$ HER catalysts. The list of possible protective layers will probably increase following years, as other authors have proposed other combinatorial metal oxides such as $\mathrm{CuWO}_{4}$, $\mathrm{Co}_{3} \mathrm{O}_{4}, \mathrm{SnO}_{2}, \mathrm{WO}_{3}, \mathrm{Ta}_{2} \mathrm{O}_{5}$ for photoanodes or $\mathrm{BaTiO}_{3}$ and $\mathrm{Ta}_{2} \mathrm{O}_{5}$ for photocathodes. ${ }^{112}$

Non-oxide materials have also been studied. Among them, $\mathrm{MoS}_{2} / \mathrm{MoS}_{x}$, one of the best performing earth-abundant catalyst for the HER reaction, ${ }^{\mathbf{3 0 4}}$ has been used few times not just as catalyst, but also as protective layer. 1-5 nm of $\mathrm{MoS}_{2}$ increases GaInP and Si photoelectrodes stability (Fig. 19b) ${ }^{\mathbf{3 0 3}}$ in acidic electrolytes. However, in 2012 Seger et al. ${ }^{\mathbf{2 0 2}}$ protected an $\mathrm{n}^{+} \mathrm{p}-\mathrm{Si}$ homojunction with $9 \mathrm{~nm}$ Ti and $35 \mathrm{~nm} \mathrm{MoS}$, and they attributed protection to $\mathrm{Ti}$, on a self-limited oxidation to $\mathrm{TiO}_{2}$. Other authors have combined up to $100 \mathrm{~nm} \mathrm{MoS}$ with $\mathrm{TiO}_{2}$ to protect

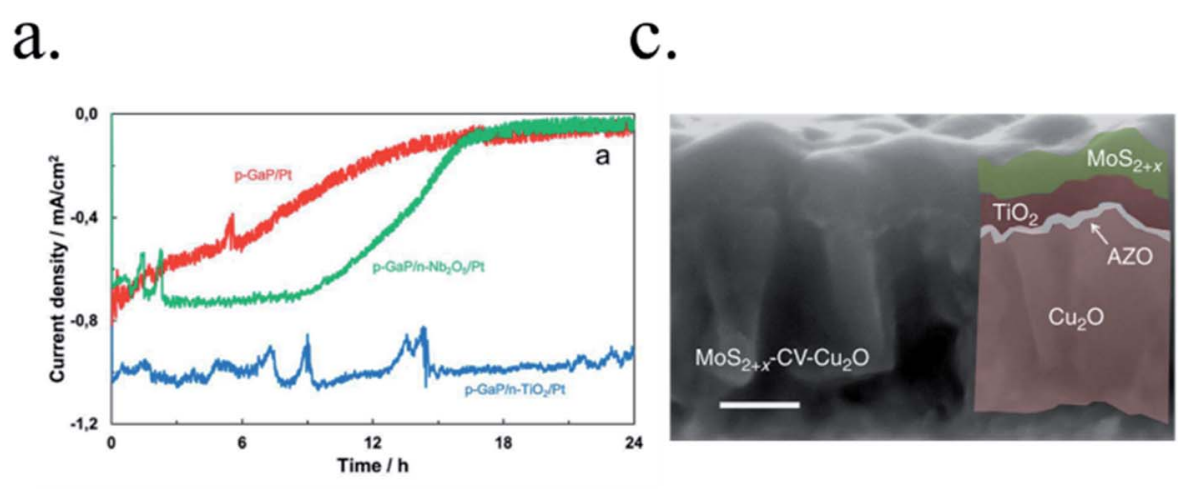

b.

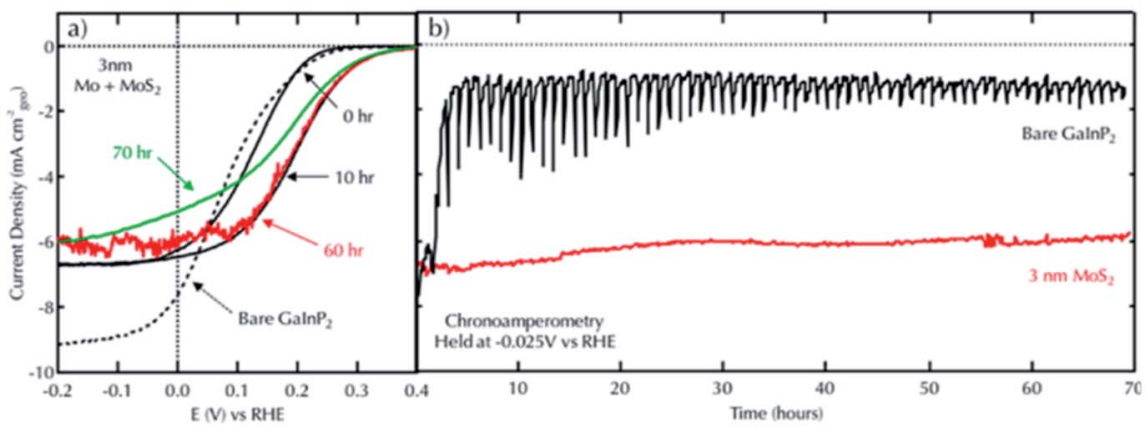

Fig. 19 (a) Stability measurements of GaP photocathodes unprotected (red) $\mathrm{Nb}_{2} \mathrm{O}_{5}$ (green) and $\mathrm{TiO}_{2}$ protected (blue) in $1 \mathrm{M} \mathrm{HClO}$. Reprinted with permission from (J. Mater. Chem. A, 2014, 2, 6847-6853). Copyright (2014) RSC. ${ }^{300}$ (b) Stability measurement of a GalnP photocathode with and without $3 \mathrm{~nm} \mathrm{MoS}$ catalyst and protective layer. Reprinted with permission from (J. Phys. Chem. Lett., 2016, 7, 2044-2049). Copyright (2016) American Chemical Society. ${ }^{303}$ (c) SEM cross section image of a $\mathrm{Cu}_{2} \mathrm{O}$ photocathode $\mathrm{AZO} / \mathrm{TiO}_{2} / \mathrm{MoS}_{2+x}$ protected. Reprinted with permission from (Nat. Commun., 2014, 5(1), 1-7). Copyright (2014) Springer Nature. ${ }^{121}$ 
$\mathrm{Cu}_{2} \mathrm{O}$ photocathodes (Fig. 19c). ${ }^{121,305}$ Laursen et al. ${ }^{306}$ protected with $\mathrm{MoS}_{2}$ a silicon photocathode by sputtering $10 \mathrm{~nm}$ Mo and reactive-annealing it with $\mathrm{H}_{2} \mathrm{~S}$ at $450{ }^{\circ} \mathrm{C}$, obtaining stable photocathode for $120 \mathrm{~h}$ in $1 \mathrm{M} \mathrm{HClO}_{4}$. Recently, King et al. ${ }^{307}$ protected a $\mathrm{n}^{+} \mathrm{p}$-Si with $3.7 \mathrm{~nm} \mathrm{SiO}{ }_{2}$ and $\sim 11 \mathrm{~nm} \mathrm{MoO}_{x} / \mathrm{MoS}_{2}$ (metallic $\mathrm{Mo}$ is sputtered and further $\mathrm{H}_{2} \mathrm{~S}$ atmosphere annealed) achieving up to 62 days $(1638 \mathrm{~h})$ stability with $>10 \mathrm{~mA}$ $\mathrm{cm}^{-2}$ photocurrent at $0 \mathrm{~V} v s$. RHE in $0.5 \mathrm{M} \mathrm{H}_{2} \mathrm{SO}_{4}$.

\section{Heterojunctions with the protective layer}

Creating effective short band gap photoelectrodes requires highly conductive, transparent, stable and kinetically efficient protective layers and catalysts, but also to maximize the photovoltage of the system. For sensible-to-corrosion photoabsorbers, the electrolyte will not be in contact with the photoabsorber due to the introduction of the protective layer in between and thus, a semiconductor-liquid junction (SCLJ) will not be present to create an electric field to separate and extract photogenerated charges.

Forming an electronic junction between two different materials (at least one of them a semiconductor) forms an heterojunction. In this case, the maximum photovoltage of the photoelectrode is governed by the electronic properties of protective layers, photoabsorbers and interfacial energetics. Introducing heterojunctions results in a more complex device (Fig. 12b-d), meanwhile it opens the possibility for higher photovoltages thanks to a larger amount of candidates available. Among them, three types of heterojunctions are considered: Schottky junctions (formed between a metal and a semiconductor), metal-insulator-semiconductor (MIS) junctions and semiconductor-semiconductor heterojunctions (composed of different materials).

\subsection{Schottky and MIS junctions}

In Section 5 has been analysed how thin (few nanometers) metallic films can protect a semiconductor from corrosion, forming a Schottky junction (Fig. 12b). However with limited stability and with significant recombination rates and Fermi level pinning caused by states in the metal-semiconductor interface, limiting electron-hole pseudo-Fermi level separation and thus, the photovoltage. ${ }^{201}$ Even so, selecting appropriate metals with work functions low for photoanodes and high for photocathodes is mandatory to obtain significant photocurrents and photovoltages. ${ }^{190}$ Very small photovoltages are obtained from just directly depositing Pt or Ni on p-Si, meanwhile $200 \mathrm{mV}$ more can be generated with a $\mathrm{p}-\mathrm{Si} / 5 \mathrm{~nm}$ Ti contact previous to Pt catalyst (Fig. 20a) ${ }^{\mathbf{1 9 6 , 1 9 9}}$ or Ni catalyst ${ }^{200}$ thanks to higher Schottky barrier created by the favourable work function of Ti.

Introducing few nanometers of insulator materials between the semiconductor and the metal film (Fig. 12c), such as $\mathrm{SiO}_{2}$ or $\mathrm{Al}_{2} \mathrm{O}_{3},{ }^{201,308}$ can passivate interfacial electronic states and enhance energy level separation in the heterojunction (forming a metal-insulator-semiconductor junction, MIS). Specifically,
$\mathrm{Al}_{2} \mathrm{O}_{3}$ is favourable to unpin the Si Fermi level, giving extra builtin potential. Regarding selected metal, Pt has higher work function than $\mathrm{Ni}$ and increases photovoltage in $\mathrm{n}$-Si photoanodes (Fig. 20b). ${ }^{308}$ Laskowski et al. ${ }^{198}$ suggest high barrier regions are formed when $\mathrm{Si}$ is oxidized to $\mathrm{SiO}_{2}$ due to electrolyte ( $\mathrm{pH} 9.8 \mathrm{~K}$-borate buffer) permeability in very thin $(\sim 3-5 \mathrm{~nm}) \mathrm{Ni}$ films, avoiding Ni/n-Si Fermi level pinning and thus, increasing photovoltage (Fig. 20c and d).

Following this, several works have focused on the passivation of Si surface states with ultrathin semiconductor layers (0$12 \mathrm{~nm}$ ) such as $\mathrm{TiO}_{2}$, although the junction is formed between the metallic film on top and the silicon, and thicker intermediate layers will increase metal to semiconductor separation, reducing formed photovoltage. ${ }^{212} \mathrm{SrTiO}_{3}$ epitaxial films, MBEdeposited by Ji et al. ${ }^{309,310}$ on p-Si with patterned $50 \mathrm{~nm} \mathrm{Ti/Pt}$ catalyst formed a stable $\left(>35 \mathrm{~h}\right.$ in $\left.0.5 \mathrm{M} \mathrm{H}_{2} \mathrm{SO}_{4}\right)$ and effective photocathode $\left(35 \mathrm{~mA} \mathrm{~cm}^{-2}\right.$ at $-0.4 \mathrm{~V}$ vs. RHE, $450 \mathrm{mV}$ photovoltage) when only few unit cells $(4-6, \sim 1.6 \mathrm{~nm})$ of the strontium titanate were deposited. The space-charge region is formed between the $\mathrm{p}$-Si and metallic $\mathrm{Ti}$, with lower work function than $\mathrm{Pt}$, as it has a work function similar to $\mathrm{p}-\mathrm{Si}$, and would generate small photovoltage. Although, these insulator layers introduce significant tunnelling resistance if thicker than $3 \mathrm{~nm}$ (ref. 186) and do not significantly increase stability to corrosion.

\subsection{Semiconductor-semiconductor heterojunctions with thick oxides}

Similar schemes can be formed with thicker conductive oxides semiconductors instead of metals (Fig. 12d), overcoming metal films limitations on thickness and transparency. In this case, heterojunctions between two semiconductor materials will be formed, where a thin insulator film can be introduced in the interface avoiding Fermi level pinning if necessary (forming a semiconductor-insulator-semiconductor (SIS) junction). Similar electronic structure to Section 3.6 will be formed, but doing so with a short band gap material and a wide band gap metal oxide has a great benefit: the major part of photon absorption will occur in the short band gap one, collecting large portion of the visible spectra. Also, short band gap materials such as Si, GaAs or CIGS are very good photoabsorbers, with minimal recombination and transport losses.

Thicker-than-tunnelling metal oxides have been widely used both to protect short band gap semiconductors and to generate a built-in electric field. N-type wide band-gap semiconductors such as $\mathrm{ZnO}, \mathrm{WO}_{3}$ or $\mathrm{TiO}_{2}$ have favourable energetics to form a heterojunction with p-type photoabsorbers such as $\mathrm{Si}$, InP or CIGS in a similar strategy to SIS solar cells. ${ }^{311}$ In 1996, Yoon et al. tested a different thickness n-type $\mathrm{WO}_{3}$ on $\mathrm{p}$-Si, achieving a better photovoltage by controlling resistivity, carrier concentration and surface band bending (Fig. 21a). ${ }^{312}$ In 1998 (ref. 313) they electron-beam evaporated $50 \mathrm{~nm} \mathrm{WO}_{3}$ on top of p-Si with 1-2 nm Pt as catalyst, and the role of a more efficient built-in field is clearly observed when introducing $\mathrm{WO}_{3}$, with a better HER catalysis when Pt is incorporated (Fig. 21b). Although, $\mathrm{WO}_{3}$ was found not to be stable if Pt was not blocking direct contact 
a.

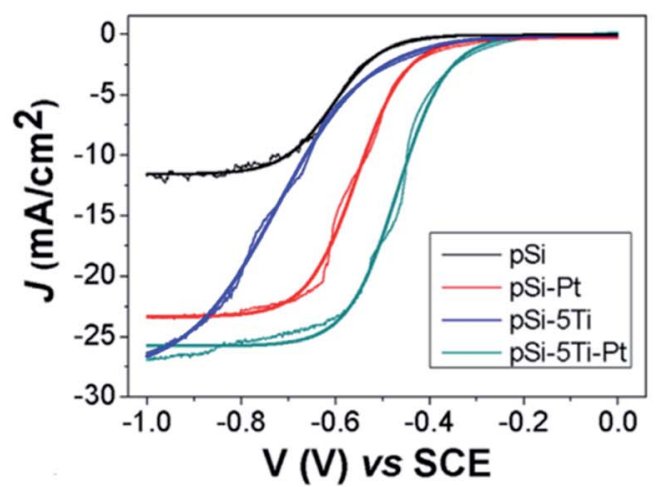

c.

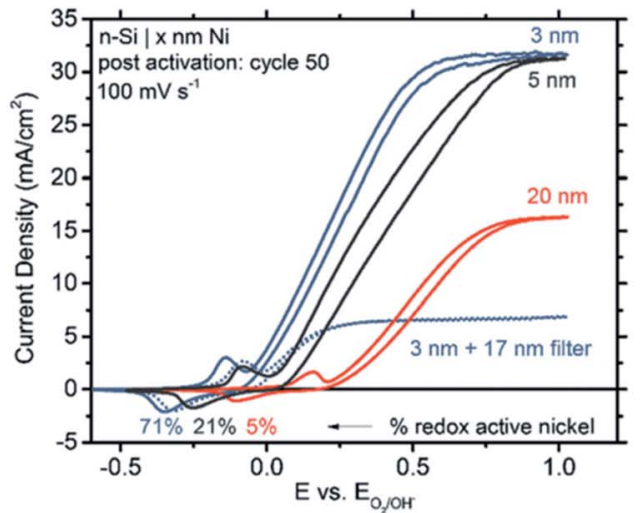

b.

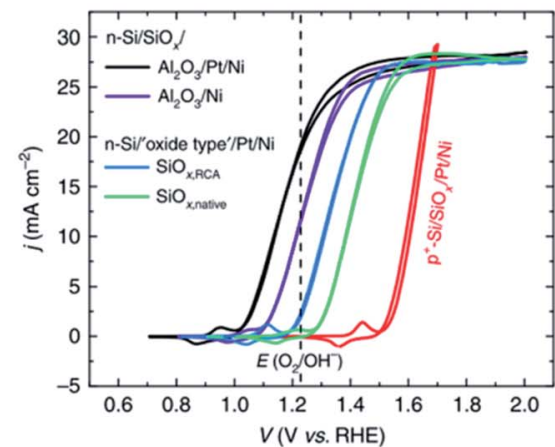

d.

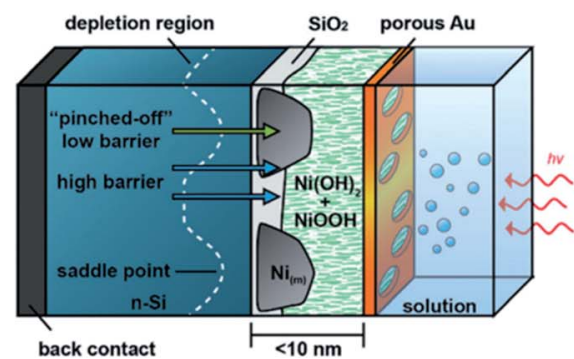

Fig. 20 (a) Cyclic voltammogram of p-Si photoanodes where higher photovoltages can be observed if $5 \mathrm{~nm}$ Ti is used to form the Schottky junction and Pt on top as HER catalyst. Reprinted with permission from (Electrochim. Acta, 2018, 271, 472-480). Copyright (2018) Elsevier. ${ }^{199}$ (b) Cyclic voltammograms of $\mathrm{n}$-Si photoanodes presenting higher MIS photovoltage if $\mathrm{Al}_{2} \mathrm{O}_{3}$ is used as ultrathin insulator layer and Pt as the metal intervening thanks to its work function, together with Ni as OER electrocatalyst. Reprinted with permission from (Nat. Commun., 2017, vol. 8, 15968). Copyright (2017) Springer. ${ }^{308}$ (c) Cyclic voltammogram and (d) scheme depicting the formation of adventitious interfacial ultrathin $\mathrm{SiO}_{2}$ preventing Fermi level pinning due to electrolyte ( $\mathrm{pH} 9.8 \mathrm{~K}$-borate buffer) penetration, and thus, forming higher photovoltage. Reprinted with permission from (Energy Environ. Sci., 2017, 10, 570-579). Copyright (2017) RSC. ${ }^{198}$

of $\mathrm{WO}_{3}$ with the acidic electrolyte $\left(0.1 \mathrm{M} \mathrm{H}_{2} \mathrm{SO}_{4}\right)$. By the introduction of an indium-doped tin oxide (ITO) layer, Coridan et $a .^{\mathbf{3 1 4}}$ demonstrated not such a good interface is formed between $\mathrm{WO}_{3}$ and $\mathrm{Si}$, and the ITO layer could also act as an ohmic contact, allowing them to create a tandem cell. Wang et al. ${ }^{315}$ also demonstrated $\mathrm{Fe}_{2} \mathrm{O}_{3}$ heterojunction with $\mathrm{n}$-Si and pSi photoelectrodes.

Transparent conductive oxides (TCO) such as ITO and AZO were tested, as theoretically should be good conductive and transparent n-type semiconductors for photocathodes and thus, form good $\mathrm{p}-\mathrm{n}$ heterojunctions. $\mathrm{ZnO}(\sim 3.1 \mathrm{eV})$ was deposited by Sun et al. as a film and as nanorods on planar p-Si and nanowire-grown $\mathrm{p}$-Si, ${ }^{316}$ achieving better light absorption and active surface area thanks to the nanostructures and HER catalysis enhanced by Ni, Pt and Pd cocatalysts (Fig. 21c). p-Type $\mathrm{Cu}_{2} \mathrm{O}$ electrodes can also form an heterojunction with $\mathrm{n}-\mathrm{ZnO}$ reaching more than $7 \mathrm{~mA} \mathrm{~cm}{ }^{-2}$, although $\mathrm{TiO}_{2}$ was required for higher stability even in $1 \mathrm{M} \mathrm{Na}_{2} \mathrm{SO}_{4}$ at reductive potentials. ${ }^{\mathbf{9 2 , 1 2 1}}$ Although, stability was limited to few minutes as $\mathrm{ZnO}$ is an amphoteric metal oxide unstable in alkaline and even more in acidic electrolytes. ${ }^{317}$
Designing a photocathode with $\mathrm{TiO}_{2}$ as n-type semiconductor and transparent protective oxide forms a $\mathrm{p}-\mathrm{n}$ junction when put in contact with a p-type photoabsorber such as Si, InP or CIGS. Seger et al. ${ }^{236}$ deeply studied the built-in fields generated between $\mathrm{p}$-Si and $\mathrm{TiO}_{2}$, and in the $\mathrm{TiO}_{2}$-electrolyte interface (Fig. 22a-c), with depletions only possible to be tunneled through if doping levels are high enough. Lin et al. ${ }^{318}$ demonstrated the junction formed between p-InP and $10 \mathrm{~nm} n$ $\mathrm{TiO}_{2}$ (Fig. 22d). Azarpira et al. ${ }^{319}$ deposited $\sim 100 \mathrm{~nm}$ n-type Ptdoped anatase $\mathrm{TiO}_{2}$ on p-type $\mathrm{Cu}(\mathrm{In}, \mathrm{Ga}) \mathrm{Se}$ to form the heterojunction of a photocathode, with Pt also enhancing HER catalysis (Fig. 22e and f). $300 \mathrm{mV}$ photovoltage was achieved, with onset potential at $\sim 0.23 \mathrm{~V} v s$. RHE but photocurrent saturation $\left(37 \mathrm{~mA} \mathrm{~cm}{ }^{-2}\right)$ at $-0.3 \mathrm{~V}$ vs. RHE, significantly worse than a commercial CIGSe PV cell. This is because directly depositing one on top of the other does not take into account interfacial recombination, states passivation, etc., which have been circumvented in CIGSe PV devices by highly optimized superficial pre-treatment, n-type CdS chemical bath deposition and multilayer TCO top contact. ${ }^{320}$ Thus, directly depositing $\mathrm{TiO}_{2}$ in 
a.

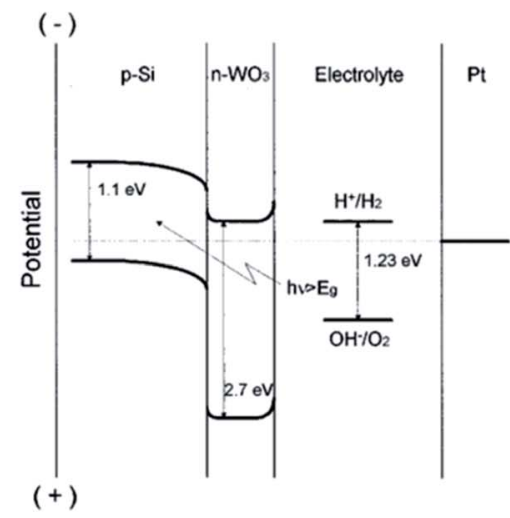

b.

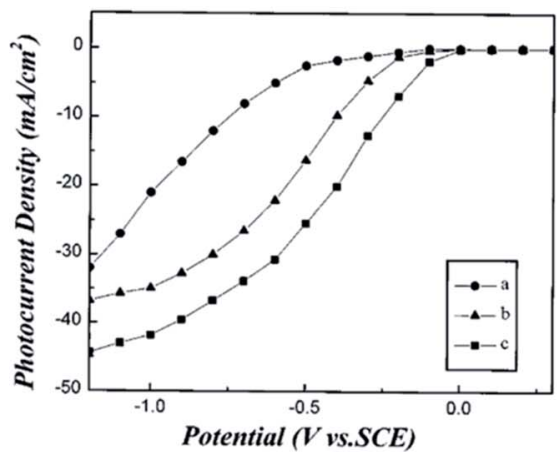

c.

(a)

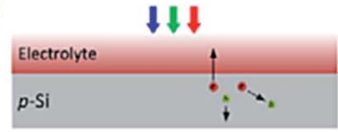

(d)

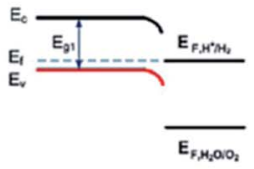

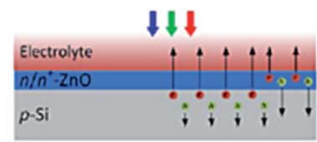

(e)

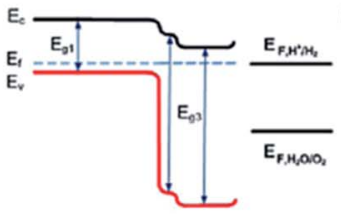

(c)

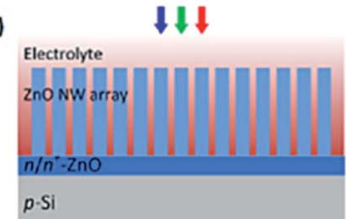

(f)

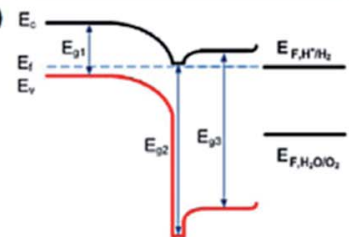

Fig. 21 (a) Scheme of a p-Si/n-WO $\mathrm{W}_{3}$ heterojunction. Reprinted with permission from (J. Appl. Phys., 15 May 1997, vol. 81, no. 10). Copyright (1997) AIP Publishing. ${ }^{312}$ (b) Cyclic voltammgrams of a $\mathrm{p}-\mathrm{Si}$, a $\mathrm{p}-\mathrm{Si} / \mathrm{n}-\mathrm{WO}_{3}$ and a $\mathrm{p}-\mathrm{Si} / \mathrm{n}-\mathrm{WO}_{3} / \mathrm{Pt}$ catalysed photoelectrodes. Reprinted with permission from (J. Appl. Phys., 1 October 1998, vol. 84, no. 7). Copyright (1998) AIP Publishing. ${ }^{313}$ (c) Schemes (top) and energy band diagrams (bottom) of p$\mathrm{Si}$ (left) $\mathrm{p}-\mathrm{Si} / \mathrm{n}^{+}-\mathrm{ZnO}$ (center) and $\mathrm{p}-\mathrm{Si} / \mathrm{n}^{+}-\mathrm{ZnO} / \mathrm{ZnO}-\mathrm{NW}$ (right). Reprinted with permission from (Nanotechnology, 2012, 23, 194013). Copyright (2012) IOP Publishingng. ${ }^{316}$

top of a short band gap photoabsorber is a simpler strategy but maybe not so effective as protecting a buried solar cell. ${ }^{240,241,321}$

Metal oxide protective layers acting as part of the heterojunctions for photoanodes also introduce some benefits. Transition metal oxides such as $\mathrm{CoO}_{x}{ }^{155,293}$ or $\mathrm{NiO}^{285}$ have high work function due to oxygen vacancies and cation oxidation states, ${ }^{322}$ what can be used when designing photoelectrodes heterojunction to increase built in electric field and also as hole transporter and electron blocking layers. $37 \mathrm{~nm}$ sol-gel nickel oxide can form a $300 \mathrm{mV}$ photovoltage $\mathrm{e}^{285}$ and $75 \mathrm{~nm}$ sputtered $\mathrm{NiO} \sim 350 \mathrm{mV}$ (ref. 172) on $\mathrm{n}$-Si. Although, these photoanodes are far from the photovoltages obtained with buried $\mathrm{p}-\mathrm{n}$ junctions (550-600 $\mathrm{mV})^{\mathbf{1 7 2}}$ due to Fermi level pinning in the $\mathrm{Si}-\mathrm{MO}_{x}$ interface. Almost no photovoltage is obtained with a $\mathrm{p}-\mathrm{NiO} / \mathrm{n}$ InP heterojunction due to strong pinning, whereas with a buried $\mathrm{p}^{+} \mathrm{n}$-InP $\sim 700 \mathrm{mV}$ were obtained. ${ }^{256}$ Zhou et al. ${ }^{323}$ coated n-Si photoanodes having $\sim 2 \mathrm{~nm} \mathrm{SiO}_{x}$ or $\sim 2 \mathrm{~nm} \mathrm{SiO}_{x} / 2-3 \mathrm{~nm}$ ALD- $\mathrm{CoO}_{x}$ with $\sim 100 \mathrm{~nm}$ sputtered $\mathrm{NiO}$, and found the thin $\mathrm{CoO}_{x}$ interlayer introduces up to $165 \mathrm{mV}$ extra photovoltage reaching $560 \mathrm{mV}$ helped by the de pinning caused by the thin $\mathrm{SiO}_{2}$ (Fig. 23a and b). $\mathrm{CoO}_{x}$ increases band bending at the interface due to $120 \mathrm{mV}$ larger work function of $\mathrm{CoO}_{x}$ in respect to NiO. This way, photovoltages close to $\mathrm{n}^{+} \mathrm{p}-\mathrm{Si}$ junctions and 30
$\mathrm{mA} \mathrm{cm}^{-2}$ stable for $1700 \mathrm{~h}$ (70 days) were obtained. Other p-type semiconductors such as $\mathrm{Fe}_{2} \mathrm{O}_{3}$ (ref. 12 and 324) have been used to form heterojunctions with $\mathrm{n}$-Si.

As explained in Section 5.2.3(a), $\mathrm{TiO}_{2}$, although being an ntype semiconductor, has been reported to be efficiently conductive for water oxidation when grown amorphous, with mid-bandgap states ( $\sim 1 \mathrm{eV}$ below the conduction band) allowing hole conductivity by hopping through them ${ }^{217,244,325,326}$ after tunnelling through the thin $\mathrm{SiO}_{2}$ interface. These energy states are considered to equilibrate with n-Si Fermi level, generating photovoltage (Fig. 23c). Ni catalyst was reported to be mandatory for properly contacting these estates through a less defective $\mathrm{TiO}_{2}$ surface and thus, allowing connexion with the OER catalysis. ${ }^{186,217}$ The fabrication process (ALD, sputtering) and specific doping conditions of $\mathrm{TiO}_{2}$ (caused by post-annealing process modifying the Ti states density, carbon contaminants, etc.) has been reported to be highly related to final SIS junction photovoltage in a $\mathrm{n}-\mathrm{Si} / \mathrm{TiO}_{2} / \mathrm{Ni}$ photoanode (Fig. 23d). ${ }^{179}$ Heterojunctions with the amorphous $\mathrm{TiO}_{2}$ have also been fabricated with other photoabsorbers, such as n-CdTe/TiO $/ 2 / \mathrm{Ni}$, with $435 \mathrm{mV}$ photovoltage and $21 \mathrm{~mA} \mathrm{~cm}^{-2} \cdot{ }^{248}$ If protective layers do not have the optimal energy band levels and interface energetic states, degenerately doped layers will screen metallic catalyst work 
a.

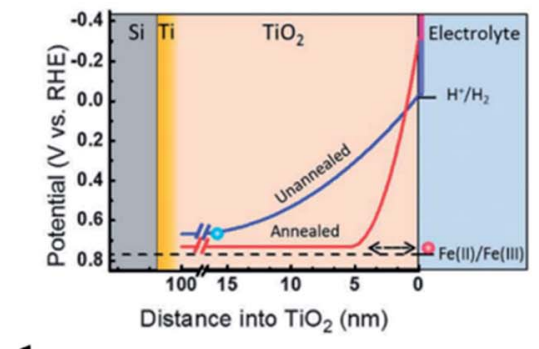

d.

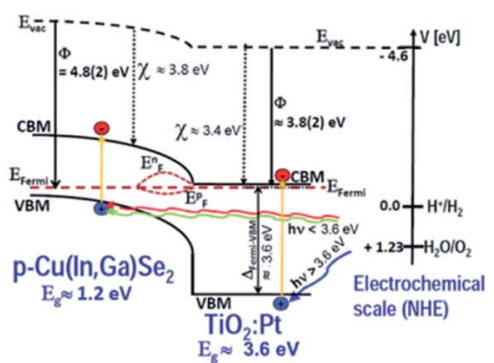

b.

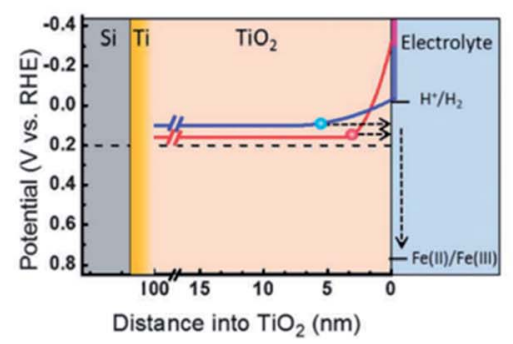

e.

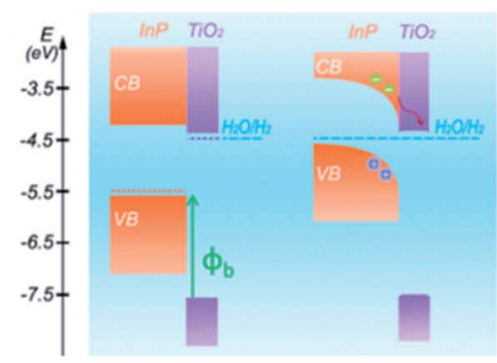

c.

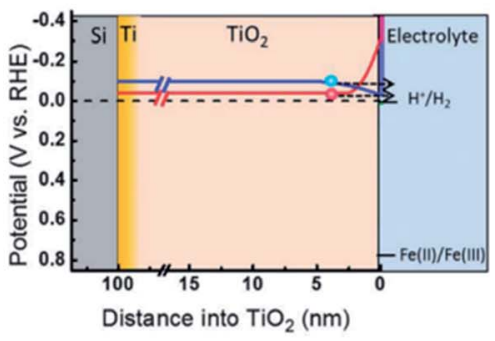

f.

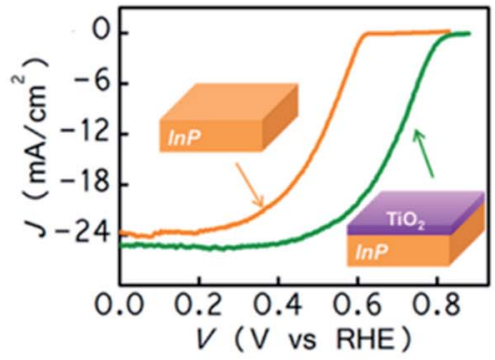

Fig. 22 The effect of annealed and unannealed $\mathrm{TiO}_{2}$ protective layers on detrimental superficial band bending at different potentials (a) $+0.77 \mathrm{~V}$ vs. RHE, (b) +0.2 V vs. RHE and (c) 0.0 V vs. RHE. Reprinted with permission from (J. Mater. Chem. A, 2013, 1, 15089). Copyright (2013) RSC. ${ }^{236}$ (d) Heterojunction formed between a p-ClGSe and $\mathrm{n}-\mathrm{TiO}_{2}$ : Pt film. Reprinted with permission from (Adv. Energy Mater., 2015, 5, 1402148). Copyright (2015) John Wiley and Sons. ${ }^{319}$ (e) Energy band diagrams and (f) cyclic voltammograms response of an InP/TiO 2 heterojuncton. Reprinted with permission from (J. Phys. Chem. C, 2015, 119, 2308-2313). Copyright (2015) American Chemical Society. ${ }^{318}$

function and limit performance. ${ }^{186}$ Meanwhile, slightly doped protective layers, if thicker, will introduce overpotentials from electrical resistivity, proportional to metal oxide thickness. To prevent this, buried junctions can maximize the obtained photovoltage by themselves, not depending on the protective layer.

\section{Buried homojunctions to maximize efficiency and cell flexibility}

As it has been analysed in previous section many efforts have been put in forming heterojunctions to directly create a built-in field between the metal oxide protective layer and a short band gap semiconductor. So far, even the achieved photovoltages have been significant, they are not as high as the ones for short band gap semiconductors reported for photovoltaic solar cells (with open circuit potentials of up to $750 \mathrm{mV}$ ). ${ }^{133,327}$ Buried p-n junctions (Fig. 12e) have been proven to generate higher built-in electric fields than SCLJ or Schottky junctions, decoupling photoabsorbers Fermi level from that of the metallic or oxide protective layer or electrolyte, also removing a constrain on the catalyst required work function value. ${ }^{186,328}$ This way, a more flexible device design is possible as each component (photoabsorber, protective layer and catalyst) can be selected more independently, as it can be observed in Fig. 24a and b. Thus, several groups have shifted the strategy and worked on adapting solar cell $\mathrm{p}-\mathrm{n}$ junctions for water splitting, obtaining some of the highest reported performances of PEC cells. ${ }^{155}$
Several photovoltaic-used schemes have been studied, being silicon the most implemented one by far. Not only because is the most used one for solar cells, dominating the solar panels market, but also because of the simple and robust cell obtained: a monocrystalline silicon solar cell can be fabricated several tens of centimetres wide, few hundred microns thick and is robust, not requiring any substrate. Also, as $\mathrm{p}-\mathrm{n}$ junctions are fabricated in silicon wafers by dopant diffusion and incorporation in its crystal lattice at fabrication temperatures of up to $1025{ }^{\circ} \mathrm{C},{ }^{178}$ further thermal steps applied at medium temperatures (up to $500{ }^{\circ} \mathrm{C}$ ) will not damage the p-n junction and will retain original output. In a buried junction electrode, photogenerated charges will migrate to the catalyst/electrolyte interface through protective layers, acting as conductive contacts: $n$ type semiconductor protective layers should be expected to be prone for electron conductivity in photocathodes (Fig. 24c), and p-type semiconductors for holes in photoanodes (Fig. 24d). Although, other strategies such as mid-band gap states in n-type semiconductors have been proposed for hole conduction (Fig. 24e) or recombining contacts (Fig. 24f), as has been discussed in Section 5.2.3. As example, photovoltages as high as $630 \mathrm{mV}$ have been obtained for silicon with buried p-n junctions. ${ }^{327}$ Other semiconductors have been tested apart from silicon with same protective and catalyst strategies, proving these to be highly reproducible in other photoabsorber materials, increasing device flexibility. ${ }^{329}$

As it was reported by Scheuermann et al. ${ }^{212}$ and Wang et al. ${ }^{329}$ once a buried junction is introduced in our device, the 
a.

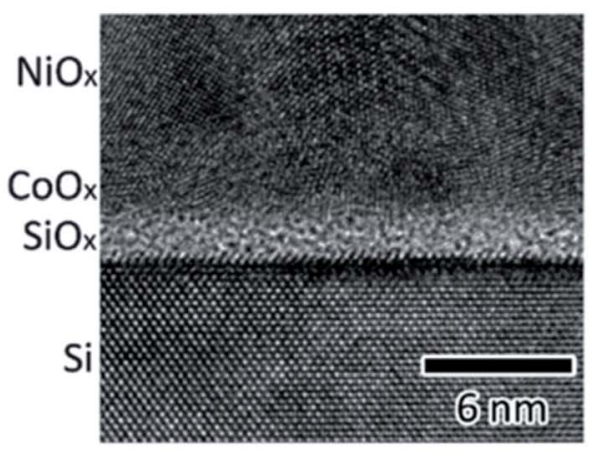

c.

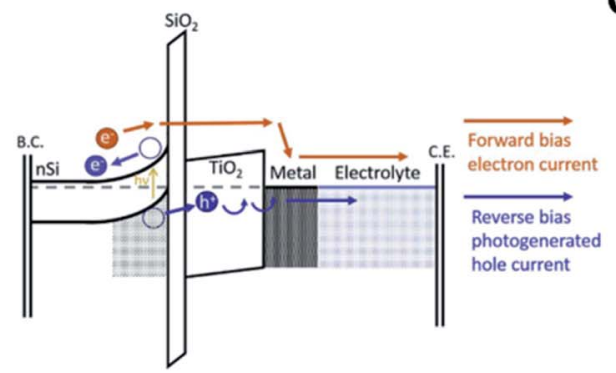

b.

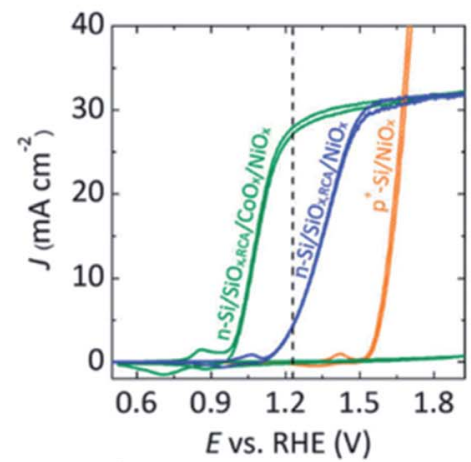

d.

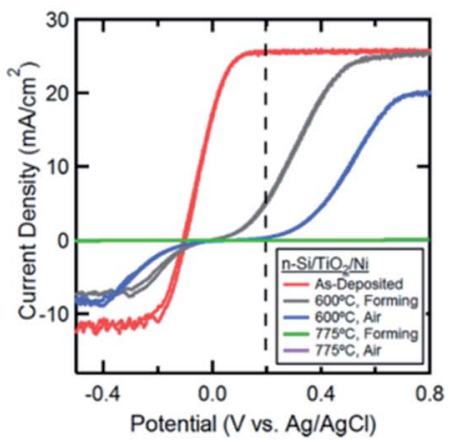

Fig. 23 (a) HRTEM cross section and (b) cyclic voltammograms of an $\mathrm{n}-\mathrm{Si} / \mathrm{SiO} \mathrm{O}_{x} / \mathrm{CoO}_{x} / \mathrm{NiO}_{x} \mathrm{SIS}$ junction (green), where higher photovoltage is obtained thanks to $120 \mathrm{mV}$ greater $\mathrm{CoO}_{x}$ work function. Reprinted with permission from (Energy Environ. Sci., 2015, 8, 2644-2649). Copyright (2015) RSC. ${ }^{323}$ (c) Band diagram of an $\mathrm{n}-\mathrm{Si} / \mathrm{SiO}_{2} / \mathrm{TiO}_{2} /$ metal/electrolyte photoanode presenting hole hopping through $\mathrm{TiO}_{2}$ intra-band gap states. Reprinted with permission from (J. Electrochem. Soc., 2016, 163(3) H192-H200). Copyright (2016) IOP Science. ${ }^{325}$ (d) Cyclic voltammograms of $\mathrm{n}-\mathrm{Si} / \mathrm{TiO}_{2} / \mathrm{Ni}$ photoanodes treated at various temperatures, showing SIS junction detrimental effects with high temperature treatments by reducing states availability in $\mathrm{TiO}_{2}$. Reprinted with permission from (ACS Appl. Mater. Interfaces, 2015, 7, 15189-15199). Copyright (2015) American Chemical Society. ${ }^{179}$

requirements of the protective layer or the co-catalyst metallic film are reduced. Optimal work function metallic films or cocatalysts to create high electric field with the photoabsorber are no longer needed, widening material selection possibilities. The protective layer just needs to be chemically stable, highly conductive, transparent and the surface must not create electronic barriers with the electrolyte, together with being kinetically efficient for the HER or OER reactions, normally achieved by the addition of co-catalyst particles or films. What is equally necessary, though, is that no electrical barriers formed between the top contact of the $\mathrm{p}-\mathrm{n}$ junction and the protective layer.

Several works have obtained this by creating degenerately doped ohmic contacts, the most used case for silicon being $\mathrm{p}^{+} /$ $\mathrm{n}^{+}$(acting like metals) top contacts in the photoanode/ photocathode buried junction, shielding the built-in electric field from protective layer's interaction. Even if an upward band bending is present on the $\mathrm{n}^{+} / \mathrm{p}^{+}$surface, its depth would be limited to few nanometers due to the high doping level, easily permitting charge tunneling through these depletions, facilitating the ohmic contact. ${ }^{203,227,329}$ Seger et al. introduced a metallic $5 \mathrm{~nm}$ Ti film between $\mathrm{n}^{+} \mathrm{p}-\mathrm{Si}$ and $\mathrm{MoS}_{x}{ }^{202}$ or $\mathrm{TiO}_{2},{ }^{145,227}$ to form an ohmic contact and to prevent $\mathrm{Si}$ oxidation into detrimental insulator $\mathrm{SiO}_{2}$ (Fig. 25a), meanwhile in a photoanode, for Mei et al. ${ }^{178}$ a similar structure acted as an ohmic recombining contact between holes from $\mathrm{p}^{+}-\mathrm{Si}$ and electrons from $\mathrm{TiO}_{2}$ conduction band (Fig. 25b).

An example of the benefits of a buried $\mathrm{p}-\mathrm{n}$ junction is the work by Scheuermann et al., ${ }^{212}$ where they tried to maximize n-Si photoanodes with few $\mathrm{nm} \mathrm{SiO}_{2}$ or $\mathrm{SiO}_{2} / \mathrm{TiO}_{2}$ layers and Ir as catalyst, reaching limited $500 \mathrm{mV}$ photovoltage (highly sensible to $\mathrm{SiO}_{2}$ thickness), whereas with a buried $\mathrm{n}^{+} \mathrm{p}-\mathrm{Si}$ junction independent $630 \mathrm{mV}$ were obtained. Similar maximum photovoltages for $\mathrm{n}-\mathrm{Si} / \mathrm{p}$ $\mathrm{Si}$ and $\mathrm{n}^{+} \mathrm{p}-\mathrm{Si} / \mathrm{p}^{+} \mathrm{n}$-Si PEC electrodes have been obtained by other authors. ${ }^{140,165,197,202,203,206,212,217,227,235,238,239,286,330}$

In recent years, several other examples of buried junctions can be found, resembling solar cell structures with other materials. In 2014, Kast et al. ${ }^{232}$ protected a commercial textured $\mathrm{n}^{+} \mathrm{p}$ silicon solar cell with $10 \mathrm{~nm} \mathrm{Ti} / 50 \mathrm{~nm} \mathrm{~F}: \mathrm{SnO}_{2} / 50 \mathrm{~nm} \mathrm{TiO}_{2}$ and $2 \mathrm{~nm} \mathrm{Ir}$ as HER catalyst to form a photocathode, obtaining onset potentials $\sim 0.6 \mathrm{~V} v s$. RHE and $>30 \mathrm{~mA} \mathrm{~cm}{ }^{-2} .610 \mathrm{mV}$ photovoltages were produced by a $\mathrm{CoO}_{x}$ protected $\mathrm{p}^{+} \mathrm{n}-\mathrm{Si}$ photoanode $\mathrm{e}^{293}$ or $>550 \mathrm{mV}$ with a radial $\mathrm{n}^{+} \mathrm{p}$ junction on Si nanowires. ${ }^{328}$

Also, Bae et al. fabricated a silicon photoanode ${ }^{287}$ and a thinned photocathode (Fig. 26a and $\mathrm{b})^{223}$ to be back- 
a.

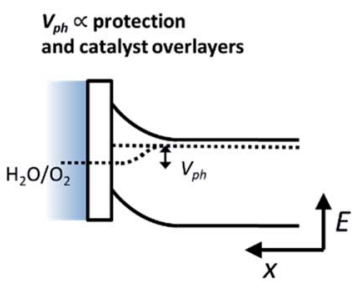

b.

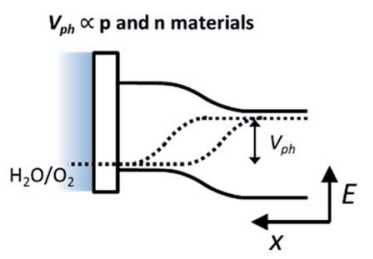

c.

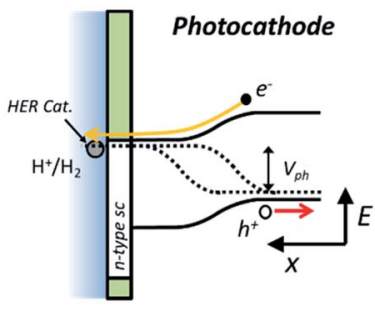

d.

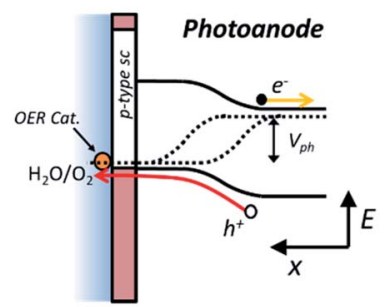

e.

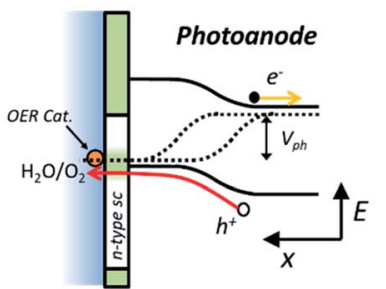

f.

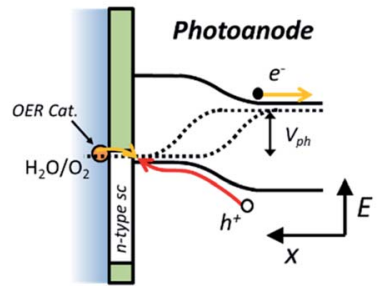

Fig. 24 Energy band schemes of (a) a junction depending on the photoabsorber/electrolyte interface or intermediate layers (i.e.: SCLJ, Schottky, MIS, SIS, ...) and (b) a buried junction, only dependent on the semiconductor materials forming the junction quality (i.e.: $\mathrm{n}-\mathrm{Si} / \mathrm{p}-\mathrm{Si}$, $\mathrm{CIGS} / \mathrm{CdS}, \ldots$... (c) Photocathode protected with an n-type semiconductor layer. (d) Photoanode protected by a p-type semiconductor hole transporting layer. Photoanodes protected with ntype semiconductors layers thanks to (e) mid-band gap states conducting holes and (f) contact for electrons recombining with holes from the photoanode.

illuminated, a configuration which would easy creating a tandem between two electrodes for a bias-free reaction. For it, they used similar strategies as previously reported: degenerately a.

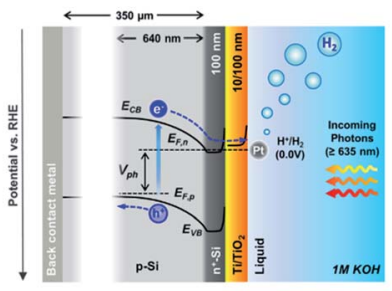

b.

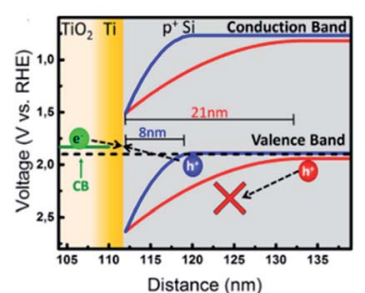

Fig. 25 Metallic thin Ti films on degenerately-doped silicon assuring ohmic contacts in (a) a photocathode (reprinted with permission from (Sol. Energy Mater. Sol. Cells, 2016, 144, 758-765). Copyright (2016) Elsevier ${ }^{145}$ ) and (b) a photoanode, where holes recombine with electrons from the conduction band of the protective layer (reprinted with permission from (J. Phys. Chem. C, 2015, 119, 15019-15027). Copyright (2015) American Chemical Society ${ }^{252}$ ). doped $\mathrm{p}^{+} / \mathrm{n}^{+}$Si surfaces with $50 \mathrm{~nm} \mathrm{NiCoO}_{x} / 5 \mathrm{~nm}$ Ti-100 nm $\mathrm{TiO}_{2}-\mathrm{Pt}$ respectively for efficient OER/HER reactions. In backillumination there is no need for transparent protective layers, although several tens of nanometers metal oxide layers are some of the best candidates to chemically protect from corrosion and to catalyze the OER reaction.

In the path of burying the photoactive part of the solar cell, $300 \mathrm{~nm}$ thick amorphous silicon $\mathrm{p}-\mathrm{i}-\mathrm{n}$ junctions could be adapted and protected with $80 \mathrm{~nm} \mathrm{TiO}_{2}$, producing $930 \mathrm{mV}$ photovoltage. ${ }^{177}$ Both a HTJ-Si $\left(\mathrm{p}^{+}\right.$-a-Si $|\mathrm{i}-\mathrm{a}-\mathrm{Si}| \mathrm{n}-\mathrm{n}-\mathrm{Si}|\mathrm{i}-\mathrm{a}-\mathrm{Si}| \mathrm{n}^{+}$-a-Si) and an $\mathrm{n}-\mathrm{i}$ hydrogenated amorphous $\mathrm{Si}(\mathrm{a}-\mathrm{Si}: \mathrm{H})$ buried junctions were protected with transparent and catalytic reactivesputtered $75 \mathrm{~nm} \mathrm{p-NiO},{ }^{254}$ with several hundred hours stability in $1 \mathrm{M} \mathrm{KOH}$ and photocurrents of 35 and $5 \mathrm{~mA} \mathrm{~cm}^{-2}$, respectively, similar to equivalent solar cell ones. In another work, an amorphous/crystalline silicon heterojunction (a-Si/c-SiHJ) was fabricated both as photoanode or photocathode, just inverting where the cell is contacted (Fig. 26c and d), with $>600 \mathrm{mV}$ photovoltages. ${ }^{331}$ This structure reported up to $13.26 \%$ solar-tohydrogen conversion efficiency, one of the highest achieved so far.

Moreover, by molecular beam epitaxy (MBE) depositing a $100 \mathrm{~nm}$ thick $\mathrm{p}^{+}$-InP layer on top of n-InP (1.3 eV band gap), Sun et al. ${ }^{256}$ fabricated a photoanode, further protected with sputtered $70 \mathrm{~nm} \mathrm{NiO}$, which was capable to generate $700 \mathrm{mV}$, whereas thinner InP $\mathrm{p}^{+}$layers produced $\sim 350 \mathrm{mV}$. An amorphous $\mathrm{p}-\mathrm{i}-\mathrm{n}$ silicon carbide (a-SiC) buried junction was also protected with $25 \mathrm{~nm} \mathrm{TiO}_{2}$ and converted into a photocathode using NiMo as catalyst by Digdaya et al. ${ }^{332}$ obtaining the $0.8 \mathrm{~V}$ photovoltage expected for the buried junction although limited stability of less than one hour in $1 \mathrm{M} \mathrm{KOH}$ was obtained.

Likewise solar cells prospects, ${ }^{131}$ one way of decreasing fabrication costs is depositing thin film photoabsorbers only few microns thick, reducing material costs and allowing for other deposition techniques to be used. Doing so on flexible substrates can reduce device cost by enabling roll-to-roll fabrication and thus, facilitating technology implementation. ${ }^{333}$ CIGS-CdS buried junctions have been adapted for water splitting $^{321,334-337}$ (also on flexible substrates ${ }^{241}$ ), together with their earth-abundant equivalent CZTS. ${ }^{240,335,338-341} \mathrm{In}_{2} \mathrm{~S}_{3}$ (ref. 339 and 342 ) or $\mathrm{ZnS}^{343,344}$ have also been implemented as buffer layers to substitute toxic CdS. Chalcopyrite and kesterite solar cells are also highly interesting because their band gap (1.0-1.5 eV) and thus, photovoltage, can be tuned by compositional variations ${ }^{333}$ reaching record $741 \mathrm{mV}$ photovoltages and $37.8 \mathrm{~mA} \mathrm{~cm}{ }^{-2}$, helping in forming tandem structures. ${ }^{345-348}$

Metallic Mo/Ti overlayers have been used on CIGS/CdS based photoelectrodes, increasing stability, photocurrent and onset potential, together with helping on lateral charges transport and avoiding detrimental interfaces between CdS and Pt particles (Fig. 27a and b). ${ }^{321}$ Efficiently extracting photogenerated charges in polycrystalline defective materials such as CIGS is important to enhance photovoltage and current, as charge diffusion lengths are significantly lower than in silicon. ${ }^{349}$ In addition, it is known for solar cells that degenerately doped transparent conductive oxide (TCO) such as $\mathrm{i}-\mathrm{ZnO} / \mathrm{Al}: \mathrm{ZnO}$ have significantly increased photovoltage. ${ }^{333}$ For PEC, directly 
a.

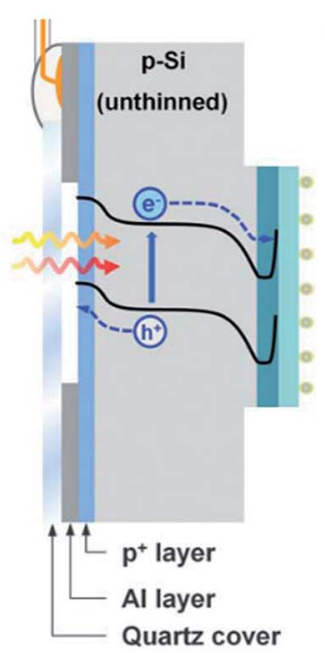

b.

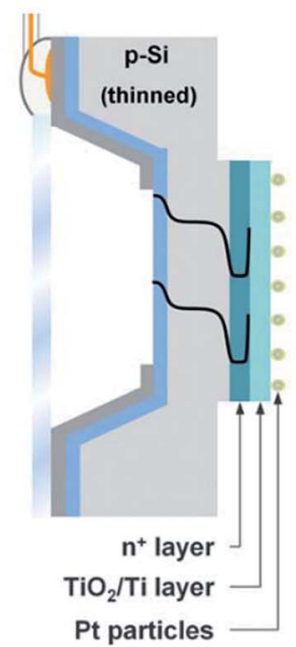

c.

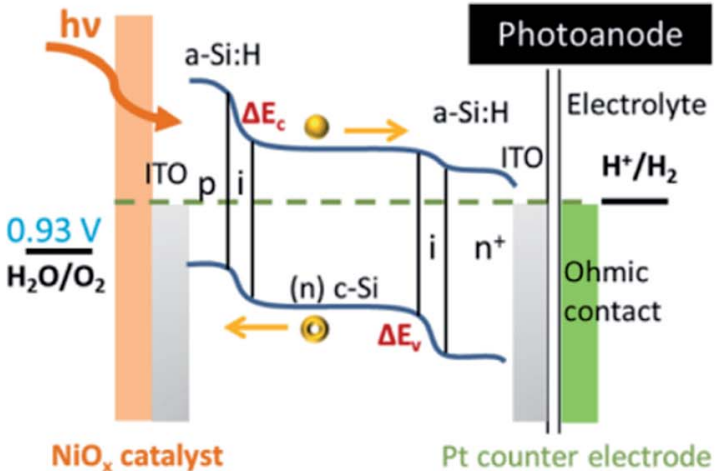

d.

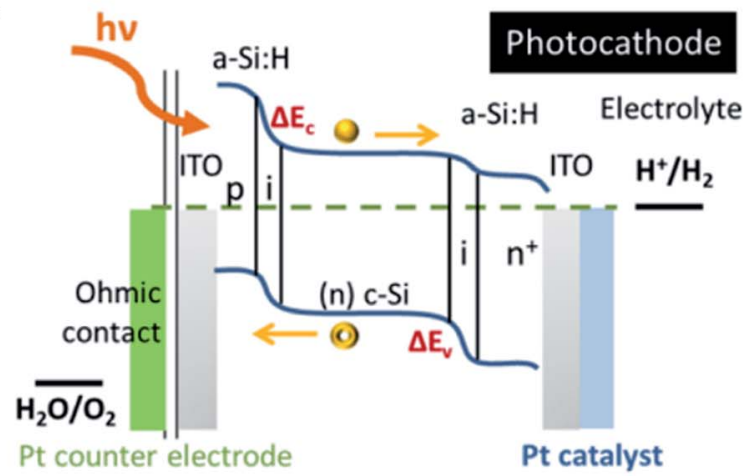

Fig. 26 (a) Back illuminated photoelectrode before thinning and (b) after thinning to properly illuminate the $p-n$ junction energy band diagrams. Reprinted with permission from (Energy Environ. Sci., 2015, 8, 650). Copyright (2015) RSC. ${ }^{223}$ Energy band diagrams of $p-i-n$ amorphous silicon (c) a photoanode and (d) a photocathode showing the role of ohmic contacts, enabling the possibility to easily invert the photoelectrode's structure by simply inverting the buried junction and selecting different catalysts. Reprinted with permission from (Nano Lett., 2015, 15, 2817-2824). Copyright (2015) American Chemical Society. ${ }^{331}$ protecting the $\mathrm{p}-\mathrm{n}$ junction proved for earth abundant CZTS significantly less effective ${ }^{350}$ than including a degenerate TCO in between n-CdS and $\mathrm{TiO}_{2}$ protective layer ${ }^{240,241,319,340}$ (Fig. 27c). As was demonstrated by our group, degenerately doped TCO extra films in between $\mathrm{TiO}_{2}$ protective layer and $\mathrm{n}$-CdS will further maximize the built-in electric field and thus, enhance charge separation and transport (Fig. 27d). ${ }^{20,241}$

Also, CIGS and CZTS photocathodes are highly sensible to temperature-assisted protection strategies. Higher than $200{ }^{\circ} \mathrm{C}$ annealing can alter the vacancy distribution, highly detrimental for final output. ${ }^{240}$ Significant efforts have been put by our group into understanding the modifications introduced by extra thermal fabrication steps. ALD has been found to allow crystalline- $\mathrm{TiO}_{2}$ deposition temperatures low enough $\left(200{ }^{\circ} \mathrm{C}\right)$ to avoid degradation of CZTSe and CZTSSe-based photoelectrodes, although pure-sulphur CZTS ones photovoltage is severely affected even at $200{ }^{\circ} \mathrm{C}$ (Fig. 27e and f). Thus, we can modify the band-gap of the original solar cells from 1.0 to $1.5 \mathrm{eV}$ but some stoichiometries are more challenging to be $\mathrm{TiO}_{2}$-protected. Even so, we can perform the HER with $450 \mathrm{mV}$ photovoltages and $28 \mathrm{~mA} \mathrm{~cm}^{-2}$ photocurrents stable for over $1 \mathrm{~h}$ at $0 \mathrm{~V} v s$. RHE in $0.5 \mathrm{M} \mathrm{H}_{2} \mathrm{SO}_{4}$.

Thus, complex buried junction schemes are proven to be readily adapted to PEC with metallic or degenerately doped intermediate layers, confirming the flexibility and advantages of protecting buried junctions. ${ }^{329}$

\section{Cell implementation strategies}

During this review focus has been put on front-illuminated metal oxide or protected photoelectrodes, the strategy followed majorly by authors in the field. Although, solar energy can be used to drive an electrochemical reaction in different implementation strategies, with different grade of external control and device complexity.

\subsection{Photoelectrode configuration}

Jacobsson $e t$ al. ${ }^{30}$ have methodically described all the possible transitions from an independent monolithic PEC device, to an electrolyser powered by photovoltaic grid energy. It is depicted in Fig. 28.

From a monolithic PEC device (a), the first step is separating with an external circuit the second electrode (b). It is shown as a metal, but the second one could be photoactive too, combining photovoltage in a tandem design (its characteristics will be discussed later). The second step is introducing a protective layer between the photoabsorber and the catalyst. In this case, the junction can be formed between the photoabsorber and the electrolyte/catalyst or the layer can intervene in forming a $\mathrm{p}-\mathrm{n}$ junction (c). A third step is considered if a perpendicular catalyst structure is set on top of the photoabsorber (electrically connected), meanwhile the rest of the surface has the protective layer (d). This way, light can still reach the photoactive semiconductor, meanwhile it is no longer possible to form the depletion with the electrolyte, thus a $\mathrm{p}-\mathrm{n}$ junction is necessary. Once the vertical catalyst is introduced, 
a.

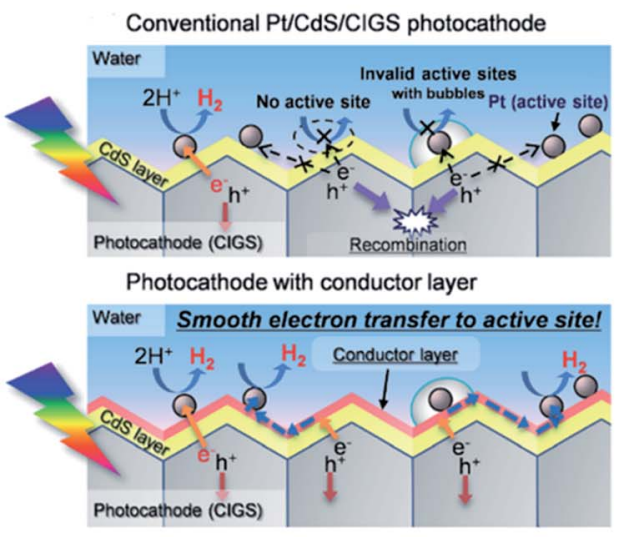

c.

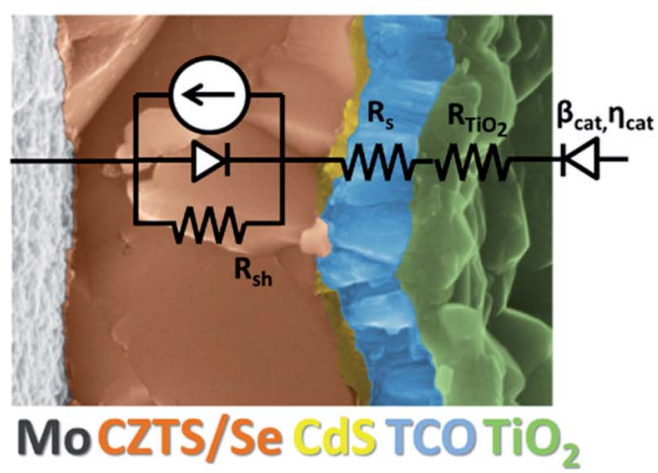

e.

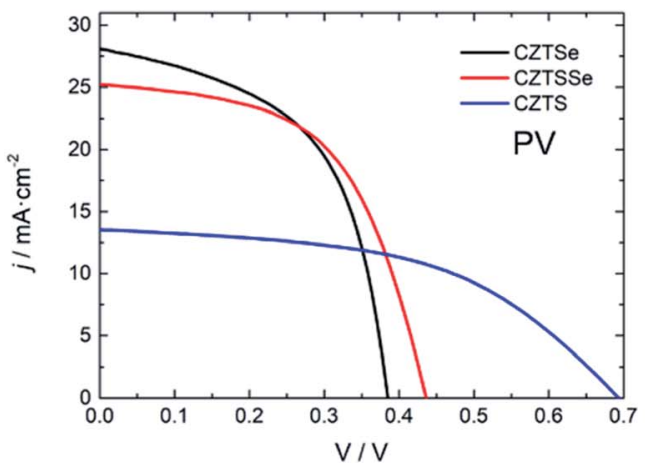

b.

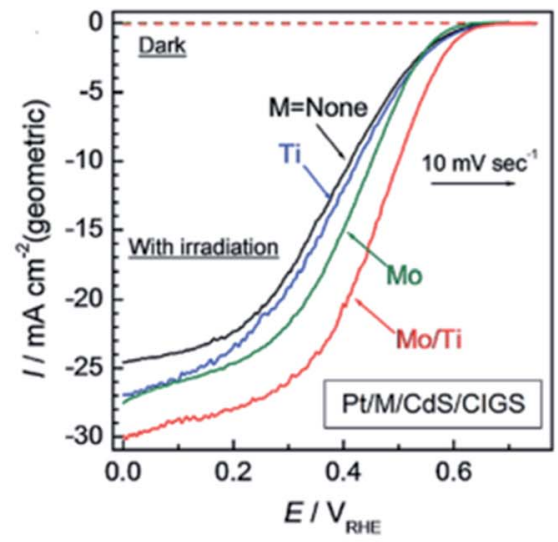

d.

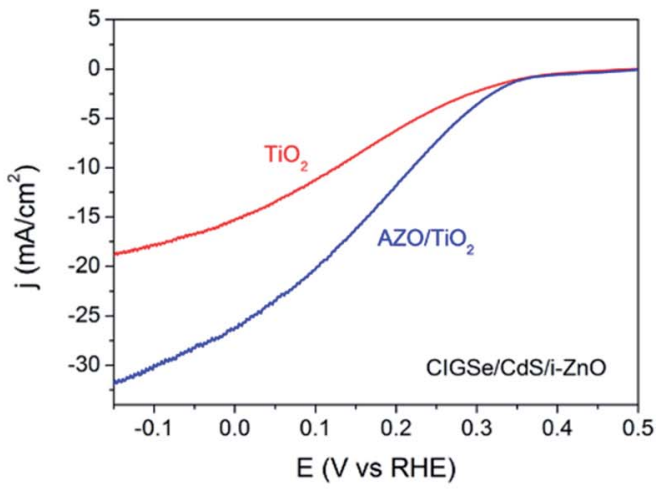

f.

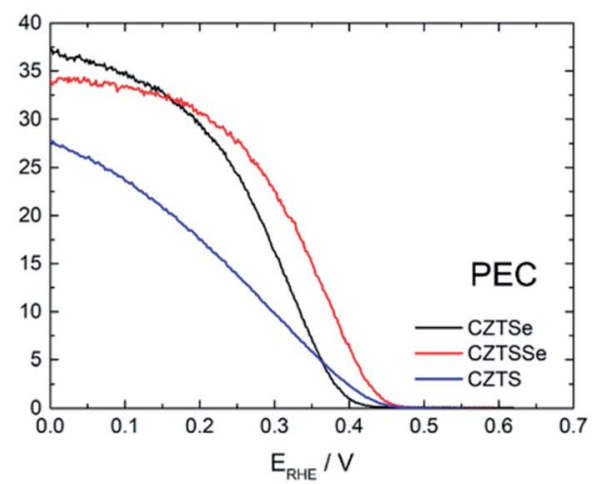

Fig. 27 (a) Charge transfer diagram from the $n$-type CdS layer to HER catalyst particles (top) and with an intermediate metallic conductive film enabling lateral conduction (bottom) and (b) corresponding cyclic voltammograms in $0.5 \mathrm{M} \mathrm{Na}_{2} \mathrm{SO}_{4}, 0.25 \mathrm{M} \mathrm{Na}_{2} \mathrm{HPO}_{4}$ and $0.25 \mathrm{M} \mathrm{NaH}_{2} \mathrm{PO}_{4}$ (aq.) ( $\mathrm{pH}$ values adjusted to 6.8 by $\mathrm{NaOH}$ addition under AM 1.5G irradiation). Reprinted with permission from (J. Mater. Chem. A, 2015, 3(16), 83008307). Copyright (2015) RSC. ${ }^{321}$ (c) Cross section and equivalent electric circuit of a CZTS/CdS buried heterojunction protected with $\mathrm{AZZ}_{2} / \mathrm{TiO}{ }_{2}$ layers and Pt catalysed. Reprinted with permission from (ACS Appl. Mater. Interfaces, 2018, 10, 13425-13433). Copyright (2018) American Chemical Society. ${ }^{240}$ (d) Linear sweep voltammograms under 1 sun illumination of CIGSe/CdS/i-ZnO heterojunctions with $300 \mathrm{~nm}$ of AZO (blue) or without the underlayer (red), subsequently protected with $100 \mathrm{~nm} \mathrm{TiO}{ }_{2}$ ALD layer and $133 \mathrm{mg} \mathrm{cm}^{-2}$ of drop casted Pt as HER. Electrolyte: $0.5 \mathrm{M} \mathrm{H}_{2} \mathrm{SO}_{4}$. Reprinted with permission from (Sol. Energy Mater. Sol. Cells, 2016, 158, 184-188). Copyright (2016) Elsevier. ${ }^{241}$ (e) J(V) curves of CZTSe (black), CZTSSe (red), and CZTS (blue) solar cells as synthesized and (f) polarization curves of the same solar cells protected with TiO ${ }_{2}$ layers grown at $200{ }^{\circ} \mathrm{C}$ and Pt drop-casted on top as HER catalyst. Reprinted with permission from (ACS Appl. Mater. Interfaces, 2018, 10, 13425-13433). Copyright (2018) American Chemical Society. ${ }^{240}$ 


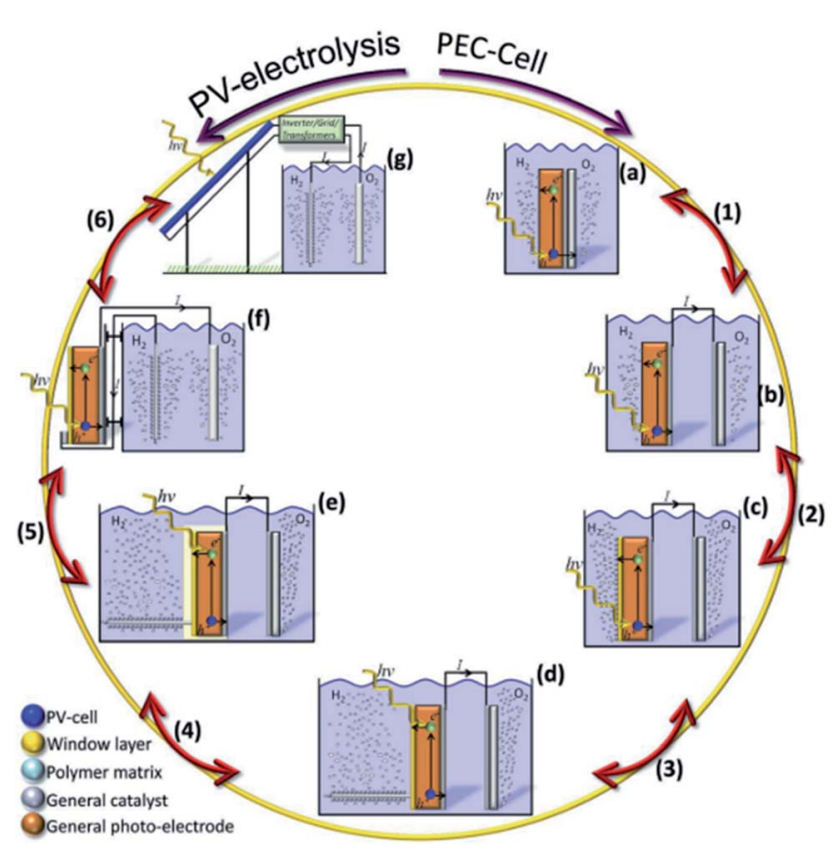

Fig. 28 Scheme of the possible transitions from a monolithic PEC device to a photovoltaic-grid powered electrolyser. Reprinted with permission from (Energy Environ. Sci., 2014, 7, 2056). Copyright (2014) $\mathrm{RSC}^{30}$

next step is directly encapsulating the photoactive part (i.e. by a polymer or glass layer) (e). Once completely isolated, there is no more the need of having the photoactive part inside the electrolyte, and connecting the independent catalyst with a wire to the semiconductor allows freely locating the absorber inside the electrolyte or outside (f). Last step consists of substituting the external photoactive semiconductor with connecting the two remaining catalyst structures with grid photovoltaic (or not) electricity, resulting in a PV-electrolyser setup (g). Jacobsson et al. have implemented several of the mentioned designs with CIGS-based devices. ${ }^{336}$ As the reader may have realized, the technology readiness is not the same for all configurations: ${ }^{14}$ both photovoltaics and electrolysers are already commercialised technologies, compared to PEC ones which are still under significant investigation. But as discussed in Section 1, PEC is designed to work at lower current densities, reducing electrochemical overpotentials and enabling higher conversion efficiencies.

Throughout the whole review the vast majority of research has been focused in configurations (b) and (c) of Fig. 28. Inplane electrodes have been discussed in increasing complexity, a path to increment its built-in electric field, its photon absorption, stability and catalytic efficiency.

\subsection{Tandem PEC devices}

For non-externally biased (unassisted) single light absorber electrodes, only large band gap semiconductors will create enough photovoltage to break the water molecule, meanwhile a dual absorber tandem structure permits absorbing a larger portion of the solar spectra (Fig. 29a and b). ${ }^{117,351}$ As Hu et al. ${ }^{352}$ calculated, efficiencies higher than $25 \%$ should be obtainable (taking into account earth abundant catalysts overpotential and resistance losses) if band gap semiconductors of $\sim 1.1$ and 1.6$1.8 \mathrm{eV}$ with high performance are found. The short band gap ones are easy to propose, as candidates are already commercial or under development: Si, GaAs, CIGS or perovskites, but the ones with larger band gap still requires more research. Chalcogenides such as CIGS and CZTS have proven the possibility to tune its band gap from 1.0 to $1.6 \mathrm{eV},{ }^{131,333,344,353,354}$ and also some perovskites, ${ }^{355}$ what can help in perfect absorption match for both electrodes to be working in the maximum power point.

The possible configuration parameters to form a tandem device are vast, and other authors have already performed thoughtful discussions. ${ }^{117,351,352,356,357}$ For example, both electrodes can be photoactive, combining their performance through the external circuit (Fig. 29c), or one of them can be a multijunction photoelectrode, coupled to a metallic counterelectrode (Fig. 29d). Also, the two photoelectrodes can be connected back-to-back ${ }^{358}$ (as in Fig. 29b) or both may require frontal illumination (Fig. 29c). Also, either the HER or OER water splitting reaction can be performed in front of the small or large band gap semiconductor, what must be decided based on the protection strategy, stability and catalyst selected. Backilluminated photoelectrodes are good candidates if the large band gap absorber can be deposited on top of them ${ }^{223,287}$ and, in principle, do not require transparent protective layers or catalysts, facilitating the search of appropriate low cost and earth abundant materials.

\subsection{Electrolyte $\mathrm{pH}$ and membranes}

Another significant cell design parameter is the electrolyte $\mathrm{pH}$. As it is commonly known, an alkaline electrolyte enhances the OER, whereas an acidic the HER one. In half-cell lab measurements, this is not a problem, but in a full device electrolytes must be either separated with a membrane or the same electrolyte must be chosen for both electrodes. Also, if no gasseparator-membrane is present, detrimental back reactions can happen of dissolved gases and explosive $\mathrm{O}_{2} / \mathrm{H}_{2}$ mixtures formed. A highly pure $\mathrm{H}_{2}$ and $\mathrm{O}_{2}$ stream is generated by water splitting, increasing gas products value, thus separating both products is important. ${ }^{17}$

Regarding the catalysts, Pt, Ir, Pd or phosphides such as NiP have 100 times higher H-binding energy in acid than alkaline, and only few earth abundant metallic catalysts such as Ni-Mo have been found relatively effective for HER in alkaline media ${ }^{36}$ (Fig. 6d). Meanwhile, few expensive catalysts (Ir or Ru) are known to be stable in acid for the OER and all others including earth abundant $\mathrm{Ni}(\mathrm{Fe}) \mathrm{O}_{x} \mathrm{H}_{y}$ require basic conditions. ${ }^{359}$ Also, if same electrolyte is used for both reactions, one of the catalysts will have to drive the water dissociation into $\mathrm{H}^{+}$and $\mathrm{OH}^{-}$before OER and HER can happen, introducing significant overpotentials, as described in Section 2(e).

Regarding this aspect, bipolar membranes allow different electrolytes to be used in each semi-reaction, ${ }^{359}$ so acid can be used in the cathode cell side and alkaline in the anode one. These membranes are composed of anion and cation selective 
a.

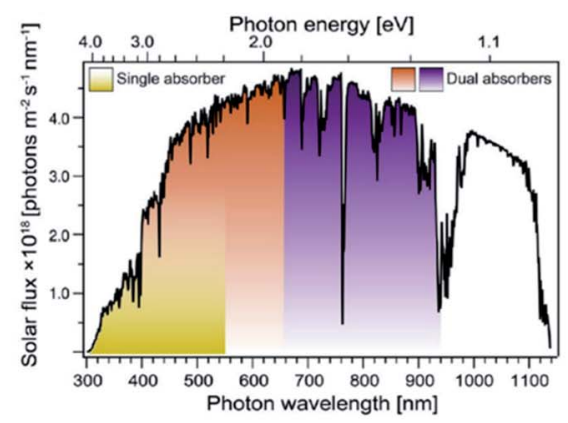

c.

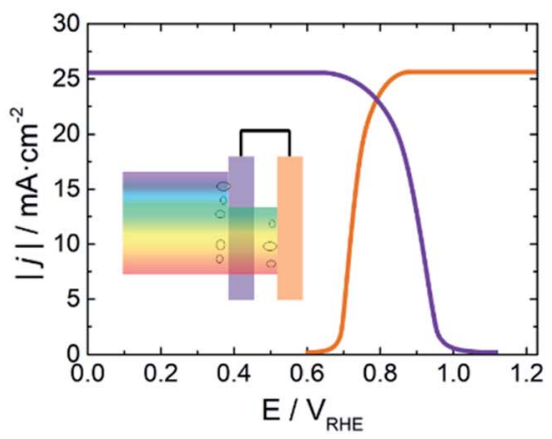

b.

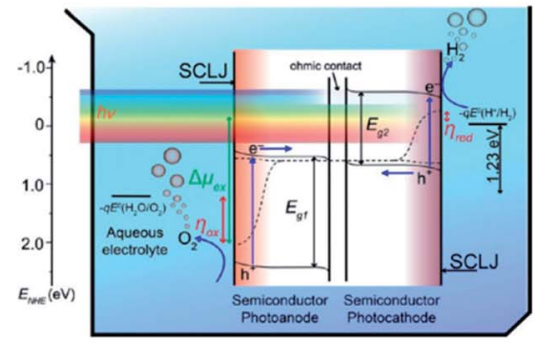

d.

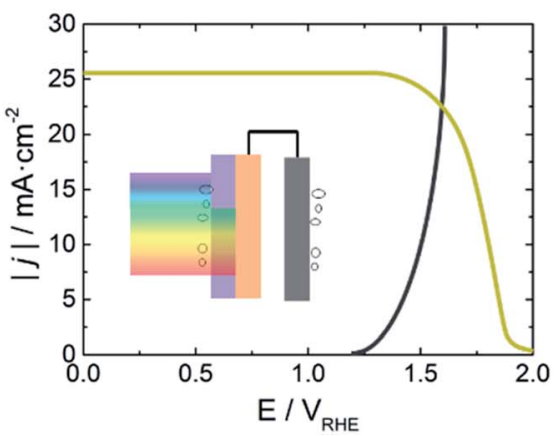

Fig. 29 (a) AM 1.5G solar flux as function of photon wavelength and photon energy. The colored areas represent the portion that can be harvested using a single band gap absorber (yellow) or a tandem one (orange + purple) to perform the bias-free water splitting reaction. (b) Tandem monolithic structure with two SCLJ, one front and the other one back illuminated. Reprinted with permission from (J. Phys. Chem. C, 2013, 117, 17879-17893). Copyright (2013) American Chemical Society. ${ }^{351}$ Cyclic voltammograms simulation of (c) a two front-illuminated photoelectrodes tandem PEC device and its schematics (inset) and (d) a multijunction photoelectrode and a metallic counter electrode with its schematics (inset).

layers transporting $\mathrm{OH}^{-}$and $\mathrm{H}^{+}$, respectively, which reacting in the interface. This way no gas or electrolyte crossover is present, and respective $\mathrm{pH}$ are maintained allowing the HER and OER to be performed most efficiently. Although, very few studies have been performed in full-cell membrane-divided schemes.

\subsection{Cell schemes}

Lab-scale measurements, with devices ranging at most few $\mathrm{cm}^{2}$, can ignore current distribution losses due to cell configuration. Although, large scale devices (several tens of $\mathrm{cm}^{2}$ ) must take in account the current distribution across the photoelectrode to the back contact and ionic conductivity of the liquid, what requires minimizing the distance from one electrode's surface to the other.

There are few works which have already faced the emerging series resistances of scale up. For example, Yao et al. ${ }^{360}$ found a photocurrent loss from 2.2 to $0.74 \mathrm{~mA} \mathrm{~cm}^{-2}$ at $1.23 \mathrm{~V} v s$. RHE when increasing a $\mathrm{BiVO}_{4}$ photoanode from 2 to $25 \mathrm{~cm}^{2}$, and attributed these losses to electrical resistance of the FTO substrate and non-linear diffusion of reactant ions in the electrolyte. Similar $75 \%$ loses caused by substrate resistivity were found by Digler et al. when scaling up $\mathrm{LaTiO}_{2} \mathrm{~N}$ photoanodes from 1 to $40 \mathrm{~cm}^{2}$. Other works, like Lee et al. ${ }^{361}$ found that introducing an Ag grid deposited on top of the FTO helped reducing the overall sheet resistance and ohmic losses for up to
$130 \mathrm{~cm}^{2} \mathrm{WO}_{3}$ photoanodes. Ahmet et al. ${ }^{362}$ found that, for 50 $\mathrm{cm}^{2} \mathrm{BiVO}_{4}$ photoanodes in neutral electrolyte, Ni grid lines on FTO helped recovering a $10 \%$ of the photocurrent lost by scale up, but the main bottleneck was the fast depletion of $\mathrm{H}^{+} / \mathrm{OH}^{-}$ species. This caused $\mathrm{pH}$ changes and potential drops up to $500 \mathrm{mV}$.

Regarding ionic conductivity of the electrolyte, cell configuration has a key role reducing the species diffusion distance through the electrolyte. Lewis ${ }^{36}$ identified four possible schemes to implement monolithic "intrinsically safe" (where $\mathrm{H}_{2}$ and $\mathrm{O}_{2}$ are generated in separated compartments) PEC electrodes (Fig. 30a-d). Nano/microwire electrodes grown integrated with the membrane would introduce almost null ionic resistance, as ions must only travel micrometer distances. Some of these include solar concentration of up to 500 times, ${ }^{17}$ a strategy to minimize device costs, expected to be significantly higher than bare photovoltaics. ${ }^{363}$ The main drawback of concentration is increasing the current density on the catalytic surface, which will turn into significant extra overpotential, together with the trade-off on an increase of temperature, enhancing electrocatalysis but reducing photovoltaic efficiency. Several other configurations have been analyzed by Minggu et al. ${ }^{364}$ for monolithic PEC electrodes or tandem separated ones, set one behind the other or one next to it (Fig. 30e-g). 
a.

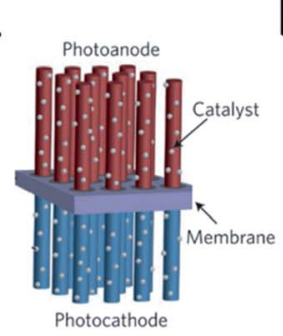

e.

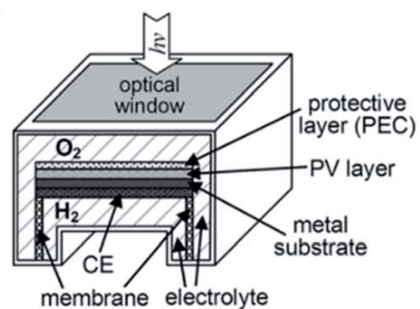

c.

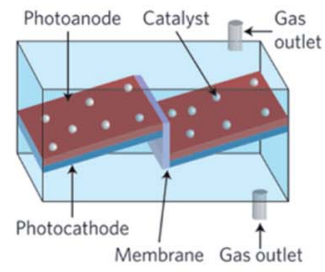

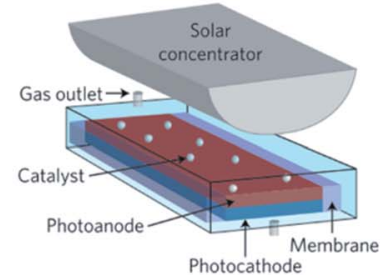

d.

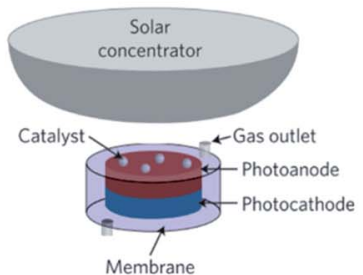

g.

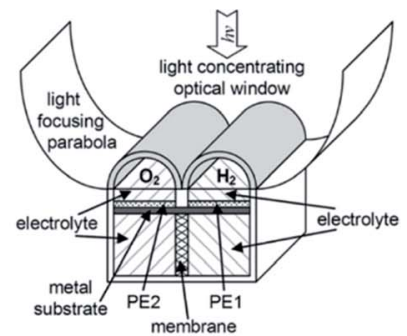

Fig. 30 (a-d) Four possible cell schemes of monolithic PEC systems with $\mathrm{H}_{2}$ and $\mathrm{O}_{2}$ generated in separated compartments. Reprinted with permission from (Nat. Nanotechnol., 2016, 11, 1010-1019). Copyright (2016) Springer Nature. ${ }^{36}$ (e) Non-biased PEC electrode, (f) PV-biased electrodes and (g) laterally-connected tandem electrodes with solar simulator. Reprinted with permission from (Int. J. Hydrog. Energy, 2010, 35, 5233-5244). Copyright (2010) Elsevier. ${ }^{365}$

\section{Resume, perspective and challenges}

Renewable energy sources will eventually be implemented globally, together with energy carriers capable to be distributed and used when necessary. PEC water splitting has demonstrated to produce hydrogen from solar energy and water with significant efficiencies, although this technology is not ready for market implementation due to lack of efficient, stable and scalable photoelectrodes.

In this review, the pathway of last decades' investigations on PEC water splitting cells has been discussed. After first discovery of the semiconductor-liquid junction producing few $\mu \mathrm{A} \mathrm{cm}{ }^{-2}$ photocurrents on $\mathrm{TiO}_{2}$, several other semiconductor materials have been tested and modified in the search of an efficient, stable and scalable device, with significant advances obtained. Other metal oxides such as $\mathrm{Fe}_{2} \mathrm{O}_{3}, \mathrm{WO}_{3}, \mathrm{BiVO}_{4}$, or $\mathrm{Cu}_{2} \mathrm{O}$ have been nanostructured and modified to maximize the built-in electric field to enhance electron-hole separation and transport, together with co-catalyst decoration for a more efficient HER/OER reaction. Even plasmonic nanocrystals have been employed to increase light absorption for energies below the band gap, with impressive doubling the photocurrent. Metal oxide photoelectrodes present good photovoltage and stability in oxidizing environments and are scalable due to earth abundant materials and low cost deposition techniques, but up to now have lacked significant photocurrent generation efficiency.

An alternative approach to overcome this has been adapting short band gap materials such as the ones used for the photovoltaic industry into PEC, mostly III-V semiconductors like GaAs, CdTe or InP, or earth abundant Si, CIGS and CZTS. Semiconductors with 1.0 to $1.8 \mathrm{eV}$ band gap are capable to absorb broad part of the solar spectra, and some of these materials are band gap tunable by composition variations like In/Ga for CIGS and S/Se in CZTS, easing implementation in tandem devices. Although, their main drawback is the instability in aqueous acidic or alkaline electrolytes.

During last decade protective layers have been studied to address this. Metallic films have been deposited on top both as catalysts and to prevent corrosion, but few nanometer thick layers, thin enough to be transparent, were not passivating enough. Tunnel-distances-thick insulator oxides present similar problems, as resistance increases dramatically if more than $\sim 5 \mathrm{~nm}$ are deposited. But protecting short band gap photoabsorbers, containing a buried junction, with semiconductor metal oxide transparent conducting and protective layers several tens of nanometers thick has enabled more than $2000 \mathrm{~h}$ stable electrodes, with photocurrents and photovoltages resembling photovoltaic cells. $\mathrm{TiO}_{2}$ and $\mathrm{NiO}$ have been the most studied and best performing protective layer materials, the former with $\mathrm{Pt}$ or Ni as HER/OER catalysts and the latter being OER catalytic too.

Yet, electron or hole conduction mechanisms across protective layers are still not fully understood. Complex electronic structure in photoabsorber-film interface, across the layer or in the layer-catalyst-electrolyte electrolytic surface are still under discussion. Both for $\mathrm{TiO}_{2}$ and $\mathrm{NiO}$, protective layers, deposition mechanism, precursor or temperature and thus, the nanoscale disorder and electronic structure have presented significant variations among different studies. Moreover, intrinsic stability of these materials when facing thousandhours scale experiments or intermittent polarization variations should not be directly assumed. Especially in highly oxidizing or reducing electrolytes, as metal oxide protective 
layers' conductivity relies on cationic or oxygen-deficient electronic structure.

In addition, few works have presented complete PEC cells capable to perform bias free solar water splitting efficiently. Systems based on III-V semiconductors have achieved about $20 \%$ solar-to-hydrogen (STH) efficiencies. ${ }^{17}$ As examples, Cheng et al. ${ }^{366}$ obtained up to $19.3 \%$ conversion efficiency with tandem monolithic GaInAs/GaInP PEC cells $\mathrm{TiO}_{2}$-protected, Licht et al. ${ }^{367}$ obtained $18 \%$ with AlGaAs/Si tandem cells with $\mathrm{RuO}_{2} / \mathrm{Pt}$ vertical catalysts, and Peharz et $a .^{368}$ close values with GaInP cells connected to an electrolyser with a polymer electrolyte membrane as separator and under up to 500 suns illumination. Although, III-V semiconductors are grown by very expensive techniques and thus, scalability is difficult due to price and material scarcity.

Some authors have studied reactor schemes and costs, where among several strategies, solar concentration is expected to facilitate the amortization of costly cells, reactors, gas separator membranes and pumping systems. ${ }^{15,363}$ Meanwhile in recent years, some works have published high efficiencies with earth abundant materials like silicon, oxides or emerging photovoltaic materials with over a $10-14 \%$ SHT conversion efficiency. ${ }^{17,369-372}$ The Department of Energy (D.O.E.) of the United States fixed a road map for PEC water splitting, where meanwhile it has been accomplished for conversion efficiencies, the use of expensive materials and techniques limits the price competitiveness of PEC produced $\mathrm{H}_{2} \cdot{ }^{17}$ PEC water splitting has long been promised with potential of achieving cheap and scalable hydrogen production directly from sun and water, although some authors have questioned this due to the rapid development of photovoltaics and low temperature earth abundant electrolysers, lowering hydrogen production costs. ${ }^{373}$ We cannot neglect the key role taxes on fossil $\mathrm{CO}_{2}$ could play both in drastically reducing $\mathrm{CO}_{2}$ emissions and facilitating renewable hydrogen implementation. ${ }^{363}$

In order to implement PEC water splitting at industrial scale, efforts must be put into the fabrication of efficient, stable and scalable photoelectrodes. Stable semiconductor materials fulfilling these requirements have not been found, and although some examples like WSe have shown promising results, ${ }^{374}$ more research is needed, and the help of computational design of multielement oxides and nitrides will for sure help finding candidates. $^{375}$

But until a single material fulfilling all requirements is found, the best strategy is protecting photoabsorbers as such used in PV for long term operation. $\mathrm{TiO}_{2}, \mathrm{NiO}$ or $\mathrm{CoO}_{x}$ have been the best performing protective layers so far, fabricated by reactive sputtering, CVD or ALD to minimize pinhole formation. The substitution of high vacuum deposition and time consuming techniques would reduce fabrication costs if pinhole-free layers can be assured. Meanwhile, finding material/electrolyte combinations so the corrosion forms undissolved products must be explored, so pinholes in the protective layer have limited effect to long-term stability of the device. ${ }^{\mathbf{1 5 5 , 2 3 8}}$ Using the protective layer as antireflective layer will for sure help in increasing photoelectrodes productivity, ${ }^{\mathbf{1 7 2}}$ together with textured silicon surfaces. ${ }^{281}$
More full cell reactor field tests should be performed during next decade to fully understand complete device stability and degradation mechanisms, ${ }^{376}$ especially in less-controlled environments, under day/night intermittent operation, temperature changes and mechanical impact caused by bubbling or electrolyte pumping: ${ }^{13,377,378}$ Regenerative strategies like electrocatalyst re-deposition in dark conditions at night could reduce a constrain, increasing available material candidates. ${ }^{\mathbf{3 0 6 , 3 7 9 , 3 8 0}}$ For a large scale deployment of water splitting, which will consume significant volume in a clean water scarcity scenario, seawater must also be studied as water-source. ${ }^{381,382}$

Although some authors have claimed demonstration or earlystage commercial devices would be possible with noble metals if cost-efficiency is matched, earth abundant alternatives must be researched for large scale deployment. ${ }^{13}$ Bias-free tandem cells will require medium band-gap semiconductors to be coupled with short ones, and chalcogenides or perovskites (band gap tunable by composition control) have shown promising results for solar cells. ${ }^{131}$ In addition, finding earth abundant transparent and conductive catalysts, especially inexistent for OER in acid and HER in alkaline, would reduce the constrains on selecting electrolytes and reactions performed on each side. Protective layers with superficial energetics prone to enhance HER or OER catalysis would simplify even more the structures. Some of the most promising earth abundant candidates have been Ni-based catalysts for OER and $\mathrm{MoS}_{x}$ for HER. NiO protective layers surface incorporates $\mathrm{Fe}$ and forms $\mathrm{Ni}(\mathrm{Fe}) \mathrm{OOH}$ in alkaline media, one of the most efficient earth abundant OER catalysts, ${ }^{172}$ or $\mathrm{MoS}_{2}$ protective and transparent layers have been recently grown and reported stable in acid with good HER catalysis. ${ }^{307}$

Furthermore, during last decade some authors have implemented photoelectrochemistry for other reactions besides water splitting. Carbon dioxide reduction reaction $\left(\mathrm{CO}_{2} \mathrm{RR}\right)$ is far more complex than water splitting, but enables the possibility to extract the greenhouse gas $\mathrm{CO}_{2}$ from the atmosphere and turn it into a reusable fuel or chemical. Commercial products like methane or ethanol production from $\mathrm{CO}_{2}$ reduction have been studied, which could directly be incorporated into the actual carbon-based fossil fuels marked, and several other molecules are possible with appropriate catalysts. The possibility of obtaining liquid products is especially interesting, as highly simplifies distribution and storage (some of the main drawbacks for $\mathrm{H}_{2}$ as energy vector implementation). Main challenges for $\mathrm{CO}_{2}$ reduction are finding appropriate catalysts and stable semiconductors to be placed in direct contact with the reaction, as the higher required reductive potentials $(>1 \mathrm{~V})$ enhance materials corrosion. ${ }^{375,383}$ Electrochemical reduction of organics such as ethanol have also been studied as hydrogen sources where lower cell potential is needed. ${ }^{384}$ Implementing photoelectrodes to redox-flow batteries has enabled the concept of "photobattery", for example with vanadium as electrolyte. ${ }^{385,386}$ For sure the development of PEC water splitting will help with identifying and adapting photoelectrodes for other electrochemical reactions.

\section{Conflicts of interest}

There are no conflicts to declare. 


\section{Acknowledgements}

Authors acknowledge Generalitat de Catalunya for financial support through the CERCA Programme, M2E (2014SGR1638). IREC also acknowledges additional support by the European Regional Development Funds (ERDF, FEDER) and by MINECO coordinated projects MAT2014-59961-C2, ENE2016-80788-C5-5R and ENE2017-85087-C3. C. R. acknowledges MINECO for his FPI grant (BES-2015-071618).

\section{Notes and references}

1 R. Heinberg and D. Fridley, Our Renewable Future, Island Press, 2016.

2 J. M. Godoy, Rev. Virtual Quim., 2018, 10, 1733-1757.

3 G. D. Berry, A. D. Pasternak, G. D. Rambach, J. R. Smith and R. N. Schock, Energy, 1996, 21, 289-303.

4 A. Fujishima and K. Honda, Nature, 1972, 238, 37-38.

5 Z. Li, J. Feng, S. Yan and Z. Zou, Nano Today, 2015, 1-19.

6 A. J. Bard, J. Photochem., 1979, 10, 59-75.

7 D. Tafalla and P. Salvador, J. Electroanal. Chem., 1989, 270(1-2), 285-295.

8 K. J. Hartig and N. Getoff, Int. J. Hydrogen Energy, 1986, 11(12), 773-781.

9 M. K. Carpenter and D. A. Corrigan, J. Electrochem. Soc., 1989, 136, 1022.

10 A. Heller, E. Aharon-Shalom, W. A. Bonner and B. Miller, J. Am. Chem. Soc., 1982, 104, 6942-6948.

11 L. A. Harris, J. Electrochem. Soc., 1977, 124, 1511.

12 H. Morisaki, H. Ono, H. Dohkoshi and K. Yazawa, Jpn. J. Appl. Phys., 1980, 19, L148-L150.

13 J. R. McKone, N. S. Lewis and H. B. Gray, Chem. Mater., 2014, 26, 407-414.

14 S. Ardo, D. Fernandez Rivas, M. A. Modestino, V. Schulze Greiving, F. F. Abdi, E. Alarcon-Llado, V. Artero, K. E. Ayers, C. Battaglia, J.-P. Becker, D. Bederak, A. Berger, F. Buda, E. Chinello, B. Dam, V. Di Palma, T. Edvinsson, K. Fujii, H. J. G. E. Gardeniers, H. Geerlings, S. M. Hosseini Hashemi, S. Haussener, F. A. Houle, J. Huskens, B. D. James, K. Konrad, A. Kudo, P. P. Kunturu, D. Lohse, B. Mei, E. L. Miller, G. Moere, J. Muller, K. L. Orchard, T. E. Rosser, F. H. Saadi, J.-W. Schüttauf, B. J. Seger, S. W. Sheehan, W. A. Smith, J. Spurgeon, M. H. Tang, R. van de Krol, P. C. K. Vesborg and P. Westerik, Energy Environ. Sci., 2018, 11(10), 27682783.

15 M. R. Shaner, H. A. Atwater, N. S. Lewis and E. W. McFarland, Energy Environ. Sci., 2016, 9, 2354-2371.

16 A. Rothschild and H. Dotan, ACS Energy Lett., 2017, 2, 4551.

17 J. W. Ager, M. R. Shaner, K. A. Walczak, I. D. Sharp and S. Ardo, Energy Environ. Sci., 2015, 8, 2811-2824.

18 M. Görlin, P. Chernev, J. F. De Araújo, T. Reier, S. Dresp, B. Paul, R. Krähnert, H. Dau and P. Strasser, J. Am. Chem. Soc., 2016, 138, 5603-5614.

19 A. Dutta and N. Pradhan, J. Phys. Chem. Lett., 2016, 144-152.
20 J. D. Benck, T. R. Hellstern, J. Kibsgaard, P. Chakthranont and T. F. Jaramillo, ACS Catal., 2014, 4, 3957-3971.

21 Y. Yan, B. Xia, Z. Xu and X. Wang, ACS Catal., 2014, 4, 16931705.

22 M. Gong and H. Dai, Nano Res., 2014, 8, 23-39.

23 L. Trotochaud, J. K. Ranney, K. N. Williams and S. W. Boettcher, J. Am. Chem. Soc., 2012, 134, 17253-17261.

24 W. Sheng, H. A. Gasteiger and Y. Shao-Horn, J. Electrochem. Soc., 2010, 157, B1529.

25 S. Trasatti, Pure Appl. Chem., 1986, 58, 955-966.

26 H. Li, S. Chen, Y. Zhang, Q. Zhang, Q. Zhang, X. Jia, L. Gu, X. Sun, L. Song and X. Wang, Nat. Commun., 2018, 9, 1-12.

27 Z. Y. Yu, C. C. Lang, M. R. Gao, Y. Chen, Q. Q. Fu, Y. Duan and S. H. Yu, Energy Environ. Sci., 2018, 11, 1890-1897.

28 H. Helmholtz, Ann. Phys. Chem., 1879, 243, 337-382.

29 O. Newman and K. E. Thomas-Alyea, Electrochemical Systems, 2004.

30 T. J. Jacobsson, V. Fjällström, M. Edoff and T. Edvinsson, Energy Environ. Sci., 2014, 7, 2056.

31 A. B. Murphy, P. R. F. Barnes, L. K. Randeniya, I. C. Plumb, I. E. Grey, M. D. Horne and J. A. Glasscock, Int. J. Hydrogen Energy, 2006, 31, 1999-2017.

32 Z. Chen, H. N. Dinh and E. Miller, Photoelectrochemical Water Splitting - Standards, Experimental Methods, and Protocols, Springer, 2013.

33 C. Jiang, S. J. A. Moniz, A. Wang, T. Zhang and J. Tang, Chem. Soc. Rev., 2017, 46, 4645-4660.

34 W. A. Smith, I. D. Sharp, N. C. Strandwitz and J. Bisquert, Energy Environ. Sci., 2015, 8, 2851-2862.

35 Y. Yang, S. Niu, D. Han, T. Liu, G. Wang and Y. Li, Adv. Energy Mater., 2017, 7, 1-26.

36 N. S. Lewis, Nat. Nanotechnol., 2016, 11, 1010-1019.

37 S. Chen and L. W. Wang, Chem. Mater., 2012, 24, 36593666.

38 T. Berger, D. Monllor-Satoca, M. Jankulovska, T. LanaVillarreal and R. Gómez, ChemPhysChem, 2012, 13, 28242875.

39 J. Wang, X. Liu, R. Li, P. Qiao, L. Xiao and J. Fan, Catal. Commun., 2012, 19, 96-99.

40 M. Jankulovska, T. Berger, S. S. Wong, R. Gómez and T. Lana-Villarreal, ChemPhysChem, 2012, 13, 3008-3017.

41 J. Fan, C. Fàbrega, R. R. Zamani, Y. Hao, A. Parra, T. Andreu, J. Arbiol, G. Boschloo, A. Hagfeldt, J. R. Morante and A. Cabot, ACS Appl. Mater. Interfaces, 2013, 5, 9872-9877.

42 J. Sá, P. Friedli, R. Geiger, P. Lerch, M. H. Rittmann-Frank, C. J. Milne, J. Szlachetko, F. G. Santomauro, J. A. van Bokhoven, M. Chergui, M. J. Rossi and H. Sigg, Analyst, 2013, 138, 1966.

43 J. Y. Kim, G. Magesh, D. H. Youn, J. W. Jang, J. Kubota, K. Domen and J. S. Lee, Sci. Rep., 2013, 3, 1-8.

44 P. Dias, A. Vilanova, T. Lopes, L. Andrade and A. Mendes, Nano Energy, 2016, 23, 70-79.

45 K. Sivula, F. Le Formal and M. Grätzel, ChemSusChem, 2011, 4, 432-449.

46 Y. Wei, L. Ke, J. Kong, H. Liu, Z. Jiao, X. Lu, H. Du and X. W. Sun, Nanotechnology, 2012, 23(23), 235401. 
47 B. S. Wang, R. Y. Li, Z. Y. Zhang, Xing-Wang, X. L. Wu, G. A. Cheng and R. T. Zheng, Catal. Today, 2019, 321-322, 100-106.

48 J. Y. Zheng, G. Song, J. Hong, T. K. Van, A. U. Pawar, D. Y. Kim, C. W. Kim, Z. Haider and Y. S. Kang, Cryst. Growth Des., 2014, 14, 6057-6066.

49 J. Su, X. Feng, J. D. Sloppy, L. Guo and C. A. Grimes, Nano Lett., 2011, 11, 203-208.

50 C. Fàbrega, S. Murcia-López, D. Monllor-Satoca, J. D. Prades, M. D. Hernández-Alonso, G. Penelas, J. R. Morante and T. Andreu, Appl. Catal., B, 2016, 189, 133-140.

51 T. W. Kim and K.-S. Choi, J. Phys. Chem. Lett., 2016, 7, 447451.

52 J. A. Seabold and K. S. Choi, J. Am. Chem. Soc., 2012, 134, 2186-2192.

53 F. F. Abdi and R. Van De Krol, J. Phys. Chem. C, 2012, 116, 9398-9404.

54 S. P. Berglund, D. W. Flaherty, N. T. Hahn, A. J. Bard and C. B. Mullins, J. Phys. Chem. C, 2011, 115, 3794-3802.

55 C. $\mathrm{Hu}, \mathrm{K} . \mathrm{Chu}, \mathrm{Y}$. Zhao and W. Y. Teoh, ACS Appl. Mater. Interfaces, 2014, 6, 18558-18568.

56 R. Wick and S. D. Tilley, J. Phys. Chem. C, 2015, 119, 2624326257.

57 A. J. Bard, J. Electrochem. Soc., 1977, 1706-1710.

58 H. Gerischer, J. Electroanal. Chem., 1977, 82, 133-143.

59 J. Luo, L. Steier, M. K. Son, M. Schreier, M. T. Mayer and M. Grätzel, Nano Lett., 2016, 16, 1848-1857.

60 J. Li and N. Wu, Catal. Sci. Technol., 2015, 5, 1360.

61 F. M. Toma, J. K. Cooper, V. Kunzelmann, M. T. McDowell, J. Yu, D. M. Larson, N. J. Borys, C. Abelyan, J. W. Beeman, K. M. Yu, J. Yang, L. Chen, M. R. Shaner, J. Spurgeon, F. A. Houle, K. A. Persson and I. D. Sharp, Nat. Commun., 2016, 7, 1-11.

62 Y. J. Jang, Y. Bin Park, H. E. Kim, Y. H. Choi, S. H. Choi and J. S. Lee, Chem. Mater., 2016, 28, 6054-6061.

63 J. Seo, H. Nishiyama, T. Yamada and K. Domen, Angew. Chem., Int. Ed., 2018, 57, 8396-8415.

64 R. Abe, M. Higashi and K. Domen, J. Am. Chem. Soc., 2010, 132, 11828-11829.

65 S. Akiyama, M. Nakabayashi, N. Shibata, T. Minegishi, Y. Asakura, M. Abdulla-Al-Mamun, T. Hisatomi, H. Nishiyama, M. Katayama, T. Yamada and K. Domen, Small, 2016, 12, 5468-5476.

66 W. J. Yin, H. Tang, S. H. Wei, M. M. Al-Jassim, J. Turner and Y. Yan, Phys. Rev. B: Condens. Matter Mater. Phys., 2010, 82, 1-6.

67 X. Huang, X. Gao, Q. Xue, C. Wang, R. Zhang, Y. Gao and Z. Han, Dalton Trans., 2020, 49, 2184-2189.

68 G. Wang, X. Xiao, W. Li, Z. Lin, Z. Zhao, C. Chen, C. Wang, Y. Li, X. Huang, L. Miao, C. Jiang, Y. Huang and X. Duan, Nano Lett., 2015, 15, 4692-4698.

69 G. Wang, H. Wang, Y. Ling, Y. Tang, X. Yang, R. C. Fitzmorris, C. Wang, J. Z. Zhang and Y. Li, Nano Lett., 2011, 11, 3026-3033.
70 C. Yang, Z. Wang, T. Lin, H. Yin, X. Lü, D. Wan, T. Xu, C. Zheng, J. Lin, F. Huang, X. Xie and M. Jiang, J. Am. Chem. Soc., 2013, 135, 17831-17838.

71 C. Fàbrega, T. Andreu, F. Güell, J. D. Prades, S. Estradé, J. M. Rebled, F. Peiró and J. R. Morante, Nanotechnology, 2011, 22, 235403.

72 C. Ros, C. Fabrega, D. Monllor-Satoca, M. D. HernándezAlonso, G. Penelas-Pérez, J. R. Morante and T. Andreu, J. Phys. Chem. C, 2018, 122, 3295-3304.

73 F. Wang, C. Di Valentin and G. Pacchioni, J. Phys. Chem. C, 2012, 116, 8901-8909.

74 F. Wang, C. DiValentin and G. Pacchioni, ChemCatChem, 2012, 4, 476-478.

75 J. N. Hart, M. Cutini and N. L. Allan, Energy Procedia, 2014, 60, 32-36.

76 S. B. A. Hamid, S. J. Teh and C. W. Lai, Catalysts, 2017, 7, 93. 77 M. Wang, F. Ren, J. Zhou, G. Cai, L. Cai, Y. Hu, D. Wang, Y. Liu, L. Guo and S. Shen, Sci. Rep., 2015, 5, 12925.

78 Y. S. Chen and P. V. Kamat, J. Am. Chem. Soc., 2014, 136, 6075-6082.

79 F. X. Xiao, S. F. Hung, J. Miao, H. Y. Wang, H. Yang and B. Liu, Small, 2015, 11, 554-567.

80 Z. Zhang, L. Zhang, M. N. Hedhili, H. Zhang and P. Wang, Nano Lett., 2013, 13, 14-20.

81 T. Wang, Z. Luo, C. Li and J. Gong, Chem. Soc. Rev., 2014, 43, 7469-7484.

82 Q. Kang, J. Cao, Y. Zhang, L. Liu, H. Xu and J. Ye, J. Mater. Chem. A, 2013, 1, 5766.

83 C. Fàbrega, F. Hernández-Ramírez, J. Daniel Prades, R. Jiménez-Díaz, T. Andreu and J. Ramon Morante, Nanotechnology, 2010, 21, 445703.

84 Y. Yang, L. C. Kao, Y. Liu, K. Sun, H. Yu, J. Guo, S. Y. H. Liou and M. R. Hoffmann, ACS Catal., 2018, 8, 4278-4287.

85 C. Fàbrega, T. Andreu, A. Tarancón, C. Flox, A. Morata, L. Calvo-Barrio and J. R. Morante, Int. J. Hydrogen Energy, 2013, 38, 2979-2985.

86 J. M. Wu, T. W. Zhang, Y. W. Zeng, S. Hayakawa, K. Tsuru and A. Osaka, Langmuir, 2005, 21, 6995-7002.

87 C. Fàbrega, D. Monllor-Satoca, S. Ampudia, A. Parra, T. Andreu and J. R. Morante, J. Phys. Chem. C, 2013, 117, 20517-20524.

88 P. M. Rao, L. Cai, C. Liu, I. S. Cho, C. H. Lee, J. M. Weisse, P. Yang and X. Zheng, Nano Lett., 2014, 14, 1099-1105.

89 X. Yang, R. Liu, Y. Lei, P. Li, K. Wang, Z. Zheng and D. Wang, ACS Appl. Mater. Interfaces, 2016, 8, 16476-16485.

90 P. Tang, H. Xie, C. Ros, L. Han, M. Biset-Peiró, Y. He, W. Kramer, A. P. Rodríguez, E. Saucedo, J. R. GalánMascarós, T. Andreu, J. R. Morante and J. Arbiol, Energy Environ. Sci., 2017, 10, 2124-2136.

91 G. K. Mor, O. K. Varghese, R. H. T. Wilke, S. Sharma, K. Shankar, T. J. Latempa, K. Choi and C. A. Grimes, Nano Lett., 2008, 8, 1906-1911.

92 A. Paracchino, V. Laporte, K. Sivula, M. Grätzel and E. Thimsen, Nat. Mater., 2011, 10, 456-461.

93 M. Zhou, J. Bao, Y. Xu, J. Zhang, J. Xie, M. Guan, C. Wang, L. Wen, Y. Lei and Y. Xie, ACS Nano, 2014, 8, 7088-7098. 
94 T. Lopes, L. Andrade, F. Le Formal, M. Gratzel, K. Sivula and A. Mendes, Phys. Chem. Chem. Phys., 2014, 16, 16515-16523.

95 B. Klahr, S. Gimenez, F. Fabregat-Santiago, J. Bisquert and

T. W. Hamann, Energy Environ. Sci., 2012, 5, 7626.

96 Y. Qiu, W. Liu, W. Chen, G. Zhou, P. C. Hsu, R. Zhang, Z. Liang, S. Fan, Y. Zhang and Y. Cui, Sci. Adv., 2016, 2(6), e1501764.

97 S. Cho, J. W. Jang, K. H. Lee and J. S. Lee, APL Mater., 2014, 2, 010703.

98 J. A. Glasscock, P. R. F. Barnes, I. C. Plumb and N. Savvides, J. Phys. Chem. C, 2007, 111, 16477-16488.

99 Y. Hu, A. Kleiman-Shwarsctein, A. J. Forman, D. Hazen, J. Park and E. W. McFarland, Chem. Mater., 2008, 20, 3803-3805.

100 A. Kleiman-Shwarsctein, Y. S. Hu, A. J. Forman, G. D. Stucky and E. W. McFarland, J. Phys. Chem. C, 2008, 112, 1590015907.

101 J. Prakash, U. Prasad, X. Shi, X. Peng, B. Azeredo and A. M. Kannan, J. Power Sources, 2020, 448, 227418.

102 P. Y. Tang, L. J. Han, F. S. Hegner, P. Paciok, M. Biset-Peiró, H. C. Du, X. K. Wei, L. Jin, H. B. Xie, Q. Shi, T. Andreu, M. Lira-Cantú, M. Heggen, R. E. Dunin-Borkowski, N. López, J. R. Galán-Mascarós, J. R. Morante and J. Arbiol, Adv. Energy Mater., 2019, 9, 1-11.

103 J. Wang, J. L. Waters, P. Kung, S. M. Kim, J. T. Kelly, L. E. McNamara, N. I. Hammer, B. C. Pemberton, R. H. Schmehl, A. Gupta and S. Pan, ACS Appl. Mater. Interfaces, 2017, 9, 381-390.

104 Q. Shi, S. Murcia-López, P. Tang, C. Flox, J. R. Morante, Z. Bian, H. Wang and T. Andreu, ACS Catal., 2018, 8, 3331-3342.

105 S. K. Pilli, T. E. Furtak, L. D. Brown, T. G. Deutsch, J. A. Turner and A. M. Herring, Energy Environ. Sci., 2011, 4, 5028-5034.

106 F. F. Abdi, L. Han, A. H. M. Smets, M. Zeman, B. Dam and R. Van De Krol, Nat. Commun., 2013, 4, 1-7.

107 G. Wang, Y. Ling, X. Lu, F. Qian, Y. Tong, J. Z. Zhang, V. Lordi, C. Rocha Leao and Y. Li, J. Phys. Chem. C, 2013, 117, 10957-10964.

108 Y. Hermans, S. Murcia-López, A. Klein and W. Jaegermann, ACS Energy Lett., 2019, 4, 2522-2528.

109 M. Barroso, C. A. Mesa, S. R. Pendleburya, A. J. Cowana, T. Hisatomi, K. Sivula, M. Grätzelb, D. R. Kluga, J. R. Durrant, S. R. Pendlebury, A. J. Cowan, T. Hisatomi, K. Sivula, M. Gratzel, D. R. Klug and J. R. Durrant, Proc. Natl. Acad. Sci. U. S. A., 2012, 109, 1-89.

110 T. Hisatomi, F. Le Formal, M. Cornuz, J. Brillet, N. Tétreault, K. Sivula and M. Grätzel, Energy Environ. Sci., 2011, 4, 2512-2515.

111 X. Yang, R. Liu, C. Du, P. Dai, Z. Zheng and D. Wang, ACS Appl. Mater. Interfaces, 2014, 6, 12005-12011.

112 R. Liu, Z. Zheng, J. Spurgeon and X. Yang, Energy Environ. Sci., 2014, 7, 2504-2517.

113 Y. Hermans, S. Murcia-López, A. Klein, R. Van De Krol, T. Andreu, J. R. Morante, T. Toupance and W. Jaegermann, Phys. Chem. Chem. Phys., 2019, 21, 50865096.
114 Y. Makimizu, J. E. Yoo, M. Poornajar, N. T. Nguyen, H. J. Ahn, I. Hwang, S. Kment and P. Schmuki, J. Mater. Chem. A, 2020, 8, 1315-1325.

115 C. C. L. McCrory, S. Jung, I. M. Ferrer, S. M. Chatman, J. C. Peters and T. F. Jaramillo, J. Am. Chem. Soc., 2015, 137, 4347-4357.

116 H. Osgood, S. V. Devaguptapu, H. Xu, J. Cho and G. Wu, Nano Today, 2016, 11, 601-625.

117 P. Peerakiatkhajohn, J.-H. Yun, S. Wang and L. Wang, J. Photonics Energy, 2016, 7, 012006.

118 M. S. Burke, L. J. Enman, A. S. Batchellor, S. Zou and S. W. Boettcher, Chem. Mater., 2015, 27, 7549-7558.

119 M. S. Faber and S. Jin, Energy Environ. Sci., 2014, 7, 35193542.

120 S. D. Tilley, M. Schreier, J. J. J. Azevedo, M. Stefik and M. Graetzel, Adv. Funct. Mater., 2014, 24, 303-311.

121 C. G. Morales-Guio, S. D. Tilley, H. Vrubel, M. Grätzel and X. Hu, Nat. Commun., 2014, 5, 1-7.

122 N. Rahimi, R. A. Pax and E. M. A. Gray, Prog. Solid State Chem., 2016, 44, 86-105.

123 Y. Duan, S. Zhou, Z. Chen, J. Luo, M. Zhang, F. Wang, T. Xu and C. Wang, Catal. Sci. Technol., 2018, 8, 1395-1403.

124 D. K. Zhong, M. Cornuz, K. Sivula, M. Grätzel and D. R. Gamelin, Energy Environ. Sci., 2011, 4, 1759-1764.

125 J. Su, L. Guo, N. Bao and C. A. Grimes, Nano Lett., 2011, 11, 1928-1933.

126 M. R. Shaner, K. T. Fountaine, S. Ardo, R. H. Coridan, H. A. Atwater and N. S. Lewis, Energy Environ. Sci., 2014, 7, 779-790.

127 R. H. Coridan, K. A. Arpin, B. S. Brunschwig, P. V. Braun and N. S. Lewis, Nano Lett., 2014, 14, 2310-2317.

128 Y. Zhao, P. Westerik, R. Santbergen, E. Zoethout, H. Gardeniers and A. Bieberle-Hütter, Adv. Funct. Mater., 2020, 1909157, 1-10.

129 C. Liu, J. Tang, H. M. Chen, B. Liu and P. Yang, Nano Lett., 2013, 13, 2989-2992.

130 S. Y. Noh, K. Sun, C. Choi, M. Niu, M. Yang, K. Xu, S. Jin and D. Wang, Nano Energy, 2013, 2, 351-360.

131 A. Polman, M. Knight, E. C. Garnett, B. Ehrler, W. C. Sinke, R. Summary, A. Polman, M. Knight, E. C. Garnett, B. Ehrler and W. C. Sinke, Science, 2016, 352, 307.

132 A. G. Aberle, Prog. Photovolt: Res. Appl., 2000, 8, 473-487.

133 Y. Lee, C. Park, N. Balaji, Y.-J. Lee and V. A. Dao, Isr. J. Chem., 2015, 55, 1050-1063.

134 T. Saga, NPG Asia Mater., 2010, 2, 96-102.

135 B. C. Huayhuas-Chipana, J. C. M. Gomero and M. D. P. T. Sotomayor, J. Braz. Chem. Soc., 2014, 25, 17371745.

136 L. F. Huang, M. J. Hutchison, R. J. Santucci, J. R. Scully and J. M. Rondinelli, J. Phys. Chem. C, 2017, 121, 9782-9789.

137 R. Parsons, J. Electroanal. Chem. Interfacial Electrochem., 1967, 13, 471.

138 P. Acevedo-Pena, J. Vazquez-Arenas, R. Cabrera-Sierra, L. Lartundo-Rojas and I. Gonzalez, J. Electrochem. Soc., 2013, 160, C277-C284.

139 S. Chen, D. Huang, P. Xu, W. Xue, L. Lei, M. Cheng, R.-Z. Wang, X. Liu and R. Deng, Semiconductor-based 
photocatalysts for photocatalytic and photoelectrochemical water splitting: will we stop with photocorrosion?, Royal Society of Chemistry, 2020.

140 N. C. Strandwitz, D. J. Comstock, R. L. Grimm, A. C. Nichols-Nielander, J. Elam and N. S. Lewis, J. Phys. Chem. C, 2013, 117, 4931-4936.

141 K. Sun, X. Pang, S. Shen, X. Qian, J. S. Cheung and D. Wang, Nano Lett., 2013, 13, 2064-2072.

142 P. A. Nikolaychuk, Silicon, 2014, 6, 109-116.

143 E. Kim and K. Osseo-Asare, Hydrometallurgy, 2012, 127-128, 178-186.

144 S. Milenkovic, V. Dalbert, R. Marinkovic and A. W. Hassel, Corros. Sci., 2009, 51, 1490-1495.

145 D. Bae, S. Shayestehaminzadeh, E. B. Thorsteinsson, T. Pedersen, O. Hansen, B. Seger, P. C. K. Vesborg, S. Ólafsson and I. Chorkendorff, Sol. Energy Mater. Sol. Cells, 2016, 144, 758-765.

146 H. J. Lewerenz, K. Skorupska, A. G. Muñoz, T. Stempel, N. Nüsse, M. Lublow, T. Vo-Dinh and P. Kulesza, Electrochim. Acta, 2011, 56, 10726-10736.

147 I. Z. Awan, A. Q. Khan, I. Z. Awan, A. Q. Khan, E. Nationale and S. De Chimie, J. Chem. Soc. Pak., 2018, 40, 602-655.

148 B. Beverskog and I. Puigdomenech, Corros. Sci., 1997, 39, 107-114.

149 R. Buckle and S. Roy, Sep. Purif. Technol., 2008, 62, 86-96.

150 S. Geiger, O. Kasian, A. M. Mingers, K. J. J. Mayrhofer and S. Cherevko, Sci. Rep., 2017, 7, 3-9.

151 S. W. F. M. Van Hövell Tot Westerflier, J. J. M. Binsma, H. N. Stein and C. Vandecasteele, J. Radioanal. Nucl. Chem., 1987, 111, 305-317.

152 D. Tromans, J. Electrochem. Soc., 2009, 156, C367.

153 A. G. Voloshchuk and N. I. Tsipishchuk, Inorg. Mater., 2002, 38, 1114-1116.

154 B. Fotouhi, R. Triboulet and M. Etman, J. Electroanal. Chem. Interfacial Electrochem., 1985, 195, 425-430.

155 D. Bae, B. Seger, P. C. K. Vesborg, O. Hansen and I. Chorkendorff, Chem. Soc. Rev., 2017, 46, 1933-1954.

156 B. Yan, G. Yue, J. Yang and S. Guha, 19th Int. Work. Act. Flatpanel Displays Devices - TFT Technol. FPD Mater., 2012, vol. 108, pp. 67-70.

157 A. Guerrero and J. Bisquert, Curr. Opin. Electrochem., 2017, 2, 144-147.

158 W. Wang, M. Xu, X. Xu, W. Zhou and Z. Shao, Angew. Chem., Int. Ed., 2020, 59, 136-152.

159 D. Kim, D.-K. Lee, S. M. Kim, W. Park and U. Sim, Materials, 2020, 13, 210.

160 A. Guerrero, M. Haro, S. Bellani, M. R. Antognazza, L. Meda, S. Gimenez and J. Bisquert, Energy Environ. Sci., 2014, 7, 3666-3673.

161 P. Xu, N. S. McCool and T. E. Mallouk, Nano Today, 2017, 14, 42-58.

162 J. Brillet, J.-H. Yum, M. Cornuz, T. Hisatomi, R. Solarska, J. Augustynski, M. Graetzel and K. Sivula, Nat. Photonics, 2012, 6, 824-828.

163 A. Bansal and N. S. Lewis, J. Phys. Chem. B, 1998, 102, 40584060 .
164 A. Bansal, X. Li, I. Lauermann, N. S. Lewis, S. I. Yi and W. H. Weinberg, J. Am. Chem. Soc., 1996, 118, 7225-7226.

165 S. Hu, N. S. Lewis, J. W. Ager, J. Yang, J. R. McKone and N. C. Strandwitz, J. Phys. Chem. C, 2015, 119, 24201-24228.

166 M. F. Lichterman, K. Sun, S. Hu, X. Zhou, M. T. McDowell, M. R. Shaner, M. H. Richter, E. J. Crumlin, A. I. Carim, F. H. Saadi, B. S. Brunschwig and N. S. Lewis, Catal. Today, 2016, 262, 11-23.

167 R. P. Feynman, Miniaturization, 1960, 282-296.

168 F. Lévy, Ref. Modul. Mater. Sci. Mater. Eng., 2016, pp. 1-16. 169 M. G. Kast, L. J. Enman, N. J. Gurnon, A. Nadarajah and S. W. Boettcher, ACS Appl. Mater. Interfaces, 2014, 6, 22830-22837.

170 G. Oskam, J. G. Long, A. Natarajan and P. C. Searson, J. Phys. D: Appl. Phys., 1998, 1927-1949.

171 K. Sun, S. Shen, J. S. Cheung, X. Pang, N. Park, J. Zhou, Y. Hu, Z. Sun, S. Y. Noh, C. T. Riley, P. K. L. Yu, S. Jin and D. Wang, Phys. Chem. Chem. Phys., 2014, 16, 4612-4625.

172 K. Sun, M. T. McDowell, A. C. Nielander, S. Hu, M. R. Shaner, F. Yang, B. S. Brunschwig and N. S. Lewis, J. Phys. Chem. Lett., 2015, 6, 592-598.

173 I. Roger, M. A. Shipman and M. D. Symes, Nat. Rev. Chem., 2017, 1, 1-13.

174 S. H. Park, Y. C. Son, W. S. Willis, S. L. Suib and K. E. Creasy, Chem. Mater., 1998, 10, 2389-2398.

175 P. J. Kelly and R. D. Arnell, Vacuum, 2000, 56, 159-172.

176 J. E. Greene, J. Vac. Sci. Technol., A, 2017, 35, 05 C204.

177 Y. Lin, C. Battaglia, M. Boccard, M. Hettick, Z. Yu, C. Ballif, J. W. Ager and A. Javey, Nano Lett., 2013, 13, 5615-5618.

178 B. Mei, T. Pedersen, P. Malacrida, D. Bae, R. Frydendal, O. Hansen, P. C. K. Vesborg, B. Seger and I. Chorkendorff, J. Phys. Chem. C, 2015, 119, 15019-15027.

179 M. T. McDowell, M. F. Lichterman, A. I. Carim, R. Liu, S. Hu, B. S. Brunschwig and N. S. Lewis, ACS Appl. Mater. Interfaces, 2015, 7, 15189-15199.

180 D. H. Lowndes, D. B. Geohegan, A. A. Puretzky, D. P. Norton and C. M. Rouleau, Science, 2012, 273, 898-903.

181 M. Orlandi, S. Caramori, F. Ronconi, C. A. Bignozzi, Z. El Koura, N. Bazzanella, L. Meda and A. Miotello, ACS Appl. Mater. Interfaces, 2014, 6, 6186-6190.

182 T. Fujii, F. M. F. De Groot and G. A. Sawatzky, Phys. Rev. B: Condens. Matter Mater. Phys., 1999, 59, 3195-3202.

183 W. A. Doolittle, A. G. Carver and W. Henderson, J. Vac. Sci. Technol., B: Microelectron. Nanometer Struct.-Process., Meas., Phenom., 2005, 23, 1272.

184 J. E. Crowell, J. Vac. Sci. Technol., A, 2003, 21, S88-S95.

185 M. C. Vasudev, K. D. Anderson, T. J. Bunning, V. V. Tsukruk and R. R. Naik, ACS Appl. Mater. Interfaces, 2013, 5, 39833994.

186 A. G. Scheuermann and P. C. McIntyre, J. Phys. Chem. Lett., 2016, 7, 2867-2878.

187 H. Van Bui, A. Y. Kovalgin and R. A. M. Wolters, ECS J. Solid State Sci. Technol., 2012, 1, P285-P290.

188 M. Ritala and M. Leskela, Nanotechnology, 1999, 10, 19-24.

189 S. M. George, Chem. Rev., 2010, 110, 111-131.

190 H. Wang, L. Zhang, Z. Chen, J. Hu, S. Li, Z. Wang, J. Liu and X. Wang, Chem. Soc. Rev., 2014, 43, 5234-5244. 
191 Y. Nakato, H. Yano, S. Nishiura, T. Ueda and H. Tsubomura, J. Electroanal. Chem., 1987, 228, 97-108.

192 Y. Nakato and H. Tsubomura, J. Photochem., 1985, 29, 257-266.

193 Y. Nakato and H. Tsubomura, Electrochim. Acta, 1992, 37, 897-907.

194 G. Nagasubramanian and A. J. Bard, J. Electrochem. Soc., 1980, 128, 1055-1060.

195 K. Nakato, S. Takabayashi, A. Imanishi, K. Murakoshi and Y. Nakato, Sol. Energy Mater. Sol. Cells, 2004, 83, 323-330.

196 C. U. Maier, M. Specht and G. Bilger, Int. J. Hydrogen Energy, 1996, 21, 859-864.

197 M. J. Kenney, M. Gong, Y. Li, J. Z. Wu, J. Feng, M. Lanza and H. Dai, Science, 2013, 342, 836-840.

198 F. A. L. Laskowski, M. R. Nellist, R. Venkatkarthick and S. W. Boettcher, Energy Environ. Sci., 2017, 10, 570-579.

199 A. Sartori, M. Orlandi, S. Berardi, A. Mazzi, N. Bazzanella, S. Caramori, R. Boaretto, M. Natali, R. Fernandes, N. Patel, C. A. Bignozzi and A. Miotello, Electrochim. Acta, 2018, 271, 472-480.

200 J. Feng, M. Gong, M. J. Kenney, J. Z. Wu, B. Zhang, Y. Li and H. Dai, Nano Res., 2015, 8, 1577-1583.

201 K. Sun, S. Shen, Y. Liang, P. E. Burrows, S. S. Mao and D. Wang, Chem. Rev., 2014, 114, 8662-8719.

202 B. Seger, A. B. Laursen, P. C. K. Vesborg, T. Pedersen, O. Hansen, S. Dahl and I. Chorkendorff, Angew. Chem., Int. Ed. Engl., 2012, 51, 9128-9131.

203 B. Mei, B. Seger, T. Pedersen, M. Malizia, O. Hansen, I. Chorkendorff and P. C. K. Vesborg, J. Phys. Chem. Lett., 2014, 5, 1948-1952.

204 R. Singh, M. A. Green and K. Rajkanan, Sol. Cells, 1981, 3, 95-148.

205 M. A. Green and A. W. Blakers, Sol. Cells, 1983, 8, 3-16.

206 Y. W. Chen, J. D. Prange, S. Dühnen, Y. Park, M. Gunji, C. E. D. Chidsey and P. C. McIntyre, Nat. Mater., 2011, 10, 539-544.

207 A. Q. Contractor and J. O. M. Bockris, Electrochim. Acta, 1984, 29, 1427-1434.

208 D. V Esposito, I. Levin, T. P. Moffat and A. A. Talin, Nat. Mater., 2013, 12, 562-568.

209 A. G. Scheuermann, D. Q. Lu, T. Ito, C. E. D. Chidsey and P. C. McIntyre, ECS Trans., 2014, 64, 265-276.

210 M. H. Lee, K. Takei, J. Zhang, R. Kapadia, M. Zheng, Y.-Z. Chen, J. Nah, T. S. Matthews, Y.-L. Chueh, J. W. Ager and A. Javey, Angew. Chem., Int. Ed., 2012, 51, 10760-10764.

211 A. G. Scheuermann, J. D. Prange, M. Gunji, C. E. D. Chidsey and P. C. McIntyre, Energy Environ. Sci., 2013, 6, 2487-2496.

212 A. G. Scheuermann, J. P. Lawrence, K. W. Kemp, T. Ito, A. Walsh, C. E. D. Chidsey, P. K. Hurley and P. C. McIntyre, Nat. Mater., 2015, 15, 1-8.

213 Z. Xia, X. Zhou, J. Li and Y. Qu, Sci. Bull., 2015, 60, 1395-1402. 214 A. G. Scheuermann, K. W. Kemp, K. Tang, D. Q. Lu, P. F. Satterthwaite, T. Ito, C. E. D. Chidsey and P. C. McIntyre, Energy Environ. Sci., 2016, 9, 504-516.

215 M. J. Choi, J. Y. Jung, M. J. Park, J. W. Song, J. H. Lee and J. H. Bang, J. Mater. Chem. A, 2014, 2, 2928-2933.
216 A. G. Scheuermann, J. P. Lawrence, A. C. Meng, K. Tang, O. L. Hendricks, C. E. D. Chidsey and P. C. McIntyre, ACS Appl. Mater. Interfaces, 2016, 8, 14596-14603.

217 S. Hu, M. R. Shaner, J. A. Beardslee, M. Lichterman, B. S. Brunschwig and N. S. Lewis, Science, 2014, 344, 1005-1009.

218 G. Campet, J. P. Manaud, C. Puprichitkun, Z. W. Sun and P. Salvador, Act. Passive Electron. Compon., 1989, 13, 175189.

219 J. Ran, J. Zhang, J. Yu, M. Jaroniec and S. Z. Qiao, Chem. Soc. Rev., 2014, 43, 7787-7812.

220 A. Singh and L. Spiccia, Coord. Chem. Rev., 2013, 257, 26072622.

221 F. Lin and S. W. Boettcher, Nat. Mater., 2014, 13, 81-86.

222 A. Kraft, B. Görig and K. H. Heckner, Sol. Energy Mater. Sol. Cells, 1994, 32, 151-158.

223 D. Bae, T. Pedersen, B. Seger, M. Malizia, A. Kuznetsov, O. Hansen, I. Chorkendorff and P. C. K. Vesborg, Energy Environ. Sci., 2015, 8, 650-660.

224 B. J. Choi, D. S. Jeong, S. K. Kim, C. Rohde, S. Choi, J. H. Oh, H. J. Kim, C. S. Hwang, K. Szot, R. Waser, B. Reichenberg and S. Tiedke, J. Appl. Phys., 2005, 98, 1-10.

225 K. Tang, A. C. Meng, F. Hui, Y. Shi, T. Petach, C. Hitzman, A. L. Koh, D. Goldhaber-Gordon, M. Lanza and P. C. McIntyre, Nano Lett., 2017, 17, 4390-4399.

226 D. H. Kwon, K. M. Kim, J. H. Jang, J. M. Jeon, M. H. Lee, G. H. Kim, X. S. Li, G. S. Park, B. Lee, S. Han, M. Kim and C. S. Hwang, Nat. Nanotechnol., 2010, 5, 148-153.

227 B. Seger, T. Pedersen, A. B. Laursen, P. C. K. Vesborg, O. Hansen and I. Chorkendorff, J. Am. Chem. Soc., 2013, 135, 1057-1064.

228 U. K. Kirner, K. D. Schierbaum and W. Göpel, Fresenius. J. Anal. Chem., 1991, 341, 416-420.

229 M. Cerchez, H. Langer, M. El Achhab, T. Heinzel, D. Ostermann, H. Lüder and J. Degenhardt, Appl. Phys. Lett., 2013, 103, 033522.

230 N. A. Deskins and M. Dupuis, Phys. Rev. B: Condens. Matter Mater. Phys., 2007, 75, 1-10.

231 A. Bally, Présentée Au Département De Physique École Polytechnique Fédérale De Lausanne, Pour L'obtention Du Grade De Docteur Ès Sciences, Thèse No 2094, 1999, 140.

232 M. G. Kast, L. J. Enman, N. J. Gurnon, A. Nadarajah and S. W. Boettcher, ACS Appl. Mater. Interfaces, 2014, 6, 22830-22837.

233 K. C. Sabat, P. Rajput, R. K. Paramguru, B. Bhoi and B. K. Mishra, Plasma Chem. Plasma Process., 2014, 34, 1-23.

234 P. F. Satterthwaite, A. G. Scheuermann, P. K. Hurley, C. E. D. Chidsey and P. C. McIntyre, ACS Appl. Mater. Interfaces, 2016, 8, 13140-13149.

235 B. Seger, D. S. Tilley, T. Pedersen, P. C. K. Vesborg, O. Hansen, M. Grätzel and I. Chorkendorff, RSC Adv., 2013, 3, 25902-25907.

236 B. Seger, S. D. Tilley, T. Pedersen, P. C. K. Vesborg, O. Hansen, M. Graetzel and I. Chorkendorff, J. Mater. Chem. A, 2013, 1, 15089-15094. 
237 J. Liang, H. Tan, M. Liu, B. Liu, N. Wang, Q. Zhang, Y. Zhao, A. H. M. Smets, M. Zeman and X. Zhang, J. Mater. Chem. A, 2016, 4, 16841-16848.

238 C. Ros, T. Andreu, M. D. Hernández-Alonso, G. PenelasPérez, J. Arbiol and J. R. Morante, ACS Appl. Mater. Interfaces, 2017, 9, 17932-17941.

239 C. Ros, N. M. Carretero, J. David, J. Arbiol, T. Andreu and J. R. Morante, ACS Appl. Mater. Interfaces, 2019, 11, 29725-29735.

240 C. Ros, T. Andreu, S. Giraldo, V. Izquierdo-Roca, E. Saucedo and J. R. Morante, ACS Appl. Mater. Interfaces, 2018, 10, 13425-13433.

241 C. Ros, T. Andreu, S. Giraldo, Y. Sánchez and J. R. Morante, Sol. Energy Mater. Sol. Cells, 2016, 158, 184-188.

242 J. Aarik, A. Aidla, T. Uustare and V. Sammelselg, J. Cryst. Growth, 1995, 148, 268-275.

243 E. Kemppainen, A. Bodin, B. Sebok, T. Pedersen, B. Seger, B. Mei, D. Bae, P. C. K. Vesborg, J. Halme, O. Hansen, P. D. Lund and I. Chorkendorff, Energy Environ. Sci., 2015, 8, 2991-2999.

244 K. Sivula, ChemCatChem, 2014, 2796-2797.

245 S. Hu, M. H. Richter, M. F. Lichterman, J. Beardslee, T. Mayer, B. S. Brunschwig and N. S. Lewis, J. Phys. Chem. C, 2016, 120, 3117-3129.

246 H. Y. Lee and J. Robertson, J. Appl. Phys., 2013, 113, 213706. 247 H. A. Huy, B. Aradi, T. Frauenheim and P. Deák, Phys. Rev. B: Condens. Matter Mater. Phys., 2011, 83, 1-7.

248 M. F. Lichterman, A. I. Carim, M. T. McDowell, S. Hu, H. B. Gray, B. S. Brunschwig and N. S. Lewis, Energy Environ. Sci., 2014, 7, 3334-3337.

249 M. F. Lichterman, S. Hu, M. H. Richter, E. Crumlin, S. Axnanda, M. Favaro, W. S. Drisdell, Z. Hussain, T. Mayer, B. S. Brunschwig, N. Lewis, Z. Liu and H.-J. Lewerenz, Energy Environ. Sci., 2015, 8, 2409-2416.

250 G. Man, J. Schwartz, J. C. Sturm and A. Kahn, Adv. Mater. Interfaces, 2016, 3, 1-8.

251 M. R. Shaner, S. Hu, K. Sun and N. S. Lewis, Energy Environ. Sci., 2015, 8, 203-207.

252 B. Mei, T. Pedersen, P. Malacrida, D. Bae, R. Frydendal, O. Hansen, P. C. K. Vesborg, B. Seger and I. Chorkendorff, J. Phys. Chem. C, 2015, 119, 15019-15027.

253 T. C. Peng, X. H. Xiao, X. Y. Han, X. D. Zhou, W. Wu, F. Ren and C. Z. Jiang, Appl. Surf. Sci., 2011, 257, 5908-5912.

254 K. Sun, F. H. Saadi, M. F. Lichterman, W. G. Hale, H.-P. Wang, X. Zhou, N. T. Plymale, S. T. Omelchenko, J.-H. He, K. M. Papadantonakis, B. S. Brunschwig and N. S. Lewis, Proc. Natl. Acad. Sci. U. S. A., 2015, 112, 36123617.

255 P. S. Patil and L. D. Kadam, Appl. Surf. Sci., 2002, 199, 211221.

256 K. Sun, Y. Kuang, E. Verlage, B. S. Brunschwig, C. W. Tu and N. S. Lewis, Adv. Energy Mater., 2015, 5, 1-8.

257 H. Sato, T. Minami, S. Takata and T. Yamada, Thin Solid Films, 1993, 236, 27-31.

258 W. L. Jang, Y. M. Lu, W. S. Hwang, T. L. Hsiung and H. P. Wang, Appl. Phys. Lett., 2009, 94, 92-95.
259 M. D. Irwin, D. B. Buchholz, A. W. Hains, R. P. H. Chang and T. J. Marks, Proc. Natl. Acad. Sci. U. S. A., 2007, 105, 2783-2787.

260 L. D'Amario, G. Boschloo, A. Hagfeldt and L. Hammarström, J. Phys. Chem. C, 2014, 118, 19556-19564.

261 S. Bai, M. Cao, Y. Jin, X. Dai, X. Liang, Z. Ye, M. Li, J. Cheng, X. Xiao, Z. Wu, Z. Xia, B. Sun, E. Wang, Y. Mo, F. Gao and F. Zhang, Adv. Energy Mater., 2014, 4, 1-6.

262 C. Y. Lin, Y. H. Lai, D. Mersch and E. Reisner, Chem. Sci., 2012, 3, 3482-3487.

263 F. Ciesielczyk, P. Bartczak, K. Wieszczycka, K. SiwińskaStefańska, M. Nowacka and T. Jesionowski, Adsorption, 2013, 19, 423-434.

264 J. Bachmann, A. Zolotaryov, O. Albrecht, S. Goetze, A. Berger, D. Hesse, D. Novikov and K. Nielsch, Chem. Vap. Deposition, 2011, 17, 177-180.

265 M. Nachman, L. N. Cojocaru and L. V. Rîbco, Phys. Status Solidi, 1965, 8, 773-783.

266 F. Jiang, W. C. H. Choy, X. Li, D. Zhang and J. Cheng, Adv. Mater., 2015, 27, 2930-2937.

267 S. K. Kuanr, G. Vinothkumar and K. S. Babu, Mater. Sci. Semicond. Process., 2018, 75, 26-30.

268 H. L. Chen and Y. S. Yang, Thin Solid Films, 2008, 516, 55905596.

269 W. Jang, Y. Lu, W. Hwang, T. Hsiung and H. P. Wang, Surf. Coat. Technol., 2008, 202, 5444-5447.

270 T. Fujii, M. Arita, K. Hamada, Y. Takahashi and N. Sakaguchi, J. Appl. Phys., 2013, 113, 083701.

271 F. Nardi, D. Deleruyelle, S. Spiga, C. Muller, B. Bouteille and D. Ielmini, J. Appl. Phys., 2012, 112, 064310.

272 C. Dette, M. R. Hurst, J. Deng, M. R. Nellist and S. W. Boettcher, ACS Appl. Mater. Interfaces, 2019, 11(6), 5590-5594.

273 D. S. Hall, D. J. Lockwood, C. Bock and B. R. MacDougall, Proc. R. Soc. A, 2015, 471, 20140792.

274 F. Lin, B. F. Bachman and S. W. Boettcher, J. Phys. Chem. Lett., 2015, 6, 2427-2433.

275 X. Wang, Y. Wang, C. Zhao, Y. Zhao, B. Yan and W. Zheng, New J. Chem., 2012, 36, 1902-1906.

276 M. Biset-Peiró, C. Fàbrega, J. R. Morante and T. Andreu, J. Phys. D: Appl. Phys., 2017, 50(10).

277 L. Trotochaud, S. L. Young, J. K. Ranney and S. W. Boettcher, J. Am. Chem. Soc., 2014, 136, 6744-6753.

278 M. Biset-Peiró, C. Fàbrega, J. R. Morante, T. Andreu, S. Murcia-López, C. Fàbrega, J. R. Morante and T. Andreu, J. Phys. D: Appl. Phys., 2017, 50(10).

279 K. L. Nardi, N. Yang, C. F. Dickens, A. L. Strickler and S. F. Bent, Adv. Energy Mater., 2015, 5, 1-10.

280 Z. Liu, C. Li, Y. Xiao, F. Wang, Q. Yu, M. B. Faheem, T. Zhou and Y. Li, J. Phys. Chem. C, 2020, 124, 2844-2850.

281 F. Li, Y. Li, Q. Zhuo, D. Zhou, Y. Zhao, Z. Zhao, X. Wu, Y. Shan and L. Sun, ACS Appl. Mater. Interfaces, 2020, 12(10), 11479-11488.

282 T. W. Hamann, Nat. Mater., 2014, 13, 3-4.

283 G. Li and S. Wang, Electroanal. Chem., 1987, 227, 213-221.

284 B. Mei, A. A. Permyakova, R. Frydendal, D. Bae, T. Pedersen, P. Malacrida, O. Hansen, I. E. L. Stephens, P. C. K. Vesborg, 
B. Seger and I. Chorkendorff, J. Phys. Chem. Lett., 2014, 5, 3456-3461.

285 K. Sun, N. Park, Z. Sun, J. Zhou, J. Wang, X. Pang, S. Shen, S. Y. Noh, Y. Jing, S. Jin, P. K. L. Yu and D. Wang, Energy Environ. Sci., 2012, 5, 7872-7877.

286 C. Ros, T. Andreu, J. David, J. Arbiol and J. R. Morante, J. Mater. Chem. A, 2019, 7, 21892-21902.

287 D. Bae, B. T. Mei, R. Frydendal, T. Pedersen, B. Seger, O. Hansen, P. C. K. Vesborg and I. Chorkendorff, ChemElectroChem, 2016, 3, 1517.

288 K. Deori and S. Deka, CrystEngComm, 2013, 15, 8465-8474. 289 C. W. Tung, Y. Y. Hsu, Y. P. Shen, Y. Zheng, T. S. Chan, H. S. Sheu, Y. C. Cheng and H. M. Chen, Nat. Commun., 2015, 6, 1-9.

290 Y. Jiang, X. Li, T. Wang and C. Wang, Nanoscale, 2016, 8, 9667-9675.

291 M. S. Burke, M. G. Kast, L. Trotochaud, A. M. Smith and S. W. Boettcher, J. Am. Chem. Soc., 2015, 137, 3638-3648.

292 F. Urbain, R. Du, P. Tang, V. Smirnov, T. Andreu, F. Finger, N. Jimenez Divins, J. Llorca, J. Arbiol, A. Cabot and J. R. Morante, Appl. Catal., B, 2019, 259, 118055.

293 J. Yang, K. Walczak, E. Anzenberg, F. M. Toma, G. Yuan, J. Beeman, A. Schwartzberg, Y. Lin, M. Hettick, A. Javey, J. W. Ager, J. Yano, H. Frei and I. D. Sharp, J. Am. Chem. Soc., 2014, 136, 6191-6194.

294 Z. Xing, H. Wu, L. Wu, X. Wang, H. Zhong, F. Li, J. Shi, D. Song, W. Xiao, C. Jiang and F. Ren, J. Mater. Chem. A, 2018, 6, 21167-21177.

295 X. Zhou, R. Liu, K. Sun, K. M. Papadantonakis, B. S. Brunschwig and N. S. Lewis, Energy Environ. Sci., 2016, 892-897.

296 E. Nurlaela, H. Wang, T. Shinagawa, S. Flanagan, S. OuldChikh, M. Qureshi, Z. Mics, P. Sautet, T. Le Bahers, E. Cánovas, M. Bonn and K. Takanabe, ACS Catal., 2016, 6, 4117-4126.

297 R. C. Kainthla, J. Electrochem. Soc., 1986, 133, 248.

298 J. A. Switzer, J. Electrochem. Soc., 1986, 133, 722.

299 S. I. Dutch, J. Chem. Educ., 1999, 76, 356.

300 M. Malizia, B. Seger, I. Chorkendorff and P. C. K. Vesborg, J. Mater. Chem. A, 2014, 2, 6847-6853.

301 N. Takeno, Atlas of Eh-pH diagrams, Natl. Inst. Adv. Ind. Sci. Technol., Tokyo, 2005, p. 285.

302 A. Standing, S. Assali, L. Gao, M. A. Verheijen, D. Van Dam, Y. Cui, P. H. L. Notten, J. E. M. Haverkort and E. P. A. M. Bakkers, Nat. Commun., 2015, 6, 1-7.

303 R. J. Britto, J. D. Benck, J. L. Young, C. Hahn, T. G. Deutsch and T. F. Jaramillo, J. Phys. Chem. Lett., 2016, 7, 2044-2049. 304 Q. Ding, B. Song, P. Xu and S. Jin, Chem, 2016, 1, 699-726. 305 J. Gu, J. A. Aguiar, S. Ferrere, K. X. Steirer, Y. Yan, C. Xiao, J. L. Young, M. Al-Jassim, N. R. Neale and J. A. Turner, Nat. Energy, 2017, 2, 1-8.

306 A. B. Laursen, T. Pedersen, P. Malacrida, B. Seger, O. Hansen, P. C. K. Vesborg and I. Chorkendorff, Phys. Chem. Chem. Phys., 2013, 15, 20000-20004.

307 L. A. King, T. R. Hellstern, J. Park, R. Sinclair and T. F. Jaramillo, ACS Appl. Mater. Interfaces, 2017, 9, 36792-36798.
308 I. A. Digdaya, G. W. P. Adhyaksa, B. J. Trzesniewski, E. C. Garnett and W. A. Smith, Nat. Commun., 2017, 8, 15968.

309 L. Ji, M. D. Mcdaniel, S. Wang, A. B. Posadas, X. Li, H. Huang, J. C. Lee, A. A. Demkov, A. J. Bard, J. G. Ekerdt and E. T. Yu, Nat. Nanotechnol., 2015, 10, 84-90.

310 J. Bao, Nat. Nanotechnol., 2015, 10, 19-20.

311 G. Campet, Z. W. Sun and P. Keou, Act. Passive Electron. Compon., 1990, 14, 47-52.

312 K. H. Yoon, C. W. Shin and D. H. Kang, J. Appl. Phys., 1997, 81, 7024-7029.

313 K. H. Yoon, D. K. Seo, Y. S. Cho and D. H. Kang, J. Appl. Phys., 1998, 84, 3954-3959.

314 R. H. Coridan, M. Shaner, C. Wiggenhorn, B. S. Brunschwig and N. S. Lewis, J. Phys. Chem. C, 2013, 117, 6949-6957.

315 X. Wang, K. Q. Peng, Y. Hu, F. Q. Zhang, B. Hu, L. Li, M. Wang, X. M. Meng and S. T. Lee, Nano Lett., 2014, 14, 18-23.

316 K. Sun, K. Madsen, P. Andersen, W. Bao, Z. Sun and D. Wang, Nanotechnology, 2012, 23, 194013.

317 A. J. Bard, Standard Potentials in Aqueous Solution, Routledge, New York, 1985.

318 Y. Lin, R. Kapadia, J. Yang, M. Zheng, K. Chen, M. Hettick, X. Yin, C. Battaglia, I. D. Sharp, J. W. Ager and A. Javey, J. Phys. Chem. C, 2015, 119, 2308-2313.

319 A. Azarpira, M. Lublow, A. Steigert, P. Bogdanoff, D. Greiner, C. A. Kaufmann, M. Krüger, U. Gernert, R. Van De Krol, A. Fischer and T. Schedel-Niedrig, Adv. Energy Mater., 2015, 5, 1-9.

320 I. Repins, M. A. Contreras, B. Egaas, C. DeHart, J. Scharf, C. L. Perkins, B. To and R. Noufi, Prog. Photovolt: Res. Appl., 2008, 16, 235-239.

321 H. Kumagai, T. Minegishi, N. Sato, T. Yamada, J. Kubota and K. Domen, J. Mater. Chem. A, 2015, 3, 8300-8307.

322 M. T. Greiner, L. Chai, M. G. Helander, W. M. Tang and Z. H. Lu, Adv. Funct. Mater., 2012, 22, 4557-4568.

323 X. Zhou, R. Liu, K. Sun, D. Friedrich, M. T. McDowell, F. Yang, S. T. Omelchenko, F. H. Saadi, A. C. Nielander, S. Yalamanchili, K. M. Papadantonakis, B. S. Brunschwig and N. Lewis, Energy Environ. Sci., 2015, 8, 2644-2649.

324 T. Osaka, J. Electrochem. Soc., 1984, 131, 1571.

325 A. G. Scheuermann, C. E. D. Chidsey and P. C. McIntyre, J. Electrochem. Soc., 2016, 163, H192-H200.

326 M. F. Lichterman, S. Hu, M. H. Richter, E. J. Crumlin, S. Axnanda, M. Favaro, W. Drisdell, Z. Hussain, T. Mayer, B. S. Brunschwig, N. S. Lewis, Z. Liu and H.-J. Lewerenz, Energy Environ. Sci., 2015, 8, 2409-2416.

327 A. G. Scheuermann, J. P. Lawrence, K. W. Kemp, T. Ito, A. Walsh, C. E. D. Chidsey, P. K. Hurley and P. C. McIntyre, Nat. Mater., 2015, 15, 99-105.

328 S. W. Boettcher, E. L. Warren, M. C. Putnam, E. A. Santori, D. Turner-Evans, M. D. Kelzenberg, M. G. Walter, J. R. McKone, B. S. Brunschwig, H. A. Atwater and N. S. Lewis, J. Am. Chem. Soc., 2011, 133, 1216-1219.

329 T. Wang and J. Gong, Angew. Chem., Int. Ed., 2015, 54, 10718-10732. 
330 B. Mei, A. A. Permyakova, R. Frydendal, D. Bae, T. Pedersen, P. Malacrida, O. Hansen, I. E. L. Stephens, P. C. K. Vesborg, B. Seger and I. Chorkendor, J. Phys. Chem. Lett., 2014, 5, 3456-3461.

331 H.-P. Wang, K. Sun, S. Y. Noh, A. Kargar, M.-L. Tsai, M.-Y. Huang, D. Wang and J.-H. He, Zootaxa, 2011, 1-34.

332 I. A. Digdaya, P. P. Rodriguez, M. Ma, G. W. P. Adhyaksa, E. C. Garnett, A. H. M. Smets and W. A. Smith, J. Mater. Chem. A, 2016, 4, 6842-6852.

333 J. Ramanujam and U. P. Singh, Energy Environ. Sci., 2017, 10, 1306-1319.

334 T. J. Jacobsson, C. Platzer-Björkman, M. Edoff and T. Edvinsson, Int. J. Hydrogen Energy, 2013, 38, 1502715035.

335 Y. Chen, X. Feng, M. Liu, J. Su and S. Shen, Nanophotonics, 2016, 5, 468-491.

336 T. J. Jacobsson, V. Fjallstrom, M. Edoff and T. Edvinsson, Sol. Energy Mater. Sol. Cells, 2015, 134, 185-193.

337 B. Koo, S. W. Nam, R. Haight, S. Kim, S. Oh, M. Cho, J. Oh, J. Y. Lee, B. T. Ahn and B. Shin, ACS Appl. Mater. Interfaces, 2017, 9, 5279-5287.

338 W. Septina and S. D. Tilley, Curr. Opin. Electrochem., 2017, 2, 120-127.

339 F. Jiang, Gunawan, T. Harada, Y. Kuang, T. Minegishi, K. Domen and S. Ikeda, J. Am. Chem. Soc., 2015, 137, 13691-13697.

340 L. Rovelli, S. D. Tilley and K. Sivula, ACS Appl. Mater. Interfaces, 2013, 5, 8018-8024.

341 D. Yokoyama, T. Minegishi, K. Jimbo, T. Hisatomi, G. Ma, M. Katayama, J. Kubota, H. Katagiri and K. Domen, Appl. Phys. Express, 2010, 3, 101202.

342 W. Septina, S. Ikeda, T. Harada, T. Minegishi, K. Domen and M. Matsumura, Chem. Commun., 2014, 50, 8941.

343 Z. Guan, W. Luo and Z. Zou, Crystengcomm, 2014, 29292936.

344 S. Y. Chae, S. J. Park, S. G. Han, H. Jung, C.-W. Kim, C. Jeong, O.-S. Joo, B. K. Min and Y. J. Hwang, J. Am. Chem. Soc., 2016, 138, 15673-15681.

345 S. Ikeda, M. Nonogaki, W. Septina, G. Gunawan, T. Harada and M. Matsumura, Catal. Sci. Technol., 2013, 3, 1849.

346 M. Dimitrievska, A. Fairbrother, E. Saucedo, A. PerezRodriguez and V. Izquierdo-Roca, Appl. Phys. Lett., 2015, 106, 073903.

347 S. Chen, A. Walsh, X. G. Gong and S. H. Wei, Adv. Mater., 2013, 25, 1522-1539.

348 C. Insignares-Cuello, F. Oliva, M. Neuschitzer, X. Fontané, C. Broussillou, T. Goislard De Monsabert, E. Saucedo, C. M. Ruiz, A. Pérez-Rodríguez and V. Izquierdo-Roca, Sol. Energy Mater. Sol. Cells, 2015, 143, 212-217.

349 G. Li, G. R. Blake and T. T. M. Palstra, Chem. Soc. Rev., 2017, 46, 1693-1706.

350 J. Wang, P. Zhang, X. Song and L. Gao, RSC Adv., 2014, 4, 21318.

351 K. Sivula and M. S. Prevot, J. Phys. Chem. C, 2013, 117, 17879-17893.

352 S. Hu, C. Xiang, S. Haussener, A. D. Berger and N. S. Lewis, Energy Environ. Sci., 2013, 6, 2984-2993.
353 A. Fairbrother, X. Fontané, V. Izquierdo-Roca, M. Espindola-Rodriguez, S. Lõpez-Marino, M. Placidi, J. Lõpez-García, A. Pérez-Rodríguez and E. Saucedo, ChemPhysChem, 2013, 14, 1836-1843.

354 J. Luo, S. D. Tilley, L. Steier, M. Schreier, M. T. Mayer, H. J. Fan and M. Gratzel, Nano Lett., 2015, 15, 1395-1402.

355 S. Yun, Y. Qin, A. R. Uhl, N. Vlachopoulos, M. Yin, D. Li, X. Han and A. Hagfeldt, Energy Environ. Sci., 2018, 11, 476-526.

356 B. Seger, O. Hansen and P. C. K. Vesborg, Sol. RRL, 2016, 1600013.

357 M. T. Mayer, Curr. Opin. Electrochem., 2017, 2, 104-110.

358 F. Urbain, P. Tang, V. Smirnov, K. Welter, T. Andreu, F. Finger, J. Arbiol and J. R. Morante, ChemSusChem, 2019, 12, 1428-1436.

359 S. Oener, S. Ardo and S. W. Boettcher, ACS Energy Lett., 2017, 2625-2634.

360 X. Yao, D. Wang, X. Zhao, S. Ma, P. S. Bassi, G. Yang, W. Chen, Z. Chen and T. Sritharan, Energy Technol., 2018, 6, 100-109.

361 W. J. Lee, P. S. Shinde, G. H. Go and E. Ramasamy, Int. J. Hydrogen Energy, 2011, 36, 5262-5270.

362 I. Y. Ahmet, Y. Ma, J. W. Jang, T. Henschel, B. Stannowski, T. Lopes, A. Vilanova, A. Mendes, F. F. Abdi and R. Van De Krol, Sustain. Energy Fuels, 2019, 3, 2366-2379.

363 B. A. Pinaud, J. D. Benck, L. C. Seitz, A. J. Forman, Z. Chen, T. G. Deutsch, B. D. James, K. N. Baum, G. N. Baum, S. Ardo, H. Wang, E. Miller and T. F. Jaramillo, Energy Environ. Sci., 2013, 6, 1983-2002.

364 L. J. Minggu, W. R. Wan Daud and M. B. Kassim, Int. J. Hydrogen Energy, 2010, 35, 5233-5244.

365 L. J. Minggu, W. R. Wan Daud and M. B. Kassim, Int. J. Hydrogen Energy, 2010, 35, 5233-5244.

366 W. H. Cheng, M. H. Richter, M. M. May, J. Ohlmann, D. Lackner, F. Dimroth, T. Hannappel, H. A. Atwater and H. J. Lewerenz, ACS Energy Lett., 2018, 3, 1795-1800.

367 S. Licht, B. Wang, S. Mukerji, T. Soga, M. Umeno and H. Tributsch, Int. J. Hydrogen Energy, 2001, 26, 653-659.

368 G. Peharz, F. Dimroth and U. Wittstadt, Int. J. Hydrogen Energy, 2007, 32, 3248-3252.

369 C. R. Cox, J. Z. Lee, D. G. Nocera and T. Buonassisi, Proc. Natl. Acad. Sci. U. S. A., 2014, 111, 14057-14061.

370 S. Nordmann, B. Berghoff, A. Hessel, B. Zielinsk, J. John, S. Starschich and J. Knoch, Sol. Energy Mater. Sol. Cells, 2019, 191, 422-426.

371 C. S. Tan, K. W. Kemp, M. R. Braun, A. C. Meng, W. Tan, C. E. D. Chidsey, W. Ma, F. Moghadam and P. C. McIntyre, Sustain. Energy Fuels, 2019, 3, 1490-1500.

372 M. Baek, G. W. Kim, T. Park and K. Yong, Small, 2019, 15, 111.

373 T. J. Jacobsson, Energy Environ. Sci., 2018, 11, 1977-1979.

374 J. R. McKone, A. P. Pieterick, H. B. Gray and N. S. Lewis, J. Am. Chem. Soc., 2013, 135, 223-231.

375 J. H. Montoya, L. C. Seitz, P. Chakthranont, A. Vojvodic, T. F. Jaramillo and J. K. Nørskov, Nat. Mater., 2016, 16, 70-81. 
376 F. Nandjou and S. Haussener, J. Phys. D: Appl. Phys., 2017, 50, 124002.

377 D. Bae, B. Seger, P. C. K. Vesborg, O. Hansen and I. Chorkendorff, ChemElectroChem, 2019, 6(1), 106-109.

378 R. E. Rocheleau, E. L. Miller and A. Misra, Energy Fuels, 1998, 12, 3-10.

379 G. Heremans, C. Trompoukis, N. Daems, T. Bosserez, I. Vankelecom, J. A. Martens and J. Rongé, Sustainable Energy Fuels, 2017, 1, 2061-2065.

380 J. Wang, L. Ji and Z. Chen, ACS Catal., 2016, 6, 6987-6992.

381 X. Gao, Y. Chen, T. Sun, J. Huang, W. Zhang, Q. Wang and R. Cao, Energy Environ. Sci., 2020, 13, 174-182.
382 S. Dresp, F. Dionigi, M. Klingenhof and P. Strasser, ACS Energy Lett., 2019, 4, 933-942.

383 E. Kalamaras, M. M. Maroto-Valer, M. Shao, J. Xuan and H. Wang, Catal. Today, 2018, 317, 56-75.

384 E. Ruiz-López, E. Amores, A. Raquel de la Osa, F. Dorado and A. de Lucas-Consuegra, Chem. Eng. J., 2020, 379, 122289.

385 C. Flox, S. Murcia-López, N. M. Carretero, C. Ros, J. R. Morante and T. Andreu, ChemSusChem, 2018, 11, 125-129.

386 S. Murcia-López, M. Chakraborty, N. M. Carretero, C. Flox, J. R. Morante and T. Andreu, Sustainable Energy Fuels, 2020, 4, 1135-1142. 